\title{
WestVirginiaUniversity
}

THE RESEARCH REPOSITORY @ WVU

Graduate Theses, Dissertations, and Problem Reports

2000

\section{Reliability-based method for stability of mine entry design and evaluation}

Zhouming (Victor) Sun
West Virginia University

Follow this and additional works at: https://researchrepository.wvu.edu/etd

\section{Recommended Citation}

Sun, Zhouming (Victor), "Reliability-based method for stability of mine entry design and evaluation" (2000). Graduate Theses, Dissertations, and Problem Reports. 2300.

https://researchrepository.wvu.edu/etd/2300

This Dissertation is protected by copyright and/or related rights. It has been brought to you by the The Research Repository @ WVU with permission from the rights-holder(s). You are free to use this Dissertation in any way that is permitted by the copyright and related rights legislation that applies to your use. For other uses you must obtain permission from the rights-holder(s) directly, unless additional rights are indicated by a Creative Commons license in the record and/ or on the work itself. This Dissertation has been accepted for inclusion in WVU Graduate Theses, Dissertations, and Problem Reports collection by an authorized administrator of The Research Repository @ WVU.

For more information, please contact researchrepository@mail.wvu.edu. 


\title{
RELIABILITY-BASED METHOD FOR STABILITY OF MINE ENTRY DESIGN AND EVALUATION
}

\author{
Zhouming (Victor) Sun
}

\author{
Dissertation submitted to the \\ College of Engineering and Mineral Resources \\ at West Virginia University \\ in partial fulfillment of the requirements \\ for the degree of
}

\author{
Doctor of Philosophy \\ in \\ Mining Engineering
}

\author{
S. Peng, Ph.D., Chair \\ Y.Luo, Ph.D. \\ F.Peng, Ph.D. \\ Department of Mining Engineering \\ M.Bugaj, Ph.D. \\ G.Hobbs, Ph.D. \\ Department of Statistics
}
Morgantown, West Virginia
2000

Keywords: Stability, reliability, mine entry design, safety factor Copyright 2000 Zhouming Sun 


\section{ABSTRACT \\ RELIABILITY-BASED METHOD FOR STABILITY OF MINE ENTRY DESIGN AND EVALUATION \\ Zhouming (Victor) Sun}

Variability in the physical properties of coal/rock is a major source of uncertainty encountered in material and site characterization, analysis and stability design of mining structures. It causes a considerable variation in strength/stress estimations of mining structures when the coal/rock properties are used. Therefore, the conventional safety factor method on stability assessment of mining structures is a special case of the more general probabilistic method in that it assumes the variability of coal/rock properties is zero. Although the use of probability and statistical methods in the analysis and design of geotechnical structures has grown rapidly in recent years, its application to mining structure design has been slow due to its relatively larger variation in the geological parameters and computation difficulty for analysis of mining structures.

The purpose of this study is to develop a reliability-based approach for designing and evaluating the stability of mining entry. In order to address the importance of this research, the conventional method of safety factor concept for mine entry design is reviewed first, then the variability of physical properties of coal/rock is analyzed. The effects of uncertainty due to coal/rock properties on stability design of mining entry are studied. A new approach of reliability-based method for the design and evaluation of mine entry is developed. The key points of this method are to use the point estimation and safety margin (or reliability indexes) methods for the purposes of parameter approximation and reliability measurement. 
Therefore, it is relatively easy in computation and yet takes the variability and uncertainties of coal/rock properties are considered. After comparing the outcomes with the conventional methods, the results of the reliability approach show that the risk assessment by the new method can be a valuable supplement and complementary to the exiting deterministic procedures such that an overly conservative approach with iiiunknown degree of confidence when using the conventional method for the design and evaluation of mining structures can be greatly reduced.

The design and evaluation methodology developed in this research is unique. It is also more realistic because it considers both safety and economic issues in mine entry design and evaluation. Although this research focuses on a fundamental study, the results will have significant impacts on current academic researchers, mining operators and government regulators in terms of ground control and mine design. It is anticipated that, by using this approach, the stability assessment will be elevated to a higher level of confidence. 


\section{ACKNOWLEDGMENTS}

The research effort represented in this dissertation was made possible through the contributions of many persons. With respect and gratitude, the author is deeply indebted to all members of his research committee: Dr. M. Bugaj, Dr. F.F. Peng, Dr. Y. Luo and Dr. G. Hobbs for their supports and invaluable suggestions during this research. Their guidance, concern, and positive thinking will long be remembered and appreciated.

Sincere gratitude and appreciation are expressed to Dr. S.S. Peng, Chairman of his advisory committee, for initially suggesting the problem, and for his supervision, interest and interesting discussions provided throughout this research. His guidance has been invaluable to the completion of this dissertation, and is greatly appreciated.

The author also expresses heartfelt appreciation to his fellow students and staffs of the Mining Engineering Department for their help.

Acknowledgment is also due to his family. Their generosity and understanding are overwhelming, and their support literally made this research effort feasible. To his wife, Chengmei Gao, and daughters Ting (Lisa) and Yu (Lena), the author sincerely thanks them for providing the motivation and inspiration that made this endeavor all worthwhile.

Finally, the author expresses his deepest appreciation and affection for the support, encouragement, and patience of his parents, Xinan Sun and Chengxu Du. The author owes special thanks to his father-in-law, Chewen Gao and mother-in-law, Gaulan Wang, who has unselfishly supported him and his family during this study. 


\section{TABLE OF CONTENTS}

Pages

ABSTRACT $\ldots \ldots \ldots \ldots \ldots \ldots \ldots \ldots \ldots \ldots \ldots \ldots \ldots \ldots \ldots \ldots \ldots \ldots$

ACKNOWLEDGMENT $\ldots \ldots \ldots \ldots \ldots \ldots \ldots \ldots \ldots \ldots \ldots \ldots \ldots \ldots$ iv

TABLE OF CONTENTS $\ldots \ldots \ldots \ldots \ldots \ldots \ldots \ldots \ldots \ldots \ldots \ldots \ldots \ldots$

LIST OF TABLES $\ldots \ldots \ldots \ldots \ldots \ldots \ldots \ldots \ldots \ldots \ldots \ldots \ldots \ldots \ldots \ldots \ldots \ldots \ldots$

LIST OF FIGURES $\ldots \ldots \ldots \ldots \ldots \ldots \ldots \ldots \ldots \ldots \ldots \ldots \ldots \ldots \ldots \ldots \ldots$

1. INTRODUCTION $\ldots \ldots \ldots \ldots \ldots \ldots \ldots \ldots \ldots \ldots \ldots \ldots \ldots \ldots \ldots$

2. LITERATURE REVIEW $\ldots \ldots \ldots \ldots \ldots \ldots \ldots \ldots \ldots \ldots \ldots \ldots \ldots \ldots$

2.1 Conventional Method on Measurement of Mine Entry Stability . . . . . 5

2.1 .1 Assessment of Roof Fall . . . . . . . . . . . . . . 6

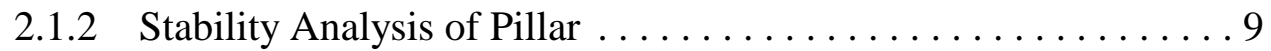

2.1.2.1 Pillar Design in Room-and-Pillar Mining . . . . . . . . 10

2.1.2.2 Chain Pillar Design in Longwall Mining . . . . . . . . 14

2.1.3 Evaluation of Floor Stability . . . . . . . . . . . . . . 25

2.2 Probability-based Principles on Assessment of Mine Entry Stability . . 28

3. VARIABILITY ANALYSIS OF COAL/ROCK PROPERTIES . . . . . . . 32

3.1 Sources of Variability of Coal/Rock Materials $\ldots \ldots \ldots \ldots \ldots \ldots \ldots$

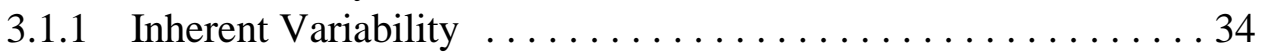

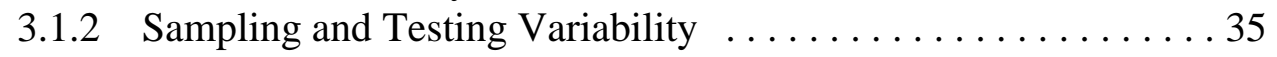

3.1.2.1 Sample Randomization and Disturbance .......... 35

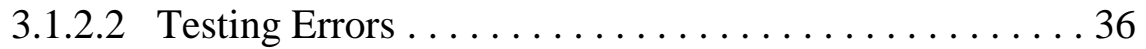

3.2 Coal/rock Classifications and Statistical Description of Variability . . . 38

3.2.1 Coal/rock Classification Systems . . . . . . . . . . . . 38

3.2.2 Variability Considerations . . . . . . . . . . . . . . . 39

3.2.3 Statistical Description of Variability . . . . . . . . . . 41

3.3 Variability Demonstrations of Coal Physical Properties . . . . . . . . . 43

3.3 .1 Pittsburgh Seam . . . . . . . . . . . . . . . . . . . 43

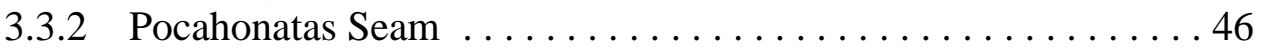


4. UNCERTAINTY EFFECTS OF COAL/ROCK PROPERTIES

ON STABILITY DESIGN OF MINING STRUCTURE $\ldots \ldots \ldots \ldots \ldots \ldots 49$

$4.1 \quad$ Mine Entry Stability vs. SF $\ldots \ldots \ldots \ldots \ldots \ldots \ldots \ldots \ldots \ldots$

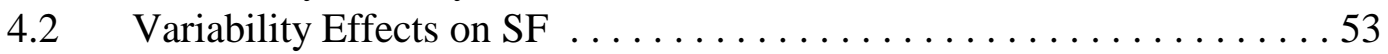

4.3 Variability, SF and Mine Entry Stabilization ............... 60

5. DEVELOPMENT OF RELIABILITY-BASED METHOD FOR

STABILITY OF MINE ENTRY DESIGN AND EVALUATION $\ldots \ldots \ldots \ldots 63$

$5.1 \quad$ Reliability and Risk Assessment $\ldots \ldots \ldots \ldots \ldots \ldots \ldots \ldots \ldots$

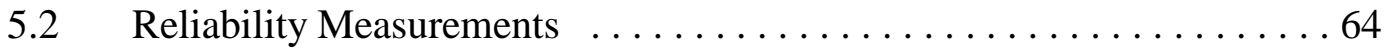

5.2.1 Safety Factor Related Methods $\ldots \ldots \ldots \ldots \ldots \ldots \ldots \ldots$

5.2.1.1 Central Safety Factor .................. 65

5.2.1.2 Reliability Index of Safety Factor $\ldots \ldots \ldots \ldots 66$

5.2.1.3 Probability of Low Safety Factor $\ldots \ldots \ldots \ldots . \ldots 68$

5.2.1.4 Statistical Safety Factor . . . . . . . . . . . . . 69

5.2.2 Capacity-Demand Method .................... 70

5.2.3 Safety Margin (Reliability Index) Method . . . . . . . . . . 72

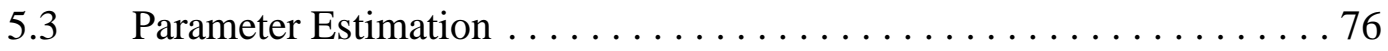

5.3.1 Monte Carlo Simulation . . . . . . . . . . . . . . . . . . 77

5.3.2 Taylor Series Expansion (FOSM) $\ldots \ldots \ldots \ldots \ldots \ldots \ldots$

5.3 .3 Moment Generation Function $\ldots \ldots \ldots \ldots \ldots \ldots \ldots \ldots$

5.3 .4 Point Estimate Method ............................ 79

5.3.4.1 Two Point Estimates $\ldots \ldots \ldots \ldots \ldots \ldots \ldots \ldots \ldots$. . . . . . 81

5.3.4.2 Four Point Estimates $\ldots \ldots \ldots \ldots \ldots \ldots \ldots \ldots$

5.3.4.3 Generalized Point Estimates $\ldots \ldots \ldots \ldots \ldots$. . . . . 86

$5.4 \quad$ PESM Method and Its General Procedure $\ldots \ldots \ldots \ldots \ldots \ldots \ldots$

$5.4 .1 \quad$ PESM Method ..................... 89

5.3.4.2 General Procedure of PESM Method ........... 89

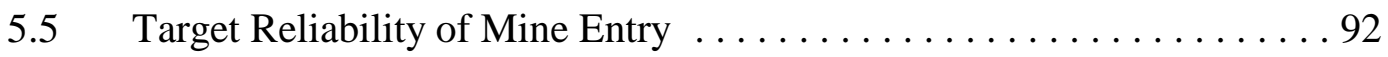

6. PESM APPLICATIONS AND COMPARISONS $\ldots \ldots \ldots \ldots \ldots \ldots \ldots \ldots$

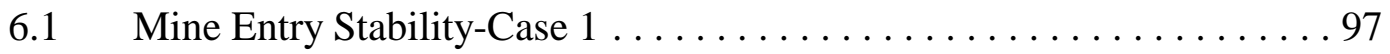

6.1.1 Evaluation Mine Entry Stability with SF Method . . . . . . . . 98

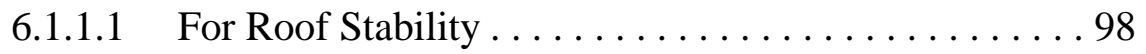

6.1.1.2 For Pillar Stability . . . . . . . . . . . . . . 100

6.1.1.3 For Floor Stability $\ldots \ldots \ldots \ldots \ldots \ldots \ldots 10 \ldots \ldots$

6.1.2 Evaluation Mine Entry Stability with PESM Method ........ 101

6.1.2.1 For Roof Reliability . . . . . . . . . . . . . . . 102

6.1.2.2 For Pillar Reliability $\ldots \ldots \ldots \ldots \ldots \ldots \ldots$

6.1.2.3 For Floor Reliability . . . . . . . . . . . . . . . . . 107

6.1.3 Stability Comparison on Mine Entry ................. 108

6.2 Longwall Pillar Stability-Case $2 \ldots \ldots \ldots \ldots \ldots \ldots \ldots \ldots \ldots \ldots$ 


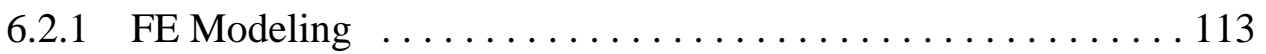

6.2 .2 FE Modeling Results . . . . . . . . . . . . . . . 114

6.2.3 SF Based Analysis on Pillar Stability . . . . . . . . . . . . 124

6.2.4 PESM Based Assessment on Pillar Stability . . . . . . . . . . . . 129

6.2.5 Comparison of Longwall Pillar Stability . . . . . . . . . . . . . 134

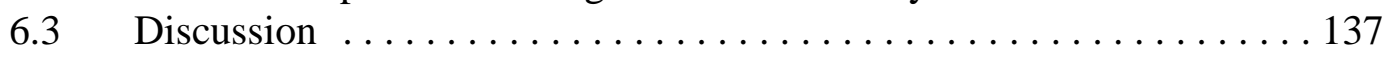

7. CONCLUSIONS AND RECOMMENDATIONS $\ldots \ldots \ldots \ldots \ldots \ldots \ldots$

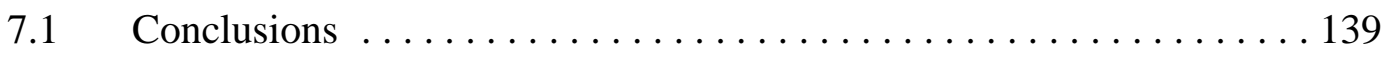

7.2 Recommendations ........................ 142

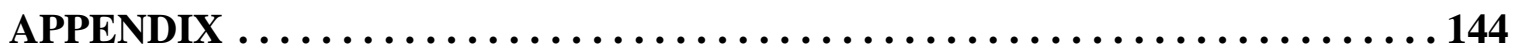

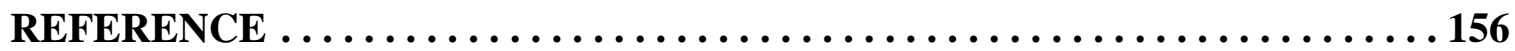

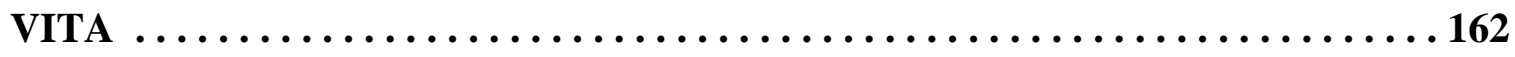




\section{LIST OF TABLES}

Tables

Pages

2.1 The Recommended Safety Factors for Design of Stable Room Pillars . . . . . . 14

3.1 Statistical Parameters Commonly Used in Data Analysis $\ldots \ldots \ldots \ldots \ldots \ldots 2$

3.2 Statistical Parameters of Pittsburgh Seam in Various Coal Mines . . . . . . . 43

3.3 Statistical Parameters of Coal Properties in Different Panels in Min A . . . . 47

$5.1 \quad$ Acceptable Risk Levels for Various Raised-bored Shafts . . . . . . . . . . . . 94

5.2 Suggested Acceptable Risks Levels for Cases Involving Human Lives . . . . . 94

5.3 Social Criterion Factor $\left(\mathrm{k}_{\mathrm{s}}\right)$ for Various Structures $\ldots \ldots \ldots \ldots \ldots \ldots$

6.1 Coal/rock Properties and Predetermined Stresses Around Mine Entry . . . . . . 99

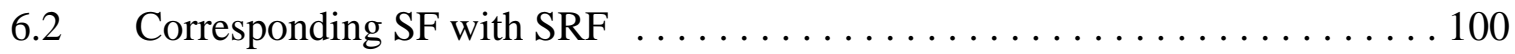

6.3 Calculated Statistics for Individual Variables of Roof $\ldots \ldots \ldots \ldots \ldots \ldots$

6.4a Initial Process for Roof Reliability Computation $\ldots \ldots \ldots \ldots \ldots \ldots \ldots$

6.4b Results of Step 5 Computation on Roof $\ldots \ldots \ldots \ldots \ldots \ldots$

6.5 Calculated Statistics for Individual Variables of Pillar (Method 1) . . . . 105

6.6 Results of Step 5 Computation of Pillar (Method 1) . . . . . . . . . 105

6.7 Calculated Statistics for Individual Variables of Pillar (Method 2) . . . . . 106

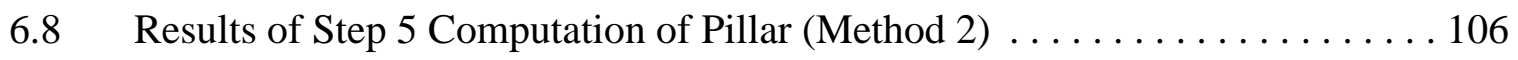

6.9 Calculated Statistics for Individual Variables of Floor . . . . . . . . . . . 107

6.10 Results of Step 5 Computation of Floor $\ldots \ldots \ldots \ldots \ldots \ldots \ldots \ldots \ldots \ldots$

6.11 Evaluation of Mine Entry Stability Using SF and Reliability Methods . . . . . 110 
6.12 Comparison of Stability Order with SF and Reliability Methods . . . . . . . 111

6.13 Young's Mordulus for Constructions of FE Models $\ldots \ldots \ldots \ldots \ldots \ldots \ldots$

6.14 Calculated Statistics for Independent Variables of Pillar . . . . . . . . . 130

6.15 Results from Step 5 Computation $\ldots \ldots \ldots \ldots \ldots \ldots \ldots \ldots \ldots \ldots \ldots \ldots \ldots \ldots \ldots \ldots \ldots$

6.16 Statistical Parameters of Safety Margin . . . . . . . . . . . . . . 131

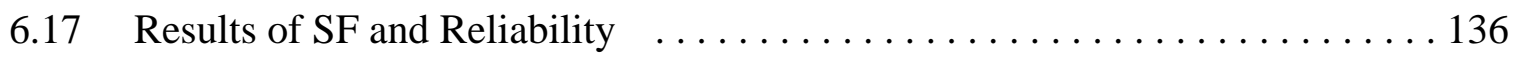

6.18 Statistical Summary of SF and Reliability $\ldots \ldots \ldots \ldots \ldots \ldots \ldots \ldots \ldots \ldots$ 


\section{LIST OF FIGURES}

$\begin{array}{ll}\text { Figures Pages } & \text { Pag }\end{array}$

3.1 Overburden Types Above Pitts. Seam . . . . . . . . . . . . . . . . . . 35

3.2 Distribution of Coal Properties in Mine- $\ldots \ldots \ldots \ldots \ldots \ldots \ldots \ldots$

3.3 Variations of Coal UCS in Different Panels ... . . . . . . . . . . . . . . . . 48

4.1 Variant SFs Used in Room-and-Pillar Mines $\ldots \ldots \ldots \ldots \ldots \ldots \ldots \ldots$

4.2 Concepts of Commonly Used Safety Factor Analysis . . . . . . . . . . . . 55

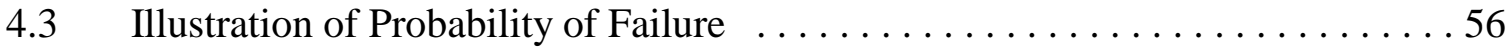

4.4 Effects of Probability of Failure Due to Proportion Changes in

Strength/stress Mean Values with a Constant Safety Factor . . . . . . . . . . . 58

4.5 Relationship among Strength/stress Variability, SF and Probability of Failure . 62

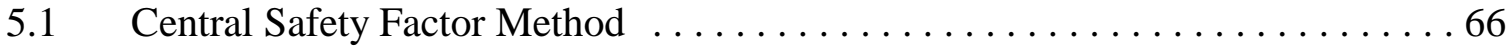

5. 2 Distribution of Coal Sample Strength $\ldots \ldots \ldots \ldots \ldots \ldots \ldots \ldots \ldots \ldots$

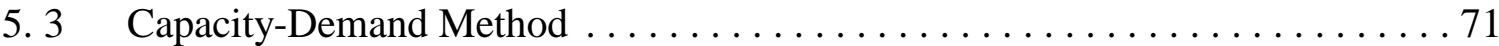

5.4 Geometrical Illustration of Reliability Index $\ldots \ldots \ldots \ldots \ldots \ldots \ldots$

5.5 Representation of One Variable(Two Points) as Loading on Rigid Beam . . . . 80

5.6 Illustration of Information Transfer $\ldots \ldots \ldots \ldots \ldots \ldots \ldots \ldots \ldots \ldots \ldots \ldots \ldots \ldots \ldots$

5.7 Representation of Two Variables (Four Points) as Loading on Rigid Plate . . . 85

5.8 Influence of Correlation Coefficient on Weighting Factors $\ldots \ldots \ldots \ldots \ldots$

5.9 Generator Illustration for Determinating Numbers of Terms $\ldots \ldots \ldots \ldots$

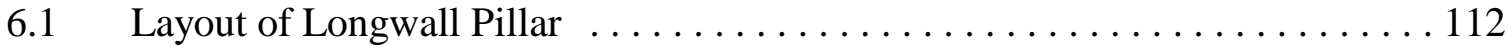




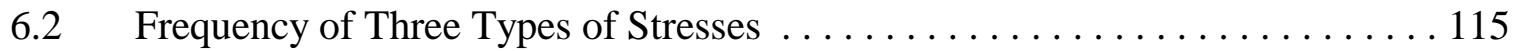

6.3 Comparison of Stresses Statistics on SM and MM $\ldots \ldots \ldots \ldots \ldots \ldots \ldots$

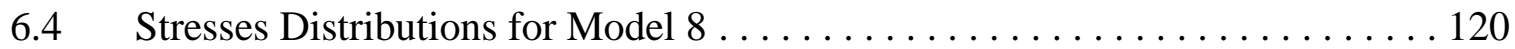

6.5 SF Based Analysis on Pillar Stability $\ldots \ldots \ldots \ldots \ldots \ldots \ldots \ldots \ldots \ldots \ldots$

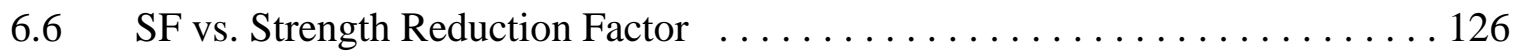

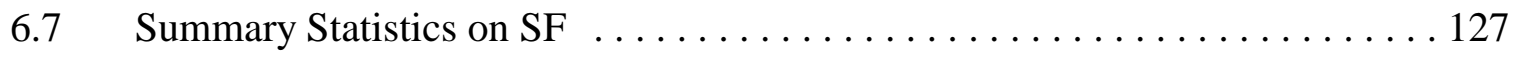

6.8 SF Reduction vs. Strength Reduction $\ldots \ldots \ldots \ldots \ldots \ldots \ldots \ldots \ldots \ldots \ldots$

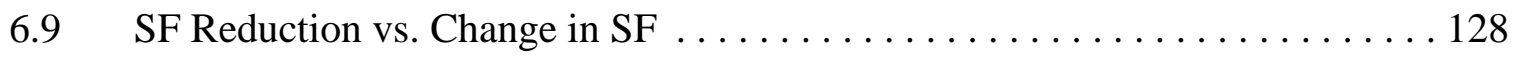

6.10 Reliability on All Groups ................................ 133

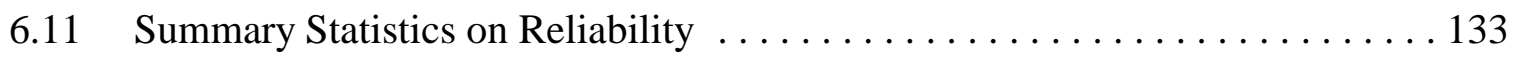




\section{CHAPTER 1}

\section{INTRODUCTION}

Performance of mine entry is a critical key in maintaining the safety and high productivity as well as resource utilization for underground mining. Design and evaluation

of mine entry, therefore, play a vital role in stability assessment of ground control and mine design. It is becoming more important now due to the rapid changes of mining environment accompanied with high mining rates and productivity.

The conventional method of mine entry design is mainly based on a commonly used safety factor (SF) approach. The stability assessment for mine entry, therefore, depends on one of the SFs of roof, pillar or floor. This approach initiated the concept of stability measurement and has its long history on entry design in both longwall and room-and-pillar mines. It is still dominating current design of mine entry due to its simplicity and common acceptance in mining engineering. However, this method has often been challenged due to its lack of scientific consideration on the variability of coal/rock physical properties and without a clear statement of confidence on the design of mine entry stability.

In reality, the true values of the physical properties for coal/rock cannot be known or determined with full accuracy. They can only be estimated from a discrete number of laboratory and/or field tests. Due to the inherent heterogeneity of coal/rock deposition and the systematic errors arising from sampling, testing, and human judgment, etc., the 
scatter/variability of coal/rock physical properties is almost always observed in the test results. This shows that the physical properties of coal/rock posses the site related characteristics. No prediction method of coal/rock properties is available so far. However, in the application of the SF method, a reduction factor is usually introduced to consider such uncertainty of coal/rock properties. Ultimately a deterministic analysis is applied. Therefore, the commonly used SF method, in general sense, represents the safety level of a structure. But it fails to determine quantitatively and qualitatively the confidence level of mine structure stability since the SF method depends on a deterministic analysis. Consequently, it could lead to either over-design or under-design of mine entry capacity. This is why mine entry failure still takes place even though a high SF is used. Conversely, some entries designed with low safety factors remain stable long after mining.

Recently in order to consider the variability of coal/rock properties, several authors initiated the probabilistic approach for stability design of mining structures(Gao and Kim 1994; Chen, Ke and Jia, 1996). In these researches, the idealized distribution of coal/rock properties were assumed and the computation process was very sophisticated. This may be why the application of the probabilistic design method for mining entry design is not appreciated so far.

In order to take the uncertainty of coal/rock properties into design consideration of mine entry, the probabilistic approach is an alternative tool for providing sound design and evaluation of mine entry performance at specific levels of safety with certain confidence. However, how to lead the ideal assumptions toward the realistic situations and make the computation process as easy as possible are the major tasks to transfer the probabilistic 
design technique into mining practice. Those are the key issues being focused in this research.

In this research, the conventional SF methods on mine entry design is reviewed first. The data on the variability of coal/rock properties and their effects on current design of mine entry stability are then presented as scientific evidences to justify the application of reliability approach. Rather than studying the mechanics of mine entry failure, the major task of this study is to develop a reliability-based procedure for assessment of stability design and evaluation of mine entry. The key issue of the newly developed method is to eliminate the idealized assumptions and simplify the reliability measurement using the point estimate and safety major methods, respectively. Based on the results of comparison with the conventional SF method, the reliability approach shows a significant improvement on the current design concept and stability evaluation of mine entry. It can be a valuable supplement to and/or complement of the existing deterministic procedure so that the current technique of mine entry design can be elevated to a higher level. 


\section{CHAPTER 2 LITERATURE REVIEW}

A major thrust of ground control in coal mine researches and practices have been focused on the improvement of mine entry performance for both longwall and room-andpillar mines. Because mine entries are the key structures of underground coal mines by virtue of performing the following functions:

- Mine entries are the lifelines through which miners, supplies and ventilating air reach the working faces; and

$\square \quad$ They are escape routes for miners in case of an emergence;

Therefore, they must remain operational despite the heavy loads induced by mining activities. Consequently, whether or not of the above functions can be maintained is directly linked to the safety of miners and the production cost to the mine operators. In order to show how the current techniques are used to ensure these mine entry functions from a design point of view, the conventional methods and probabilistic principles on stability assessment of mine entry are reviewed in the followings.

\subsection{Conventional Methods for the Measurement of Mine Entry Stability}

Generally, performance disturbance of mine entry is mainly caused by a roof fall, pillar crush or floor heave or combination of these events within the mine lifetimes. In order 
to avoid those damages, stability design for roof, pillar and floor was formulated to facilitate the determination of those failures by many researchers. A conventional safety factor, as a yardstick, is usually used to represent the stability of roof, pillar or floor although the various critical values of safety factors were recommend by various authors (Obert and Duvall, 1967; Salamon, 1967; Holland, 1964; Bieniawaski; 1983; Mark, 1995).

In general, the conventional safety factor, $\mathrm{SF}$, is defined as a ratio of average strength, $\mathrm{R}$, to average stress, $\mathrm{S}$, of a structure as:

If $\mathrm{SF}$ is larger than one, the structure is considered stable. Otherwise, it is unstable.

$$
S F=\frac{R}{S}
$$

This concept has been widely used in stability design and evaluation of mine roof, pillar and floor for a long time. It is still dominating the current assessment of mine entry stability in both longwall and room-and-pillar mining due to its simplicity and common acceptance by practioners. The applications of safety factor analysis on stability of roof, pillar and floor in mine entry are summarized as follows:

\subsubsection{Assessment of Roof Fall}


"Roof fall is the natural or spontaneous fall of rock from the mine roof and rib. Roof fall occurs frequently in U.S. underground coal mines, and often it kills or injures people working underground. To the mine operators, the cleanup of roof fall materials and resupport of the fall area are extremely expensive, especially if the fall has hindered production. Roofs fall in most cases is sudden. The causes of mast roof falls, however, are not fully known, and prediction methods have only begun to be studied (Peng, 1986)." Part 80, Title 30, of the Federal Regulation Code (CFR 1999; Fed. Reg., 1980) requires that the mine operations must report any roof problem to MSHA (Mine Safety and Health Administration) if it affects ventilation, and passage of persons on active working section.

The failure phenomena and mechanisms of roof falls in mine entry have been investigated (Su and Peng, 1984; USBM, 1992). To assess a roof fall, several traditional approaches, involving the beam theory, pressure arch theory, and dome theory, among others, have been used and attempted to explain the causes and results of a roof fall (Adler and Sun, 1976). Currently, the finite element structure analysis is widely used to model the stress redistribution or deformation of the roof due to the existence of underground openings (Hsiung and Peng, 1985; Park and Ash, 1985). Despite the differences among those proposed approaches, the safety factor analysis is eventually performed to evaluate the roof stability based on the several failure criteria listed below:

$\downarrow$ Octahedral Shear Failure Criterion (Su and Peng, 1987) 


$$
\begin{gathered}
S F=\frac{\tau_{o c t}}{\tau} \\
\tau_{o c t}=A+B \sigma_{o c t}+C \sigma_{o c t}^{2} \\
\sigma_{o c t}=\frac{1}{3} I=\frac{1}{3}\left(\sigma_{1}^{2}+\sigma_{2}^{2}+\sigma_{3}^{2}\right)
\end{gathered}
$$

where $\tau_{\text {oct }}$ is the octahedral shear strength of a roof rock under a given octahedral normal stress, Goct, psi; $\tau$ is the shear stress of the roof, psi; A, B and C are coefficients obtained from laboratory experiments; $\sigma_{1}, \sigma_{2}$ and $\sigma_{3}$ are the maximum, intermediate and minimum principal stresses, psi, respectively.

\section{Tensile Failure Criterion}

In the conventional stress and strength analysis, the immediate roof of an opening can be regarded as a beam with fixed ends. The safety factor of the roof is estimated by

$$
S F=\frac{2 \sigma_{t} t}{k \gamma L^{2}}
$$

where $\sigma_{\mathrm{t}}$ is the shear strength of the roof material, psi; $\mathrm{t}$ is the thickness of the roof, $\mathrm{ft} ; \quad \gamma$ is unit weight of the roof material, pcf; L is roof span or entry width, $\mathrm{ft}$, and $\mathrm{k}$ is a strength reduction factor. 
$\downarrow$ Von-Mises Failure Criterion

If a roof fall is due to cutters by shearing failure, the safety factor for the Von-Mises failure criterion (Jiang, 1981; Su and Hasenfus, 1995; Peng and Wang, 1996) is used to determine roof instability resulting from the initiation of shearing failure. It is as defined as

$$
\begin{gathered}
S F=\frac{\sigma_{c}}{\sigma_{v o n}} \\
\sigma_{v o n}=\sqrt{\frac{\left(\sigma_{1}-\sigma_{2}\right)^{2}+\left(\sigma_{2}-\sigma_{3}\right)^{2}+\left(\sigma_{3}-\sigma_{1}\right)^{2}}{2}}
\end{gathered}
$$

where $\quad \sigma_{\text {von }}$ is the Von-Mises stress, psi; $\sigma_{\mathrm{c}}$ is uniaxial compressive strength of roof material, psi.

$\downarrow$ Coulomb Failure Criterion

The Coulomb criterion assumes that the shear failure of materials loaded in compression is induced if the shear stress along the potential shear failure planes is equal or larger than the cohesive strength plus the frictional resistance. The safety factor can be derived in terms of the minimum and maximum principal stresses. That is

$$
S F=\frac{\sigma_{c}+q \sigma_{3}}{\sigma_{1}}
$$


where $\alpha$ is internal frictional angle, $\sigma_{1}$ is maximum and $\sigma_{3}$ is minimum principal stresses, respectively.

$$
q=\frac{1+\sin \alpha}{1-\sin \alpha}
$$

No critical value of SF for roof stability has been proposed so far. However, if the SF is larger than one, the roof is assumed in a stable condition. Otherwise, it fails. Strength reduction is always applied in order to take uncertainties into consideration even though no rules can be followed for selection of a reasonable reduction factor.

\subsubsection{Stability Analysis of Pillar}

Pillar in coal mine, connecting with roof and floor, is a main support in mining entry for both room-and-pillar and longwall mines. An appropriate pillar design, therefore, is stipulated not only for the stability of pillar itself but also for the roof and floor as well.

The conventional concept of pillar design, based on the ultimate strength theory, assumes that the stresses within a pillar are uniformly distributed and pillar will fail when the average stress reaches the average compressive strength of the pillar. Therefore, three steps are required for pillar design. (1) calculation of pillar stress; (2) calculation of ultimate pillar strength; and (3) calculation of a pillar safety factor defined as the ratio of the ultimate pillar strength to average pillar stress (Peng and Dutta, 1992; Biniwaski, 1992).

Due to different mining methods, two types of pillar design approaches are used: one 
for room-and-pillar and the other for longwall mining.

\subsubsection{Pillar Design In Room-and-Pillar Mining}

$\square$ Pillar Load: For room-and-pillar mining, the pillar load is estimated based on the tributary area loading concept (Peng, 1986). The average pillar load can be calculated by

$$
P=\frac{H \gamma(W+B)(L+B)}{W \times L}
$$

whereH is overburden depth, $\mathrm{ft}$; $\mathrm{B}$ is opening width, $\mathrm{ft}$; $\mathrm{W}$ and $\mathrm{L}$ are pillar width and length, $\mathrm{ft}$, respectively; $\gamma$ is average density of overburden, $1.1-1.2 \mathrm{lb} / \mathrm{in}^{2}-\mathrm{ft}$.

$\square$ Pillar Strength: The strength of a coal pillar is depending upon many factors, such as pillar geometry, pillar sizes and weak interfaces in pillar. There are significant differences between the actual strength of rock and the strength of a small laboratory specimen. For many years, various pillar strength formulas have been proposed, in which the size and shape effect have been taken into account. Generally, there are two types of expressions:

$$
\begin{gathered}
\sigma_{p}=\sigma_{c}[A+B(w / h)] \\
\sigma_{p}=K w^{a} / h^{b}
\end{gathered}
$$


$\sigma_{\mathrm{p}}$ is pillar strength, psi; $\sigma_{\mathrm{c}}$ is in-situ coal strength incorporating the size effect, psi; A, B, a and $\mathrm{b}$ are constants expressing the shape effect; $\mathrm{K}$ is a constant characteristic of a coal seam; $\mathrm{w}$ and $\mathrm{h}$ are pillar width and height, respectively.

The following formulas were proposed for estimation of pillar strength.

- Holland-Gaddy Formula (1957)

$$
\begin{gathered}
\sigma_{p}=\frac{k \sqrt{w}}{h} \\
k=\sigma \sqrt{D}
\end{gathered}
$$

where $\sigma$ is the strength obtained by testing a cubical specimen, psi; D is the edge dimension of the specimen tested, in; $\mathrm{w}$ and $\mathrm{h}$ are pillar width and height, in, respectively.

- Holland Formula (1964)

$$
\sigma_{p}=k \sqrt{\frac{w}{h}}
$$

where $\mathrm{k}$ is the crushing strength obtained by testing a sample composed of 1 -in cubes, psi. 
- Obert-Duvall Formula (1967)

$$
\begin{gathered}
\sigma_{p}=\sigma_{c}\left(0.778+0.222 \frac{w}{h}\right) \\
\sigma_{c}=\frac{k}{\sqrt{36}} \quad h>36 \\
\sigma_{c}=\frac{k}{\sqrt{h}} \quad h<36 \\
k=\sigma \sqrt{D}
\end{gathered}
$$

where $\sigma_{\mathrm{c}}$ is the average strength of cubical test specimens, psi.

- Salamon-Munro Formula (1967)

$$
\sigma_{p}=1320 \frac{w^{0.46}}{h^{0.66}}
$$

- Bieniawski Formula (1983)

$$
\sigma_{p}=\sigma_{c}\left(0.64+0.36 \frac{w}{h}\right)
$$

where $\mathrm{h}$ is the pillar height, in; $\sigma$ is the uniaxial compressive strength of coal specimens tested in the Laboratory, psi and D is diameter or cube side dimension, in. 
$\square$ Safety Factor: It is straightforward to calculate the safety factor for a room pillar since based on the tributary area concept it is assumed that the load on the pillar is uniformly distributed. As soon as the mining geometry and pillar strength are determined, the SF of pillar can be calculated based on its definition. Table 2.1 summarizes the recommended safety factor for design of stable pillars in room-and-pillar mining by different authors.

Table 2.1 The Recommended Safety Factors for Design of Stable Room Pillars

\begin{tabular}{l|c|c|c|c}
\hline \multicolumn{1}{c|}{ Author } & Year & Range & Average & Remark \\
\hline Obert \& Duvall & 1967 & $2-4 * / 4-8$ & & $*_{\text {for short term }}$ \\
Salamon & 1967 & $1.31-1.88$ & 1.57 & only \\
Hollad & 1964 & $1.70-2.0$ & & \\
Bieniawski & 1983 & $1.0-2.5$ & 1.73 & \\
Mark & 1995 & $1.3-1.5$ & & \\
\hline
\end{tabular}

\subsubsection{Chain Pillar Design in Longwall Mining}

For longwall mining, chain pillars, in addition to overburden weight (or called a development load), are also subjected to abutment loads. In general, the development load which is present right after the development of a longwall panel, is estimated by the tributary area loading concept. The abutment loads occur where portions of the weight of overburden that have been supported by the excavated longwall panel are transferred to the pillars. The abutment loads include the side abutment load and front abutment load. The following methods have been proposed for the design of chain pillar stability based on safety factor 
analysis.

\section{$\square$ ALPS Method}

Analysis of Longwall Chain Pillar Stability (ALPS) is proposed by Mark (1992). In this method, the loads on longwall pillars consists of two parts, namely development loads $\left(\mathrm{L}_{\mathrm{d}}\right)$ and abutment loads.

The tributary area theory is used to estimate the development loads. That is

$$
L_{d}=H W_{p} \gamma
$$

where $\mathrm{H}$ is overburden depth, $\mathrm{ft}$; $\mathrm{W}_{\mathrm{p}}$ is the width of pillar system, $\mathrm{ft}$; and $\gamma$ is unit weight of the overburden, pcf.

The abutment loads are calculated based on a wedge concept due to overburden on chain pillars. The abutment angle, $\beta$ is used to estimate the abutment loads which are defined by King and Whattaker (1971). Two equations are used to quantify the side abutments. $L_{s}$ is for critical and supercritical panels and $L_{s s}$ for subcritical panels:

$$
L_{s}=\frac{\gamma H^{2} \tan \beta}{2}
$$


where $\mathrm{W}_{\mathrm{m}}$ is panel width, $\mathrm{ft} ; \beta \mathrm{i}$ abutment angle, assuming $21^{\circ}$

The front abutment load, $L_{f}$ is proportional to the side abutment load $\left(\mathrm{L}_{\mathrm{s}}\right)$ and can be given by

$$
L_{f}=F\left(L_{s}\right)
$$

where $\mathrm{F}$ is a front abutment load factor; For a headgate, $\mathrm{F}_{\mathrm{h}}=0.5$ while for a tailgate

$\mathrm{F}_{\mathrm{t}}=0.7$

The distribution coefficient, $\mathrm{R}$ of the side abutment is

$$
R=1-\left(\frac{D-W_{t}}{D}\right)^{3}
$$

$$
L_{s s}=\gamma\left(\frac{H W_{m}}{2}-\frac{W_{m}^{2}}{8 \tan \beta}\right)
$$

where $D$ is the extent of side abutment influence zone, $D=9.3(H)^{0.5}$ according to Peng and Chiang (1984).

The headgate loading $L_{H}$ is

$$
L_{H}=L_{d}+L_{s} F_{h R}
$$


and the tailgate loading $L_{T}$ is

$$
L_{T}=L_{d}+\left(1+L_{t}\right) L_{s}
$$

The bleeder loading $\mathrm{L}_{\mathrm{B}}$ is

$$
L_{B}=L_{d}+L_{s} R
$$

One of the above three designs loading may be used as the nominal loading (L), depending upon the proposed use of the entry system.

Chain pillar strength, $\sigma_{p}$ is estimated by Bieniawski equation where in-situ coal strength, $\sigma_{\mathrm{c}}$ is assumed to be $900 \mathrm{psi}$. Then, the load-bearing capacity of an individual chain pillar is estimated as

$$
B_{p}=\frac{144 \sigma_{p} l_{p}}{l_{p}+W_{E}}
$$

and the load-bearing capacity of the chain pillar system is

$$
B=\Sigma B_{p}
$$

Therefore, the stability factor is simply defined as the load-bearing capacity (B) divided by the nominal design loading (L). That is 


$$
S F=\frac{B}{L}
$$

A stability factor of $1.0-1.3$ is suggested for design of stable chain pillar system by ALPS method.

\section{$\square$ Carr and Wilson's Method}

When a pillar is initially developed, Carr and Wilson (1982) assume that it consists of two zones, an outer "yield" zone and an elastic inner core. The yield zone has failed and can take no more loads, but it provides constraint to the core, which usually take most of the load-bearing capacity of the pillar. Initially, the greatest stresses in the pillar are found at the boundary between the two zones. As additional longwall loadings are applied, the stress in the pillar core increases until it equals the peak stress at the yield zone boundary. Up until this point, which Wilson calls the Limit of Roadway Stability (LRS), both the pillar and entries adjacent to it are expected to be stable. Further loading of the pillar causes the yield zone to expand and result in increased horizontal stresses that can damage the nearby roadways. Finally the Ultimate Limit (UL) is reached when the entire core has yielded. Any additional loads will now be transferred to adjacent pillars. The following steps are required to use their method.

- Estimation of the total side abutment load (pounds per foot of gate entry)

$$
L_{s s}=0.5 W_{m} \gamma\left(H-\frac{W_{m}}{1.2}\right) \quad W_{m}<0.6 H
$$




$$
L_{s}=0.15 \gamma H^{2} \quad W_{m}>0.6 H
$$

where $\mathrm{W}_{\mathrm{m}}$ is panel width, $\mathrm{ft}$; $\mathrm{H}$ is overburden depth, $\mathrm{ft}$.

- Calculation of the peak abutment stress $\sigma(\mathrm{psf})$ and shape constant $\mathrm{C}(\mathrm{ft})$

$$
\begin{gathered}
\sigma \equiv=\frac{k q s+\sigma}{\sigma-q}{ }_{o}^{L} \\
k=\frac{1+\sin \varphi}{1-\sin \varphi} \\
q=\gamma H
\end{gathered}
$$

- Calculation of the average abutment stress on each pillar

Suppose that a pillar system consists of 2 pillars, pillar A and pillar B. The average abutment stresses are respectively

$$
\sigma_{A}=\frac{\sigma-q}{x_{2}-x_{1}}\left[C\left(e^{-\frac{x_{1}}{C}}-e^{-\frac{x_{2}}{C}}\right)\right]
$$




$$
\sigma_{B}=\frac{\sigma-q}{x_{4}-x_{3}}\left[C\left(e^{-\frac{x_{3}}{C}}-e^{-\frac{x_{4}}{C}}\right)\right]
$$

where $\mathrm{x}_{1}, \mathrm{x}_{2}, \mathrm{x}_{3}, \mathrm{x}_{4}$ are coordinates of the edges of pillars $\mathrm{A}$ and $\mathrm{B} ; \mathrm{x}_{1}=$ width of entry $\mathrm{A}, \mathrm{ft}$, $\mathrm{x}_{2}=\mathrm{x}_{1}+$ width of pillar A, $\mathrm{ft} ; \mathrm{x}_{3}=\mathrm{x}_{2}+$ width of entry B, $\mathrm{ft} ; \mathrm{x}_{4}=\mathrm{x}_{3}+$ width of pillar $\mathrm{B}, \mathrm{ft}$.

- Estimation of the total initial average pillar stress on each pillar

$$
\begin{gathered}
\sigma_{P A}=\sigma_{A}+q \\
\sigma_{P B}=\sigma_{A}+q
\end{gathered}
$$

The load-bearing capacities for the pillars are calculated by using the solutions of Wilson pillar strength integrals (LRR abd UL) in different roof-floor conditions.

For yielding roof and floor condition (YRF):

The total pillar resistance (lb) 


$$
\begin{gathered}
L R S=8(Y 1)+(Y 2)+3(Y 3)+Y 4 \\
Y 1=\left(\frac{m p^{\prime}}{2}\right)\left[\frac{\left(\frac{2 x_{b}}{m}+1\right)^{k+1}-1}{(k+1)(2 / m)}-x_{b}\right] \\
Y 2=\left(w^{\prime}-2 x_{b}\right)\left(\frac{m p^{\prime}}{2}\right)\left[\left(\frac{2 x_{b}}{m}+1\right)^{k}-1\right] \\
Y 3=\left(w-2 x_{b}\right)\left(\frac{m p^{\prime}}{2}\right)\left[\left(\frac{L x_{b}}{m}+1\right)^{k}-1\right] \\
Y 4=\left(w^{\prime}-2 x_{h}\right)\left(w-2 x_{h}\right)\left(k q-\sigma_{o}\right) \\
U L=8(Y 1)+2(Y 2) \\
x_{b}=\frac{m}{2}\left[\left(\frac{8}{p}\right)^{\frac{1}{k-1}}-1\right] \\
\left(X_{b}=W / 2\right)
\end{gathered}
$$


For rigid roof and floor condition (RRF):

The total pillar resistance (lb)

$$
\begin{gathered}
L R S=8(R 1)+(R 2)+3(R 3)+R 4 \\
R I=\frac{k p^{\prime} m}{F}\left[\left(\frac{m}{F}\right) e^{\frac{x_{b F}}{m}}-\frac{m}{F}-x_{b}\right] \\
R 2=\left(w^{\prime}-2 x_{b}\right)\left(\frac{k p^{\prime} m}{F}\right)\left[\left(\frac{m}{F}\right) e^{\frac{x_{b F}}{m}}-1\right] \\
R 3=\left(w-2 x_{b}\right)\left(\frac{k p^{\prime} m}{F}\right)\left[\left(\frac{m}{F}\right) e^{\frac{x_{b F}}{m}}-1\right] \\
R 4=\left(w^{\prime}-2 x_{b}\right)\left(w-2 x_{b}\right)\left(k q+\sigma_{o}\right) \\
x_{b}=\left(\frac{m}{F}\right) \ln \left(\frac{q}{p^{\prime}}\right) \\
F L=\left(\frac{k-1}{k}\right)^{2}+\left(\frac{k-1}{k}\right) \tan ^{-1} k \\
(R 1)+2(R 2)
\end{gathered}
$$


where $\mathrm{x}_{\mathrm{b}}$ is width of yielding zone, $\mathrm{ft}$; $\mathrm{w}$ is a least pillar dimension, $\mathrm{ft}$; $\mathrm{w}$ ' - a greatest

pillar dimension, $\mathrm{ft}$; $\mathrm{p}^{\prime}$ is uniaxial strength of fractured coal, $\mathrm{psf} ; \mathrm{m}$ is extraction height, $\mathrm{ft}$.

For determination of chain pillar stability, three cases are possible:

(a) If the applied stress is less than the LRS, the pillar is presumed stable;

(b) If applied stress exceeds the LRS but is still less than the UL, then the entry may be damaged but no load transfer occurs; and

(c) If the applied stress is greater than the UL, then additional load, or the transferred remnant load (TRL) will be transfered to the pillar in the next row.

In a latter paper, Carr et al., (1985) proposed using a "pillar resistance to load ratio," or stability factor. They suggested that a stability factor of 1.4 should be used for abutment pillars subjected to tailgate loading, while 1.0 is adequate for single-use pillars.

\section{$\square$ Hsiung and Peng's Method}

Hsiung and Peng's method directly incorporates some properties of the roof and floor into the pillar design, such as Young's modulus of coal, immediate roof, main roof and floor. This method was developed from numerical model by using three-dimensional finite element model and multi-variable regression technique (Husung and Peng, 1985). The final result 
of the modeling for a square pillar in three-entry systems is

$$
\begin{gathered}
\log w=-4.676 \times 10^{-3} \frac{E_{i}}{E_{c}}-4.04 \times 10^{-3} \frac{E_{m}}{E_{c}}-3.33 \times 10^{-2} \log \frac{E_{f}}{E_{c}}-7.29 \times 10^{-2} \log \sigma_{c} \\
+0.5144 \log H+0.0494 \log \frac{L}{2}+0.1941 \log W_{m}
\end{gathered}
$$

where $\mathrm{w}$ is chain pillar width, $\mathrm{ft}$; $\mathrm{E}_{\mathrm{i}}$ is Young's modulus of immediate roof, psi; $\mathrm{E}_{\mathrm{c}}$ is Young's modulus of coal, psi; $\mathrm{E}_{\mathrm{m}}$ is Young's modulus of main roof, psi; $\mathrm{E}_{\mathrm{f}}$ is Young's modulus of floor, psi $\sigma_{\mathrm{c}}$ is minimum uniaxial compressive strength of laboratory coal specimen, psi; $\mathrm{H}$ is overburden depth, $\mathrm{ft} ; \mathrm{W}_{\mathrm{m}}$ and $\mathrm{L}$ are panel width and length, $\mathrm{ft}$, respectively.

For a rectangular pillar $\left(\mathrm{W}_{\mathrm{c}} \mathrm{xB}_{\mathrm{c}}\right)$, the following converting equation is used

$$
w=W_{c}^{0.85} B_{c}^{0.15}
$$

\section{$\square$ Choi and McCain's Method}

This method combined results from field studies, numerical modeling and practical experience (Choi and McCain, 1979). The pillar load and pillar strength estimate are combined into a single equation.

$$
P=0.6 H-1.2 \sqrt{\frac{H^{2}}{4}-\frac{5}{3}\left[\left(\frac{w_{A} l_{p}}{l_{p}+w_{e}}\right)\left(\frac{\sigma_{p}}{24.9 S F}\right)-\left(w_{A} H\right)-\left(\frac{w_{e} H}{2}\right)\right]}
$$


However, the SF can be derived by rearranging the above equation. That is

$$
\begin{gathered}
S F=\frac{A w_{A}^{1.5}}{H w_{A}-B} \\
A=\frac{l_{p} \sigma_{c}}{24.9 h\left(l_{p}+w_{e}\right)} \\
B=\frac{3}{5}\left[\left(\frac{0.6 H-P}{1.2}\right)^{2}-\frac{H^{2}}{4}\right]-\frac{w_{e} H}{2}
\end{gathered}
$$

where $\mathrm{H}$ is overburden depth, $\mathrm{ft}$; $\mathrm{w}_{\mathrm{A}}$ is abutment pillar width, $\mathrm{ft}$; $\mathrm{l}_{\mathrm{p}}$ is pillar length, $\mathrm{ft}$; we is entry width, $\mathrm{ft}$; SF is safety factor, 1.3; and $\sigma_{\mathrm{p}}$ is pillar strength, psi, determined by the Holland-Gaddy formula.

Choi and McCain suggested that a safety factor of 1.3 should be employed with their method.

\subsubsection{Evaluation of Floor Stability}

Generally, floor failure includes floor heave and floor buckling. Floor heave is due mainly to pillar punching into the floor. Floor buckling is the combination of strong floor rock and high in-situ horizontal stress. The characteristics of floor failure were conducted 
by some researchers. However, stability analysis of floor in mining practice is mainly based on the foundation engineering theory (Hans, 1975). Chung and Pytel (1992) modified this method in order to estimate the floor bearing capacity under mining conditions. The floor baring capacity, therefore, depends on both geometry and properties of pillar, entry, and immediate floor and main floor. Finally, the floor stability is also evaluated by using safety factor analysis although no "critical value" of safety factor is recommended yet according to their study. The floor safety factor is defined as

$$
S F=\frac{q}{\sigma_{v}}
$$

where $\sigma_{\mathrm{v}}$ is the stress of floor underneath the pillar, psi; and $\mathrm{q}$ is the floor bearing capacity, psi which is calculated by the following equation:

$$
\begin{gathered}
q=C(1) x N_{m} \\
C(1)=\left[2070-167\left(W_{c}\right)\right] \times k \\
\beta=\frac{B L}{2(B+L) t}
\end{gathered}
$$




$$
\begin{gathered}
r=\frac{0.6 C(2)}{C(1)} \\
N_{m}=\frac{r N_{c}^{*}\left(N_{c}^{*}+\beta-1\right)\left[(k+1) N_{c}^{* 2}+(1+\beta r) N_{c}^{*}+\beta-1\right]}{[r(r+1)+r+\beta-1]\left[\left(N_{c}^{*}+\beta\right) N_{c}^{*}+\beta-1\right]-\left(r N_{c}^{*}+\beta-1\right)\left(N_{c}^{*}+1\right)}
\end{gathered}
$$

where $\mathrm{C}(1)$ and $\mathrm{C}(2)$ are the cohesive strengths of the immediate (or weaker) and main floors, psi, respectively; $\mathrm{W}_{\mathrm{c}}$ is the nature water content of the immediate floor, $\%$; $\mathrm{k}$ is a strength reduction factor; $\mathrm{N}_{\mathrm{m}}$ is the modified bearing capacity factor; $\mathrm{r}$ is the strength ratio of the main to immediate floors; $\mathrm{N}_{\mathrm{c}} *$ is the bearing capacity factor; $\mathrm{B}$ and $\mathrm{L}$ are pillar width and length, respectively, $\mathrm{ft}$; and $\mathrm{t}$ is thickness of the immediate floor, $\mathrm{ft}$.

Throughout the literature reviews, it is recognized that many failure criteria have been proposed to deal with the stability of mine entry. But the safety factor analysis is utilized eventually as a final assessment on stability design and evaluation of mine roof, pillar and floor. And, it has a long history and wide practice base. However, the following questions are always asked when this approach is used:

- Which method(s) should be used for estimation of structure strength of roof, pillar and floor?

- Which number of safety factor should be selected as the "critical value"? 
- How much confidence can be depended on the selected safety factor for that structure stability?

- How significant is the effects on stability of roof, pillar and floor due to uncertainties of coal/rock properties and loadings ? and

- How can the stability of mine entry be evaluated as a whole ?

The preceding questions are critical because they are not only a fundamental study in coal mine ground control but also an important issue for mine operators in terms of safety and economic. However, those problems cannot be solved by using the safety factor analysis alone due to its limitations in that average values both structure strength (or capacity) and stress (or demand) are used and the variations of strength and stress are not taken into account.

\subsection{Probability-based Principles on Assessment of Mine Entry Stability}

Probabilistic analysis on structure stability initiated early in the 60's in geotechnical engineering. Wane, et al. (1964) introduced the probabilistic approach as a method of parameter selection for analysis of structure behavior since random phenomena are involved. Casagrana (1964) pointed out that risks are inherent in any project and probabilistic concept may be one of the alternatives to deal with them. Whitman (1964) illustrated the 
applications of the probabilistic risk concept in geotechnical fields with practical examples. Bowles et al., (1987) stated that the probabilistic approach has the advantage of explicitly determining the degree of safety for particular structure, and quantitatify all risk factors. Keaton and Echoff (1990) extended the probabilistic approach into flood, landslide and earthquake hazard management. In the United Kingdom, Grosschalk et al., (1994) published an engineering guide to seismic risk for dams, as an objective means of determining realistic and satisfactory levels of safety. According to the probabilistic approach, the issue as to how much risk is acceptable is central.

The probabilistic concept in the mining engineering is still new although the conventional safety factor analysis on stability of mining structure was refereed as "a factor of ignorance" due to much more uncertainties around underground mining environment. Coal/rock properties as random variables were mentioned from a few literatures (Unrug et al., 1995; Hirt and Shakoor, 1992; Sun and Peng, 1997). The probabilistic approach was also introduced by a few authors to deal with such uncertainties in a current stage for mining structure as follows;

Pytel et al., (1994) modified their deterministic approach for mine floor design by using reliability principles in order to better understand the weak floor failure and its impact on panel/pillar in the Illinois Basin. They concluded that the ultimate bearing capacity of weak floor strata, nature water content, weak floor strata deformability, angle of internal friction, immediate floor and main floor thicknesses behaved as random variables. They considered that those properties had lognormal or gussion distribution and used the capacity- 
demand approach with Taylor Series expansion method to obtain the reliability. However, they concluded that "This technical become extremely laborious and time-consuming" since the joint density function of all random variables are involved in their method, then "an approach based on conditional distribution function was utilized" (Pytel et al., 1994).

According to the results from the laboratory testing conducted by Gao and Kim (1994), the properties of rock (even hard rock around nuclear waste repositories) were consistent with the well-known Weibull's distribution due to the nature of the inherent variability of the rock. Therefore, the probabilistic approach was recommended for design of rock structure rather than using the traditional safety factor approach.

Chen et al., (1996) introduced the potential applications of probabilistic analysis on mining excavation stability. Based on the beam theory, one hypothetic example of roof stability was demonstrated by using the probabilistic approach. The thickness of an immediate roof, tensile strength and unit wight of roof were treated as random variables. Those variables were assumed as normal distributions in order to easily perform the capacity-demand approach with Taylor Series expansion for determination of the probability of failure of the roof. The results showed that the probability of failure was correspondent to the safety factor once certain constrains were given.

Peng et al., (1996) initiated the probability-based assessment of roof fall in mine entry by incorporating the finite element structure analysis to determine stress redistribution on the roof. The failure index on each element was determined within the domain of interest in the roof by converting the safety factors to probability of failure which considered the 
uncertainty of rock properties. Then dynamic programming approach was utilized to trace the potential domain of roof fall.

Recently, Sun and Peng (1997) modified this concept and extended their research area to the development of a reliability-based method on analysis of stability of mine entry system. Their approach uniquely established a general procedure to take the variability of both the loads induced by mining activities and the coal/rock properties into consideration. Rather than using the capacity-demand approach with a Taylor Series expression, safety margin, depending on the failure function of roof, pillar and floor was utilized to measure the reliability. Point estimate method to estimate statistical parameters was introduced due to its advantages of no distribution requirement and relative ease for reliability computation. Eventually, the reliability of roof, pillar and floor were determined. They concluded that the conventional safety factor analysis "really does not fully meet the requirements for stability design and evaluation of the mine entry system once the mine entry failure is recognized as a probabilistic concept". The reliability analysis was addressed and "It is anticipated that, by using this approach, the current techniques of stability assessment will be elevated to a higher level of confidence." 


\section{CHAPTER 3}

\section{VARIABILITY ANALYSIS ON COAL/ROCK PROPERTIES}

The mechanical and physical properties of coal measure rock strata in coal mines (i.e., uniaxial compressive strength, shear strength, Young's modules, Poisson's ratio, unit wight, etc.) play a vital role in stability design and evaluation on underground openings. Due to its variability both randomly and systematically, the properties of roof, coal seam, and floor from either the laboratory or in-situ tests exhibit some mathematical distributions rather than a deterministic value from one site to another. Therefore, it is essential to understand those characteristics for formulation of a probability-based approach rather than only using the conventional safety factor (SF) analysis to evaluate the stability of underground openings. Consequently, a quantitative level of confidence on structure safety can be obtained.

The magnitude and accuracy of mechanical properties of coal measure rock strata in coal mines control safety assessment of ground control in practice because some of the properties have to be incorporated into both capacity and demand estimations in the design process of a mining structure. Any failure criterion, eventually, depends on coal/rock properties. Therefore, tremendous studies have been focused on qualification of coal/rock properties for the last 50 years. However, in most cases, these studies had only limited success. Thus it is very dangerous to generalize the findings and use them in all cases. An 
understanding of the sources of the variability from coal/rock properties and basic statistical principles as well as knowledge about the possible range of variability is necessary for optimizing and accurate design of underground mining structures.

The following sections show the sources of variability, coal/rock classifications and variability descriptions as well as variability demonstrations of the coal/rock properties.

\subsection{Source of Variability of Coal/Rock Materials}

Variability of coal/rock properties can be attributed to two types of errors (or difference between measured and true values): random and systematic. Random errors generally related to the inherent variability of the material and are usually unpredictable and uncontrollable. Systematic errors, on the other hand, are generally associated with sampling and testing bias, and depend on the human element, and may be predicted or controlled, but only to a certain degree. 


\subsubsection{Inherent Variability}

During design procedure on underground mining structure, the physical properties of coal/rock are frequently conceptualized as homogeneous, isotropic, horizontally-bedded layer with constant values. In reality, due to long past accumulation of coal/rock generations, the impurity's components, i.e., nitrogen, sulfur, iron and various inorganic substances (i.e. ash) are chemically and structurally a part of coal. These impurities, which are separable, constitute coal seam and affect its characteristic. Generally, the rock formations immediately above and below the coal seam represent a large portion of the material in coal refuse. The character of that rock varies from seam to seam and geographically within a single coal seam, depending on the geological condition proceeding and following the deposition of the coal forming materials. Inorganic sedimentary rock, such as claystone, siltstone, shale, sandstone and occasionally limestone, comprise the bulk of the strata in which the coal is contained. Therefore, the physical properties of coal/rock often exhibit significant variation from point to point, even within nominally a homogenous layer. A typical overburden strata above Pittsburgh seam as shown in Fig. 3.1 (Peng, 1986) indicates that formation process of coal/rock may have different stages even for same coal seam. 


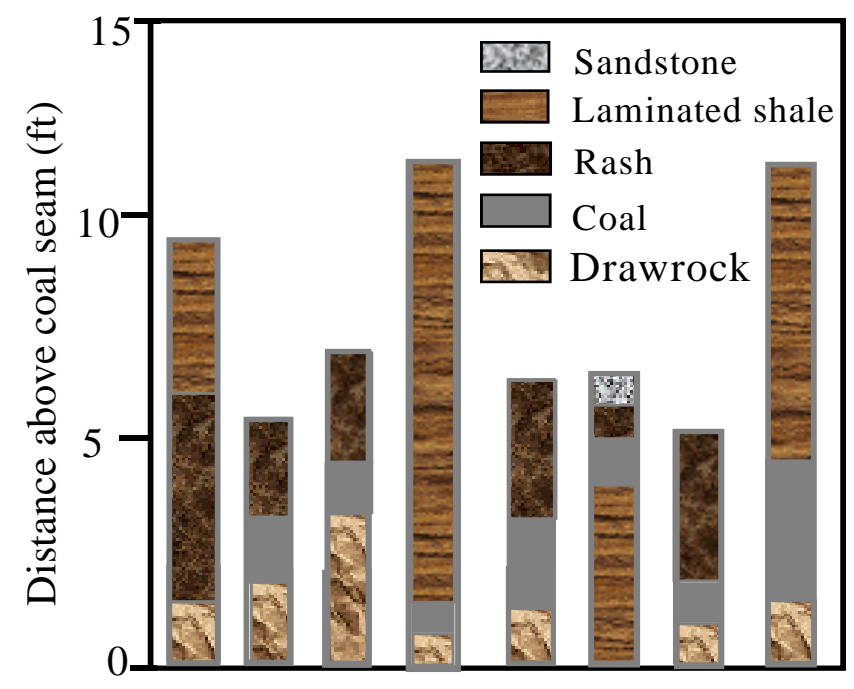

Fig. 3.1 Overburden Types Above Pitts. Seam

\subsubsection{Sampling and Testing Variability}

Systematic errors causing variability in the measured values of the coal/rock properties primarily stem from human inability to obtain truly representative and truly undisturbed samples as well as from the limitations of the existing testing procedures to simulate the actual environment that the coal/rock are subjected to in-situ. Sampling and testing of coal/rock specimens are two types of sources causing the systematic variability.

\subsubsection{Sample Randomization and Disturbance}

Due to geological and economic constrains, sample size is usually limited. So randomization procedure is often inapplicable in practice for mine entry design. Generally, sample disturbances during transportation to the laboratory and/or preparation for testing, and 
unscrupulous performance of the standard test procedures by humans compound these errors. All "undisturbed" samples undergo some degree of disturbance before, during and after sampling, although most of these disturbances can be reduced in extent by the use of appropriate sampling techniques and equipments, and careful workmanship. The magnitudes of sample disturbances depend on such factors as type of sampler, sampling procedure, time between sampling and testing, handling of the sample, type of laboratory test, and coal/rock properties to be determined. Generally, sample disturbances can be taken place once it is subjected to any one of the following conditions:

- change in stress condition;

- change in water content;

- disturbance of the coal/rock structure;

- chemical change;

- change from attached materials on top and bottom; and

- mixing and segregation of coal/rock constituents.

\subsubsection{Testing Errors}

Both laboratory and field tests are subjected to errors originating from the use of substandard and/or poorly calibrated testing equipment, as well as the human element involved in testing. Consequently, testing should be coordinated and performed by qualified personnel, and extreme care should be exercised in following the prescribed standard procedures. Most of the errors in these tests may stem from inaccurate calibrations on size and shape effects of specimens, water content determination, specimen transportation, 
storage, preparation and placement into the testing apparatus. In many instances, it can be difficult to control or detect these problems during testing.

Human errors in testing ranges from sample mistakes, such as misreading or misrecording a measurement, to judgmental errors in interpreting a standard procedure, or employing inappropriate assumptions (i.e., performing a triaxial test within an unrepresentative range of confining pressures). The causes of human error are not completely understood; they probably arise from the physiological and psychological attributes of man (Ingles, 1979). In mining engineering, it is a common practice to test coal/rock samples in the laboratories to simulate actual conditions in the fields. This requires difficult-to-verify assumptions about the state of stress, strength, moisture content, attached materials from top and floor and field geological conditions associated with the samples. In interpreting the test results, additional assumptions are made concerning the boundary conditions and the uniformity of the stresses and strains in the sample during testing. Many of these assumptions are necessary to facilitate analysis and interpretation of test results; however, they are all potential causes of bias, and, ultimately, of errors in response and performance prediction (Vanmarcke, 1977). Currently, computerized data acquisition are being used in-situ testing. This may be able to make a remarkable reduction on the testing errors due to human elements.

From studying the precision and accuracy of soil tests (Lumb,1970), Lumb suggested that the inherent variability of natural material overwhelms the effects of test imprecision. It has also been pointed out that, while repeatability from one laboratory or operator to another is not of much concern for tests on the properties of undisturbed material, a real 
problem exists for classification tests, which are performed on disturbed material samples.

\subsection{Coal /Rock Classifications and Statistical Descriptions of Variability}

Generally, there are two types of methods, which may be summarized for estimation of rock mass quantity. One is a classification method by characterizing the quality of rock mass in various ranks. Other is a probabilistic approach to consider coal/rock properties as random variables due to uncertainty behavior both inherent and systematic.

\subsubsection{Coal/rock Classification Systems}

The quality of rock mass can be measured by classification methods. This approach was first initiated via tunneling application in 1946. Since that time, RQD (Rock Quality Designation) system was developed by Deere and Deere in 1963 (Kirkaldie, ed., 1988). Based on RQD, two other classification systems were formulated. One is the $\mathrm{Q}$ system by Barton et al., (1974) and the other the RMR system (Rock Mass Rating) by Bieniawski (1976). These preceding systems were substantiated for civil engineering applications. Later on, MRMR (Mining Rock Mass Rating) system, specifically for mining applications, was developed by Laubscher and Taylor (1976) and modified by Laubscher (1984). Currently, the CMRR (Coal Mining Roof Rating) system was constructed by Molinda and Mark (1994) ranks a coal mine roof as a function of individual unit properties. Regardless of some discrepancies among those systems and its laborious process of characterizations, 
they are widely used as a general guideline for different fields in practice for estimations of coal/rock quality with a single deterministic rank. However, without considerable insight, intuition, experience and engineering judgment, it may be difficult to utilize those classification systems in more appropriate way.

\subsubsection{Variability Considerations}

Due to random behavior of both inherent and systematic, most current studies on coal/rock properties intend to take variability into account. Rock mass properties, especially for coal measure rock strata in coal mines, have been gradually characterized with probabilistic approach so that variances of coal/rock properties can be taken into consideration. For example, on the compressive strength of coal, even in relatively close locations, the difference could be as much as five times or more (Unrug et al. 1995). The range in coefficient of variances of coal strength varied from $15 \%$ to $43 \%$ with an average of $28 \%$ for samples obtained from 12 mines and approximately 20 coal samples were tested from each mine (Hirt and Shakoor, 1992). They concluded that coal compressive strength is highly variable within and between seams. This suggests that the compressive strength of coal should be determined individually for each mine with large number of sample size from varied mine locations to represent horizontal and vertical variations within the seam. Pytel et al., (1994) concluded that properties of weak floor strata, such as ultimate bearing capacity, nature moisture content, weak floor strata deformability, angle of internal friction, immediate floor and main floor thicknesses, behaved as random variables. They considered those properties had lognormal or gussion distribution. Thus, the capacity-demand approach 
with Taylor Series expansion method was utilized to design the floor capacity with the reliability analysis. According to the results from the laboratory testing conducted by Gao and Kim (1994), they concluded that the properties of rock (even hard rock around nuclear waste repositories), were consistent with the well-known Weibull's distribution due to the nature of the inherent variability of rock. Therefore, the probabilistic approach was recommended for the design of rock structure rather than using the traditional safety factor approach. Chen et al., (1996) introduced the potential applications of probabilistic analysis to mining excavation stability. Based on beam theory, the hypothetic example for assessment of roof stability was demonstrated by using the probabilistic approach. The thickness of immediate roof, tensile strength and unit weight of roof were treated as random variables and were assumed as normal distribution in order to easily perform the capacitydemand approach with Taylor Series expansion for the determination of the probability of failure of the roof. Sun and Peng (1993) presented a large variation of coal/rock properties for U.S. coal mines in a data bank. Peng et al., (1996) initiated a probability-based assessment on roof fall in mine entry by incorporating the finite element structure analysis. It was intended to take variation of rock properties into consideration.

\subsubsection{Statistical Descriptions of Variability}

Basically, statistics and probability methods can be used to describe and account for the variability of coal/rock properties since these methods allow people to better understand and to quantify coal/rock variability and aid in making inferences about a particular site on coal/rock type from a limited number of measurements. Therefore, an understanding of the 
basic statistical principles and knowledge about the possible range of variability of coal/rock properties is necessary for the design of mining structure on reliability basis.

Overall probability is one of the most used methods on variability study in geological engineering. By using this method, the coal/rock properties can be measured as random variables with traditional statistical data treatment techniques. Some common statistical formulas used in data analysis are listed as Table 3.1 (Hogg and Criag, 1995). 
Table 3.1 Statistical Parameters Commonly Used in Data Analysis

\begin{tabular}{|c|c|c|c|}
\hline Parameter & Estimating Formula & Significance & \\
\hline Mean & $\bar{x}=\frac{\sum x_{i}}{n}$ & Measure of central tendency & $(3.1)$ \\
\hline $\begin{array}{l}\text { Standard } \\
\text { Deviation }\end{array}$ & $s=\sqrt{\frac{\sum\left(x_{i}-\bar{x}\right)^{2}}{n-1}}$ & $\begin{array}{l}\text { Measure of dispersion about } \\
\text { the mean }\end{array}$ & $(3.2)$ \\
\hline $\begin{array}{l}\text { Coefficient of } \\
\text { Variation }\end{array}$ & $C V=\frac{s}{x} 100 \%$ & $\begin{array}{l}\text { Measure of the degree of } \\
\text { spread from the mean }\end{array}$ & $(3.3)$ \\
\hline $\begin{array}{l}\text { Coefficient of } \\
\text { Skewness }\end{array}$ & $\beta_{1}=\frac{\frac{1}{n} \sum\left(x_{i}-\bar{x}\right)^{3}}{s^{3}}$ & Measure of asymmetry & $(3.4)$ \\
\hline $\begin{array}{l}\text { Coefficient of } \\
\text { Kurtosis }\end{array}$ & $\beta_{2}=\frac{\frac{1}{n} \sum\left(x_{i}-\bar{x}\right)^{4}}{s^{4}}$ & Measure of peakedness & $(3.5)$ \\
\hline $\begin{array}{l}\text { Coefficient of } \\
\text { Correlation }\end{array}$ & $r_{x y}=\frac{\sum\left(x_{i}-\bar{x}\right)\left(y_{i}-\bar{y}\right)}{\sqrt{\sum\left(x_{i}-\bar{x}\right)^{2}\left(y_{i}-\bar{y}\right)^{2}}}$ & $\begin{array}{l}\text { Measure of linear } \\
\text { dependence of two } \\
\text { parameters }\end{array}$ & $(3.6)$ \\
\hline
\end{tabular}

Notes:

$\mathrm{X}_{\mathrm{i}}$ - value of each observation.

n - sample size. 


\subsection{Variability Demonstrations of Coal Physical Properties}

This section presents some tested results for coal properties conducted in the laboratories. Those data are partial evidences to show considerable variations of coal characteristics under coal mining environment. Therefore, the effects of variations of coal/rock properties on current design methods should be understood. And, a new method need to be developed to consider strength/stress variations in the design and evaluation procedures.

\subsubsection{Pittsburgh Seam}

About 200 Pittsburgh coal samples with uniaxial compressive strength (UCS) can be obtained from ROCKDBASE (Sun and Peng, 1997). Table 3.2 shows some statistical parameters of those data in terms of different coal mines.

Table 3.2 Statistical UCS Parameters of Pittsburgh Seam in Various Coal Mines

\begin{tabular}{c|c|c|c|c}
\hline $\begin{array}{c}\text { Mine } \\
\text { ID }\end{array}$ & $\begin{array}{c}\text { No. of } \\
\text { Sample }\end{array}$ & $\begin{array}{c}\text { Mean } \\
(\mathrm{psi})\end{array}$ & $\begin{array}{c}\text { Standard } \\
\text { Deviation }(\mathrm{psi})\end{array}$ & $\begin{array}{c}\text { Coefficient of } \\
\text { Variation (\%) }\end{array}$ \\
\hline Mine - 1 & 20 & 3,951 & 1,252 & 32 \\
Mine - 2 & 20 & 3,775 & 964 & 26 \\
Mine - 3 & 20 & 5,482 & 1,182 & 22 \\
Mine - 4 & 121 & 3,192 & 803 & 25 \\
\hline
\end{tabular}


It can be seen from Table 3.2 that the variability of coal strength is different in different mines, even though the mean strengths are close enough, i.e., Mine-1 and Mine-2. The distributions of coal properties (i.e., unaxial compressive strength, Young's modulus, Poisson's ratio and water contents) in Mine-4, as an example, are shown in Fig. 3.2. It can be observed that all properties of the coal are dispersed to certain degrees. Only few of them seem to follow a normal distribution. That fact of information justify further study on the stability of mine entry by reliability principle rather than the traditional safety factor analysis.

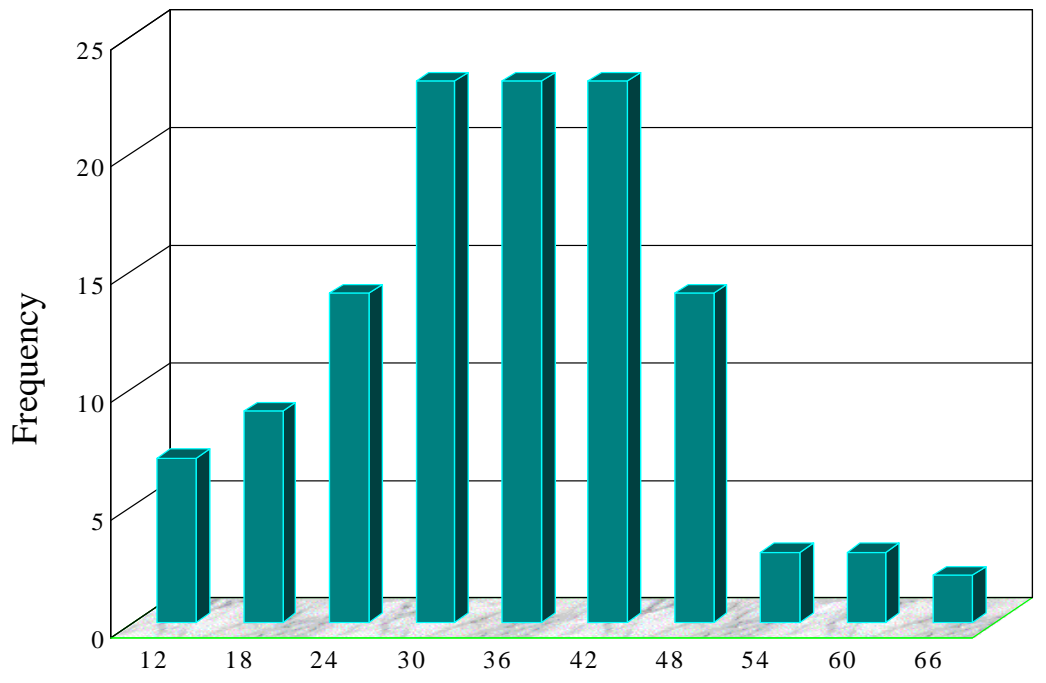

(b) Distribution of Young's Modulus $\left(\mathrm{x} 10^{\wedge} 4 \mathrm{psi}\right)$ 


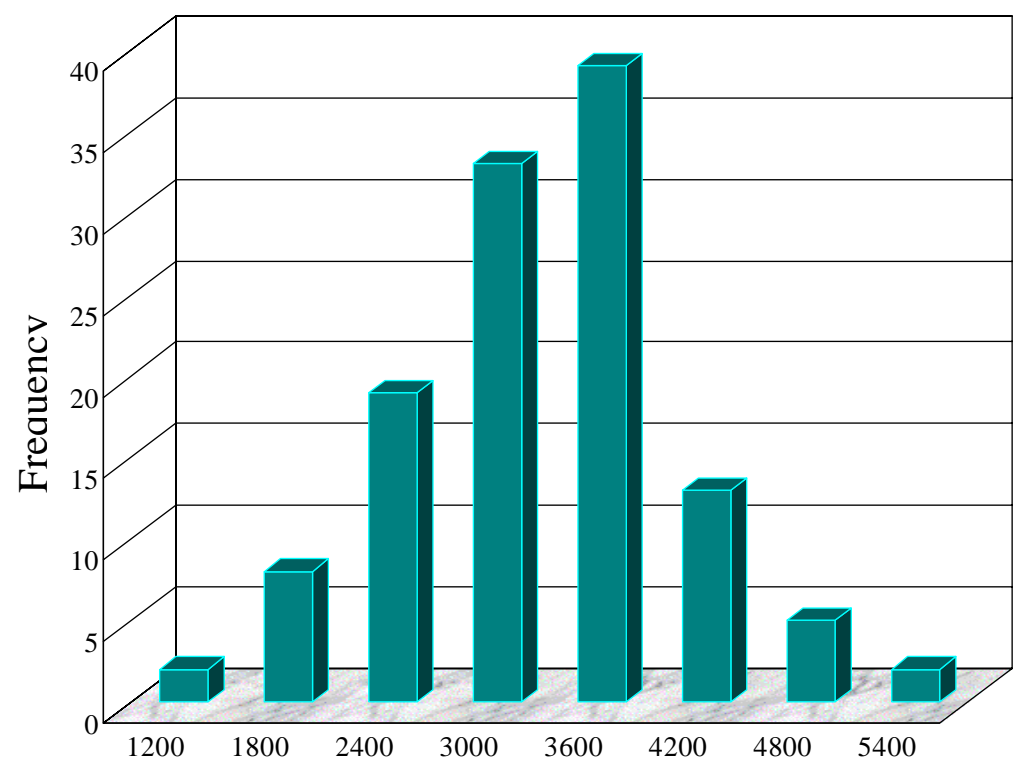

(b) Distribution of Strength (psi)

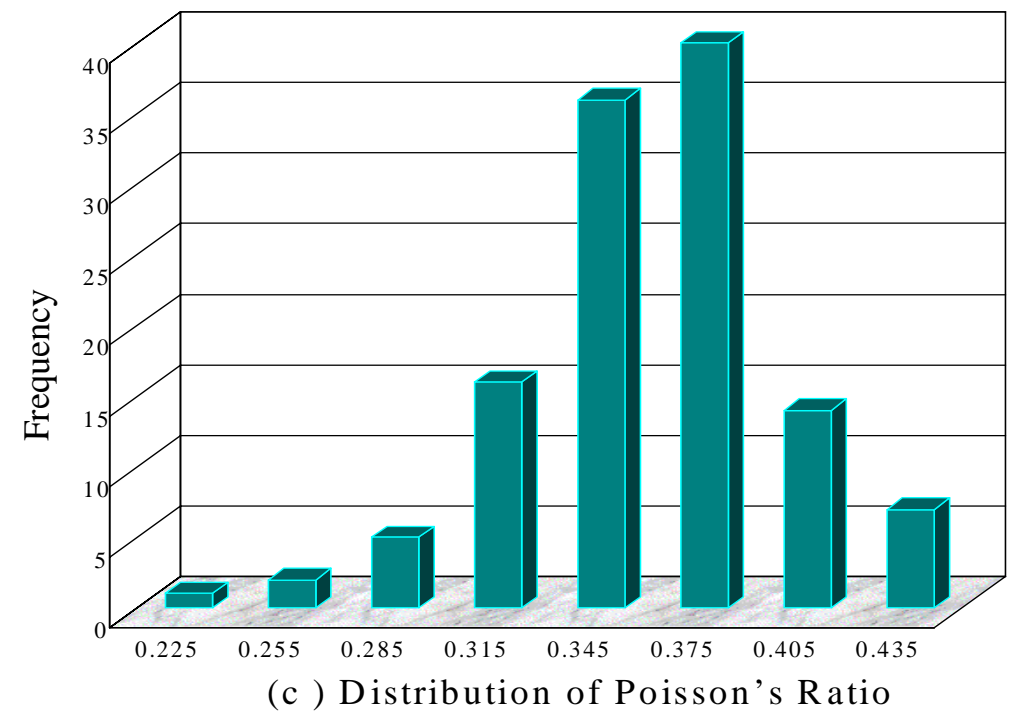




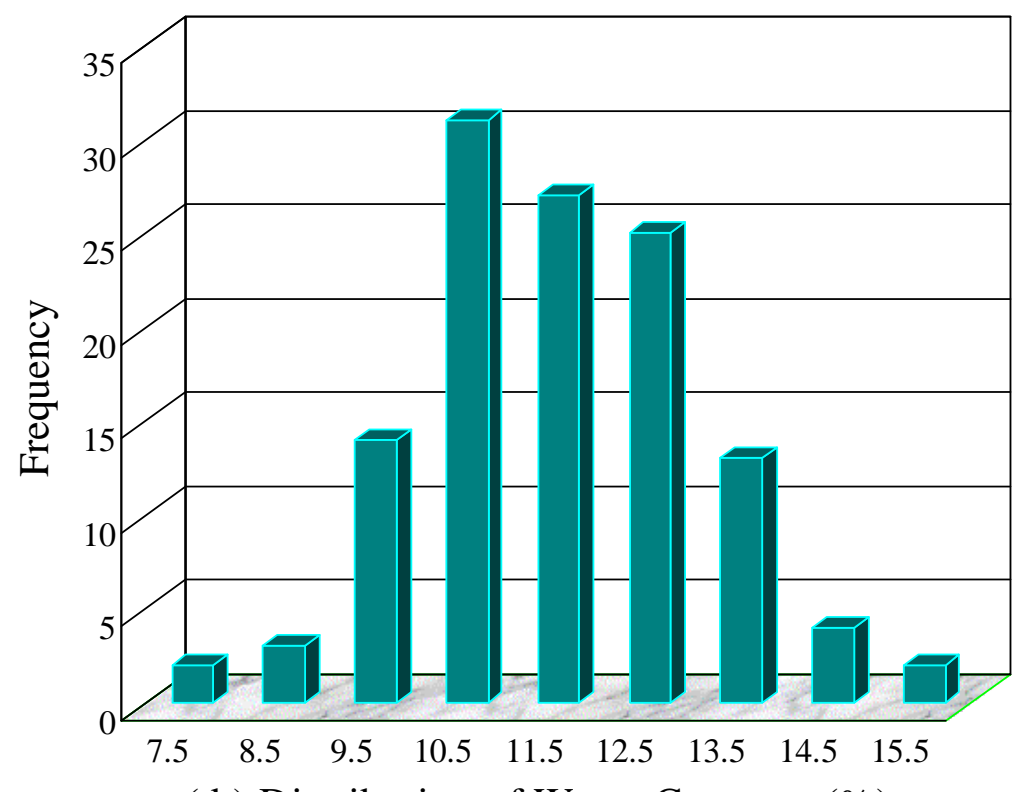

(d) Distribution of Water Contents (\%)

Fig. 3.2 Distributions of Coal Properties in Mine-4

\subsubsection{Pocahonatas Seam}

The statistical parameters of uniaxial compressive strength (UCS) may vary in different panels even in the same mine. This case study shows that a total of 121 coal samples from Pocahonatas seam is queried from ROCKDBASE (Sun and Peng, 1997). The statistical parameters of the uniaxial compressive strength of Pocahonatas seam in Mine A are summarized in Table 3.3. 
Table 3.3 Statistical UCS Parameters of Coal Properties in Different Panels in Mine A

\begin{tabular}{l|c|c|c|c|c|c}
\hline \multicolumn{1}{c|}{$\begin{array}{c}\text { Statistic } \\
\text { parameters }\end{array}$} & Panel 1 & Panel 2 & Panel 3 & Panel 4 & Panel 5 & Panel 6 \\
\hline $\begin{array}{l}\text { No. of sample } \\
\text { Mean (psi) }\end{array}$ & 19 & 20 & 16 & 28 & 20 & 19 \\
$\begin{array}{l}\text { Standard } \\
\text { Deviation (psi) }\end{array}$ & 353 & 382 & 879 & 296 & 233 & 543 \\
$\begin{array}{l}\text { Coefficient of } \\
\text { Variation }\end{array}$ & 0.33 & 0.48 & 0.66 & 0.30 & 0.23 & 0.32 \\
$\begin{array}{l}\text { Coefficient of } \\
\text { Skewness }\end{array}$ & -0.39 & 3.13 & 2.35 & -0.40 & -0.23 & -0.71 \\
$\begin{array}{l}\text { Coefficient of } \\
\text { Kurtosis }\end{array}$ & 0.22 & 1.77 & 1.64 & 0.08 & 0.03 & -0.18 \\
\hline
\end{tabular}

Fig. 3.3 shows the means and standard deviation of the uniaxial compressive strength in six different panels of Mine A. It can be recognized that the standard deviation of the coal strength is not proportional to the means. The coal properties may vary considerably in the same mine. It is anticipated that the stability of mine entry will not stand on the same levels, e.g. Panel 1 and Panel 5 due to different coefficients of variations if all other conditions are assumed to be the same. 


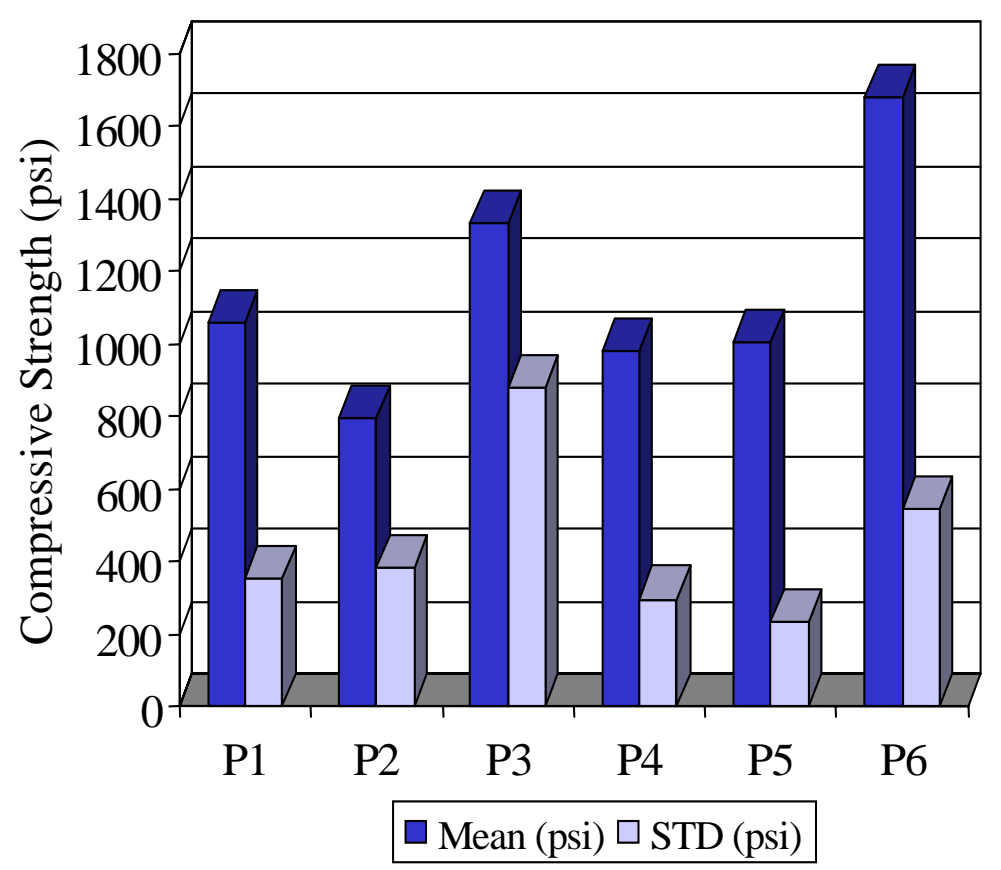

Fig. 3.3 Variations of Coal UCS in Different Panels 


\section{CHAPTER 4}

\section{UNCERTAINTY EFFECTS OF COAL/ROCK PROPERTIES ON STABILITY OF MINE ENTRY DESIGN}

Based on the conceptual principle of the conventional safety factor method, the variability of structure strength/stress is ignored from assessment procedure. The effects of strength/stress variation on structure stability, therefore, cannot be recognized from using the safety factor methodology and many basic questions related to structure stability cannot be answered according to this method. The following sections analyze the fallacies of design by the safety factor method and emphasize the uncertainty effects of coal/rock properties on mine entry design.

\subsection{Mine Entry Stability vs. SF}

As described early, a mine entry consists of three major components, i.e. roof, pillar and floor. The performance of mine entry, therefore, depends on a stable condition of either roof, pillar or floor. In other words, a mine entry failure may take place from either a single component or combination of these components. Although the criteria of mechanical failures may have different modes for roof, pillar and floor due to the functions of each component and expert insight, the conventional safety factor (SF) is eventually used in all methods to 
determine the stability condition of the components and mine entry.

The common term "safety factor" (SF) for the assessment of structure stability is defined as the ratio of the mathematical expectations of the carrying capacity, $E[R]$ to that of the loading-induced member stress, E[S], i.e.,

$$
S F=\frac{E[R]}{E[S]}=\frac{\bar{R}}{\bar{S}}
$$

Obert and Duveall (1967) recommended a SF of 2 to 4 for compressive failure and 4 to 8 for tensile failure. These wide ranges of SF imply that a higher SF is required for situations where a structure for long term service is subjected to more uncertainty. For pillar design in room-and-pillar mining, the pillar load is calculated by the tributary loading concept whereas the pillar strength is estimated by different methods. Salamon and Manro (1967) recommended a SF from 1.31 to 1.88 with an average of 1.57 for South African coals. Holland (1964) suggested a safety factor of 1.7-2.0. Bieniawski (1983) suggested a SF between 1.0 and 2.5 with an average of 1.73 . However, due to using a fixed coal pillar strength (930 psi), he suggested it "should be used as a guide only and the local experience should be taken into consideration." According to their investigations on the determination of safety factors against pillar crushing in 12 mines. Hirt and Shakoor (1992) found a SF ranging from 2 to 46 which were considered to be "overdesign" when compared with the recommended safety factor of 1.5 to 2.0. Recent research on retreat mining pillar stability (Mark et al., 1995) concluded that failed and stable pillars occur approximately in equal proportions when the SF ranged from 0.75 to 1.5 . After having reviewed more than 500 
cases of current pillar design practice in the U.S. room-and-pillar mines shown in Fig. 4.1, Tsang et al., (1995) concluded that the calculated SFs vary considerably and that the current practice of pillar design has very little or no usage of any suggested SF in real life of pillar design.

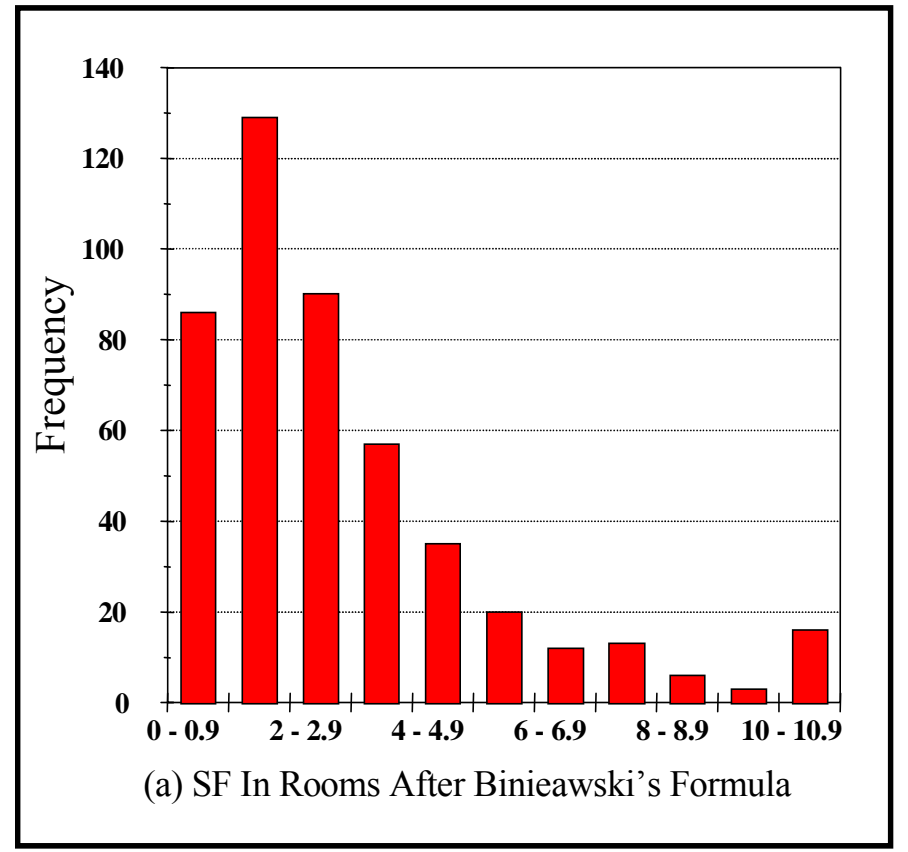




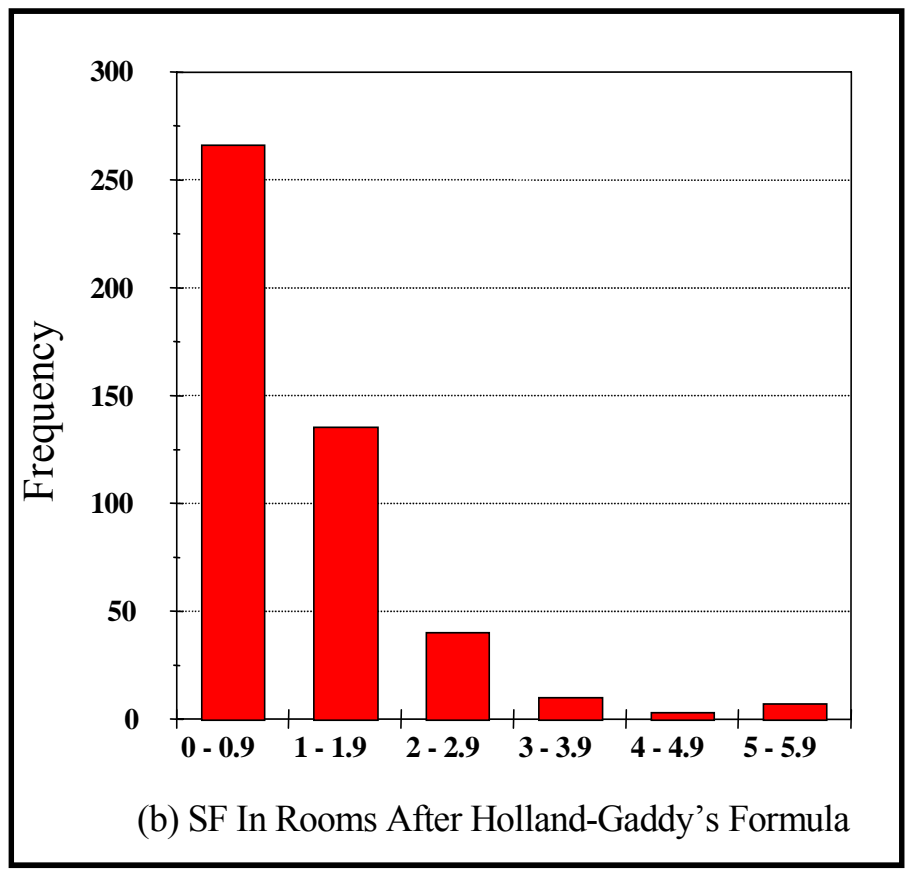

Figure 4.1 Variant SFs Used in Room-and-Pillar Mines

In longwall mining, Mark (1992) recommended a SF between 1.3 and 1.5, using a fixed coal pillar strength of 900 psi. However, Su and Hasenfus (1996) concluded that a coal pillar strength of about 950 psi \pm 150 psi will be sufficient for most U.S. bituminous coal seams for practical purposes.

To incorporate the considerable variability of coal/rock properties, the strength reduction factor is always introduced into the design practices based on the designer's experience although there is no rational basis for its selection (Fairhurst, 1973).

Overall, the concept of SF has a long history and has played a vital role in mine entry design and ground control practice due to its simplicity and common acceptance in 
engineering. It, in general sense, represents the safety level of a structure. However, the following comments and questions arouse frequently in its long history of application to the mine entry design:

$\square$ The SF is a single quantity derived from the classical deterministic structure design. It fails to scientifically incorporate the variability of coal/rock properties and loads induced by mining activity. In reality, the safety factor is referred as an "ingnoranace factor" even though the strength reduction factor is taken into account.

$\square$ The SF fails to clearly convey the level of confidence on structure stability quantitatively and qualitatively. For instance, there are many proposed methods for estimating the coal pillar strength without appropriately taking its variability in a specific site into consideration. Because of that, if the SFs of pillars in Mine A and Mine B are 1.5 and 1.3, respectively, it is not necessary true that the pillars in Mine A are safer than those in Mine B unless the coal/rock properties for both mines have identical statistical characteristics under similar loading conditions. Furthermore, there are no evidences why, for example, a SF of 1.5 and 1.3 is required for pillars in Mine A and Mine B, respectively, and how much safer is the pillars in Mine A than those in Mine B? $\square \quad$ The SF is misused to directly link with the possibility of structure failure. One cannot infer a value from one to another because the former is a deterministic value whereas the latter is a probabilistic analysis. In other words, there is no one-to-one relationship between the SF and potential failure (or stable condition). No pillar can be designed for $100 \%$ stable no matter how big the SF is. The pillar which has the SF within the "overdesign" range could have an intolerably higher probability of failure than others, depending on the uncertainty of 
strength and stress around those pillars.

\subsection{Effects of Variability on SF}

In general, once the means of strength and stress are used with a deterministic value of strength reduction factor, it leads to oversimplify the strength and stress distributions so that they appear as degeneration functions rather than in a dispersion manner. Therefore, much information is lost by forcing the continuous distributions of strength/stress into the nominal type of the categorical data. Under this situation, only three types of situations can be categorized for stability assessment by the formulated concept of the commonly used safety factor method as shown in Fig. 4.2. The questions raised above can be attributed to the concept of safety factor analysis. 


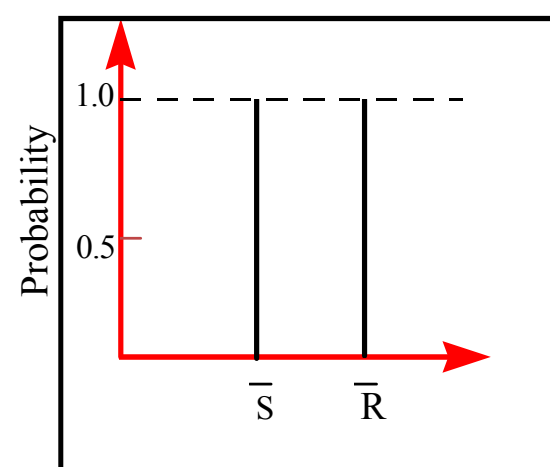

Type 1 (stable)

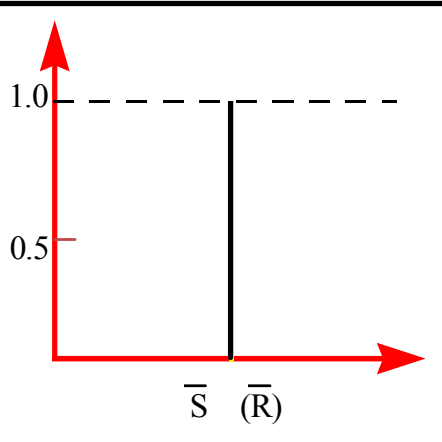

Type 2 (neutral)

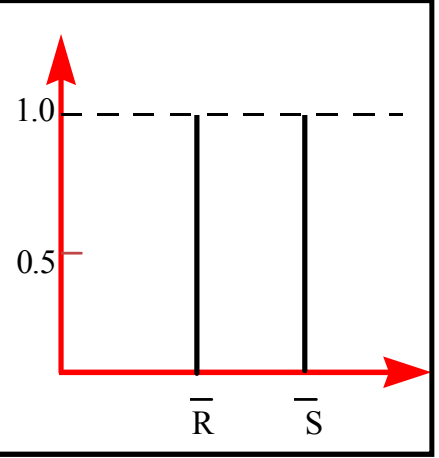

Type 3 (unstable)

Figure 4.2 Concepts of Commonly Used Safety Factor Analysis

Type 1 provides a stable condition since the mean strength, $\mathrm{R}$ is larger than the mean stress, $\mathrm{S}$ (or $\mathrm{SF}>1$ ). Type 2 indicates a balance condition due to equivalence of strength and stress (or SF $=1$ ). The structure is said to be in unstable or failure condition if the mean strength is less than the mean stress as shown in Type 3 (or $\mathrm{SF}<1$ ). Does a structure has the same degree of stability once two different SFs, i.e., 1.2 and 2.0, are used ? How do we quantify the stability difference if SFs are not the same? If a structure has $50 \%$ chance in an unstable condition when $\mathrm{SF}=1$, then, is it stable when $\mathrm{SF}=1.3$ ? Without taking the variability of stress/strength into consideration, the preceding questions may have no unique and solid answers.

Conceptually, if the dispersions of strength/stress are given, the stability can be evaluated by the probability of failure as shown in Fig. 4.3. If the strength/stress dispersions are assumed as normal distributions, the probability of failure, $P_{f}$ can be expressed as 


$$
P_{f}=\left[\frac{1}{2}-\Phi(\kappa)\right]
$$

where $\Phi$ is the Laplace function and $\kappa$ is a reliability index.

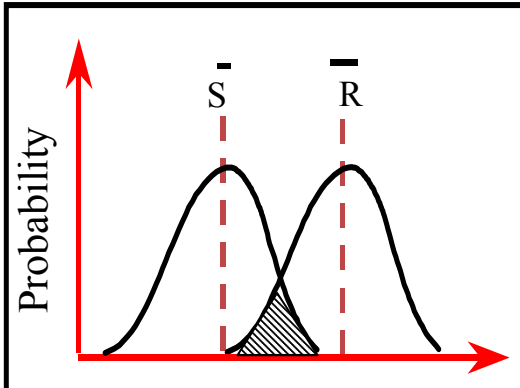

(a) Overlap with large variations

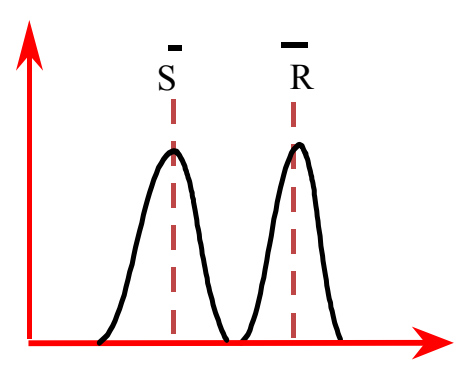

(b) No overlap with small variations

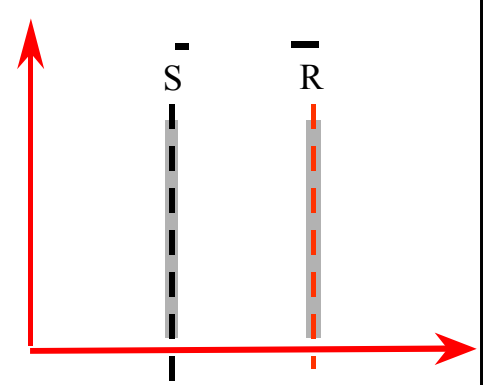

(c) No variations

Figure 4.3 Illustration of Probability of Failure

The shaded area as shown in Fig. 4.3a indicates a finite probability of failure whose magnitude is a function of the degree of overlap of the two distributions even though the mean strength is larger than the mean stress. As the overlap decreases under the same means but different variations of strength/stress, the shaded area (probability of failure) decreases proportionately as shown in Fig. 4.3b. However, if no variations of strength/stress is assumed as shown in Fig. 4.3c, then no failure will take place as long as the mean strength is larger than the mean stress. Thus there is a rational explanation for changes in probability of failure that goes with changes in strength/stress. Therefore, the stability of mining structure, in reality, not only depends on the mean values of strength/stress, but also subjects 
to the magnitudes and distributions of strength and stress. Without taking consideration of the latter, three possibilities exist in which the safety factor may remain the same but the probability of failure varies:

Case 1: The mean strength and stress may be changed in the same proportion but no change in the standard deviations. Thus

$$
S F=\frac{\bar{R}}{\bar{S}}=\frac{K \bar{R}}{k \bar{S}}=C
$$

Where $K R$ reflects a shift in mean strength, either right or left depending on $K$ (greater or less than one); similarly for $k s$. Fig. 4.4a illustrates the shift for $k>1$; Fig. 4.4b illustrates the shift for $k<1$. This demonstrates the limitation of SF as an indicator of failure incidences. 


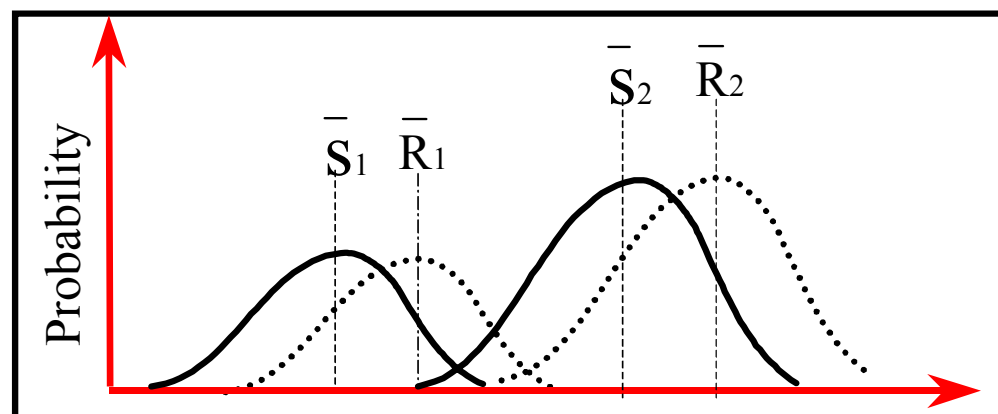

(a)

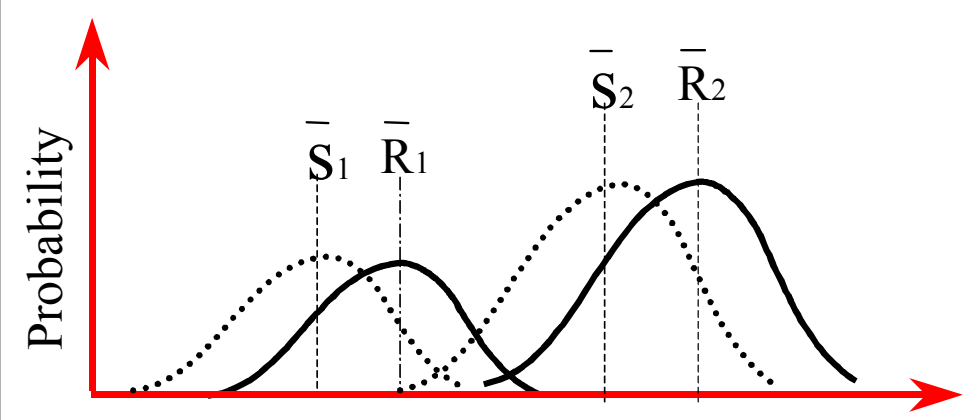

(b)

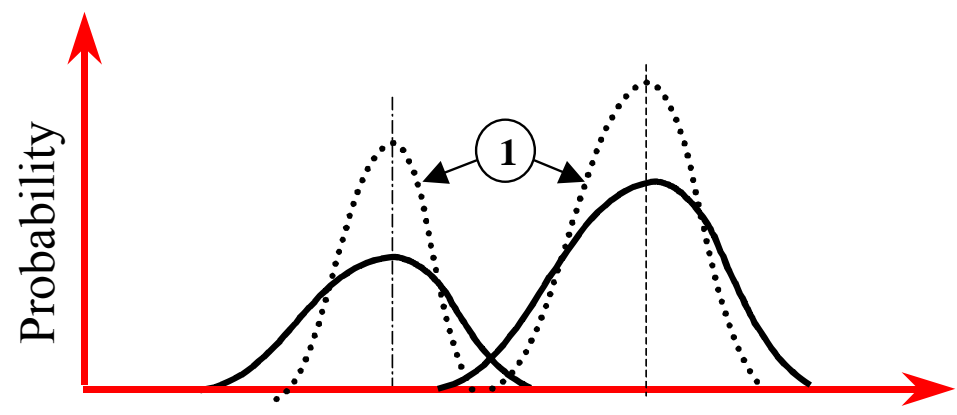

(c)

Figure 4.4 Effects of Probability of Failure Due to Proportional Changes in Mean Strength and Stress 
Case 2: If the mean values of strength/stress distributions are hold constant and the standard deviations are varied. As shown in Fig. 4.4c, decreasing the standard deviation of both distributions reduces the overlap area. Furthermore, reduction in overlap is observed when the standard deviation of but one distribution is reduced. Curve 1 shows the effect of decreasing one or both standard deviation, that is, the overlap and probability of failure decreases under constant means of strength and stress. Since the mean values did not change, the safety factor remains the same, but the probability of failure does change.

Case 3: It is possible to changes both the mean values and standard deviations without affecting the safety factor as shown in the next section.

It can be concluded that the commonly used SF method, in general sense, represents the safety level of a structure. But it fails to determine quantitatively and qualitatively the confidence level of stability since the SF depends on the deterministic analysis which ignores or irrationally consider the uncertainty of mining conditions due to the variability of coal/rock properties and loads as a results of mining activities. The probability of failure may vary from a relatively low value to near unity because of strength/stress variations even though the safety factor remains a constant. Consequently, it could lead to either over-design or under-design of mine entry capacity without recognizing the shortcomings in design by using the safety factor method.

\subsection{Variability, SF and Mine Entry Stabilization}


Since the variations of physical properties are inevitable, how doses it affect the stability design and evaluation of mining entry in both quantitative and qualitative manners? In other words, what kind of relationship among the variability, SF and stability can be formulated if the factor of uncertainty of structure strength/stress must be considered in the assessment procedure? To simplify the answer for such a sophisticated problem, the relationship among variability, $\mathrm{SF}$ and reliability index is derived in general as follows:

If the statistical parameters for the random variables of coal strength, $R$ and stress, $\mathrm{S}$ are known, the reliability index can be derived as

$$
\begin{gathered}
\kappa=\frac{E[R]-E[S]}{\sqrt{\operatorname{Var}[R]+\operatorname{Var}[S]-2 \rho \sqrt{\operatorname{Var}[R] \operatorname{Var}[S]}}} \\
=\frac{\mu_{R}-\mu_{S}}{\sqrt{\sigma_{R}^{2}+\sigma_{S}^{2}-2 \rho \sigma_{R} \sigma_{S}}}
\end{gathered}
$$

where $\mu_{R}$ and $\sigma_{R}^{2}$ are the expected value and variance of pillar strength, respectively, $\mu_{S}$ and $\sigma_{\mathrm{S}}^{2}$ are the expected value and variance of stress applied on the pillar, respectively, and $\rho$ is the correlation coefficient between strength and stress.

Based on this formula, the relationship among SF, variation and reliability index can be derived if Eq. 4.1 is incorporated and the structure strength and stress are assumed to be independent of each other (or $\rho=0$ ). 


$$
\kappa=\frac{S F-1}{\sqrt{C V_{R}(S F)^{2}+C V_{S}}}
$$

where $\mathrm{CV}_{\mathrm{R}}$ and $\mathrm{CV}_{\mathrm{S}}$ are coefficient of variations of pillar strength and stress, respectively.

Based on Eqs. 4.4 and 4.5, the relationship among the variability, SF and probability of failure (or stability) is shown in Fig. 4.5. It clearly shows that the structure stability is a function of both the SF and the variability of strength/stress. Under a constant safety factor, for example when $\mathrm{SF}=2.2$, the probability of failure is different when the variability of strength and stress is different. 


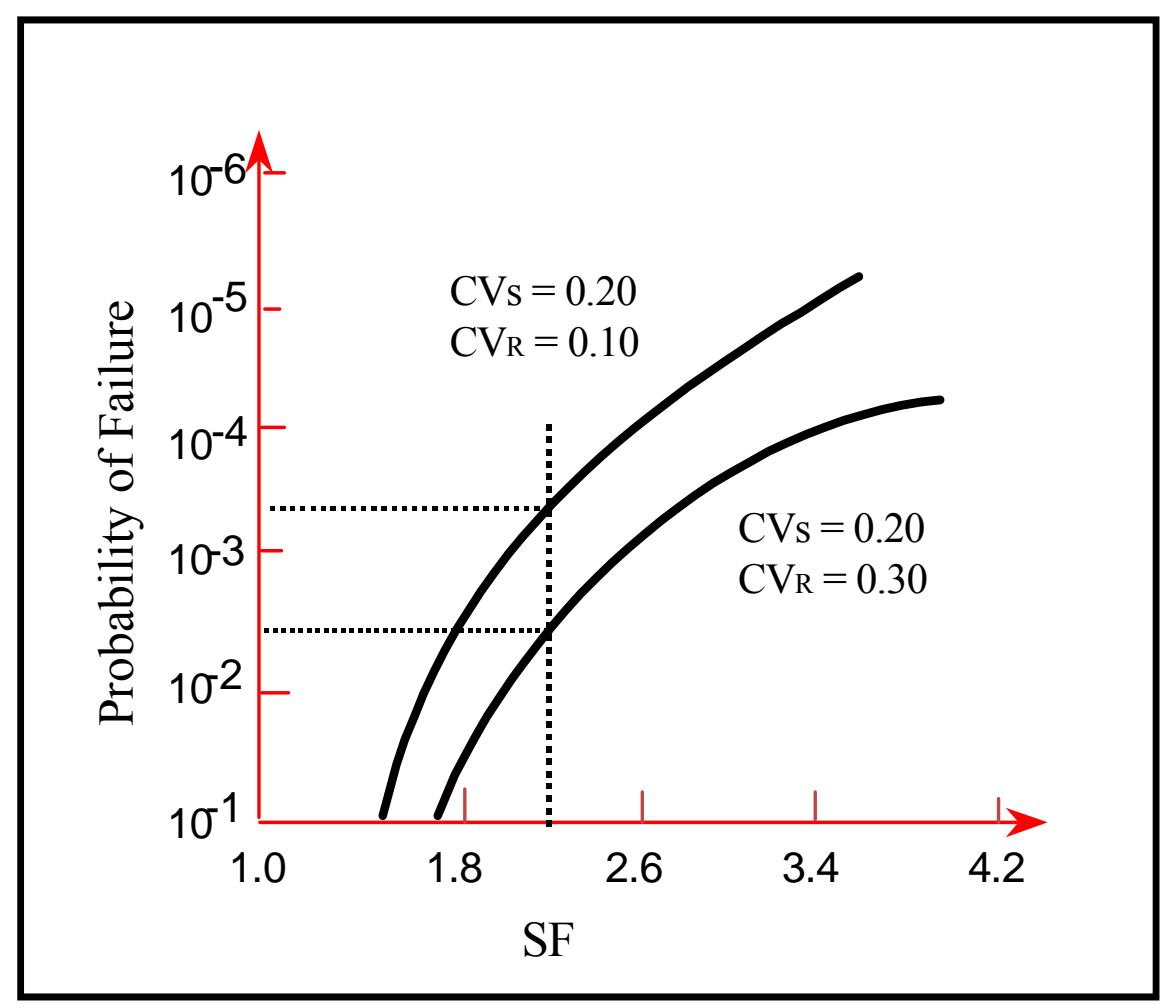

Figure 4.5 Relationship among Strength/stress Variability, SF and Probability of Failure 


\title{
CHAPTER 5
}

\section{DEVELOPMENT OF RELIABILITY-BASED METHOD FOR STABILITY DESIGN AND EVALUATION ON MINE ENTRY}

\begin{abstract}
Variability in the physical properties of coal/rock is a major source of uncertainty encountered in material and site characterization, and analysis and stability design of mining structures. It causes a considerable variation in strength/stress estimations of mining structures when the coal/rock properties are used. Therefore, the conventional safety factor method of stability assessment of mining structures is a special case of the more general probabilistic method by assuming the variability of coal/rock properties is zero. Although the use of probability and statistical methods in the analysis and design of geotechnical structures has grown rapidly in recent years, its application to mining structure design has been delayed due to the relatively larger variations in the geological parameters and computation difficulty in mining applications.

The purpose of this chapter is to develop a reliability-based approach for designing and evaluating the stability of mining entry by considering strength/stress variations in assessment procedures so that it can be a valuable supplement and complement tool to the exiting deterministic procedures. Consequently when using the conventional method the design and evaluation of mining structures, the results would not be over conservative and a certain degree of confidence can be assured with the results.
\end{abstract}




\subsection{Reliability and Risk Assessment}

Reliability, $P_{s}$ is the probability of an object (item or system) performing its required function adequately for a specified period of time under the stated conditions. It is referred as the probability of safe behavior and is a complementary of probability of failure, $P_{f}$. That is

$$
P_{s}=1-P_{f}
$$

The philosophical reasons for the using the reliability method in the assessment of mine entry stability, as compared to the safety factor method, is that it encounters the variable nature of parameters in the physical science which is the particular domain of probability theory and statistics. Furthermore, the reliability method provides the needs for a rational approach in design and analysis although the acceptance of a level of reliability must be reviewed within the context of possible costs, risks, and associated social benefits. Finally, the reliability can provide an economic standard and uniform criteria so that it places increasing emphasis on accuracy and realism in design.

\subsection{Reliability Measurements}

Reliability measurements have been developed for different stages ranging from the simple to the sophisticated in computation procedures (Haugen, 1968; Hart, 1982). In terms 
of mining practices, reliability measurement cab be categorized into three groups. They are safety factor-based method, capacity-demand method and safety margin (reliability index) method. The safety factor-based method assesses the risk of failure from the basis of allowable safety factors which are learned from previous experiences for the considered system in its anticipated environment. It may include a central safety factor, reliability index of safety factor, probability of low safety factor and statistics of safety factor. The capacitydemand method requires the capacity (i.e., stress) and demand (i.e., strength) probability distributions. If the maximum demand exceeds the minimum capacity, the distribution will overlap and there will be nonzero probability of failure. A safety margin (reliability index) method is based on the mechanical failure in engineering fields. It assesses the probability of failure by concerning the difference between the capacity and demand functions. Each group is described in detail as follows:

\subsubsection{Safety Factor-based Methods}

\subsubsection{Central Safety Factor Method}

According to the theory of reliability, the central safety factor, also called the conventional safety factor method, is a special case of the reliability measurement as shown in Fig. 5.1. It can be seen that both the variability of strength, $\mathrm{R}$ and stress, $\mathrm{S}$ are treated as zero because their probabilities of density functions are assumed to be constants and concentrate at their mean points, $\mathrm{R}$ and $\mathrm{S}$, respectively. In this case, the reliability can be represented by a SF completely. Hence, the following statements can be postulated under this condition. 


$$
\begin{array}{lll}
S F=1+\Delta t & \rightarrow & (100 \% \text { stable }) \\
S F=1 & \rightarrow & (50 \% \text { stable }, 50 \% \text { failure }) \\
S F=1-\Delta t & \rightarrow & (100 \% \text { unstable })
\end{array}
$$

where $\triangle \mathrm{t}>0$.

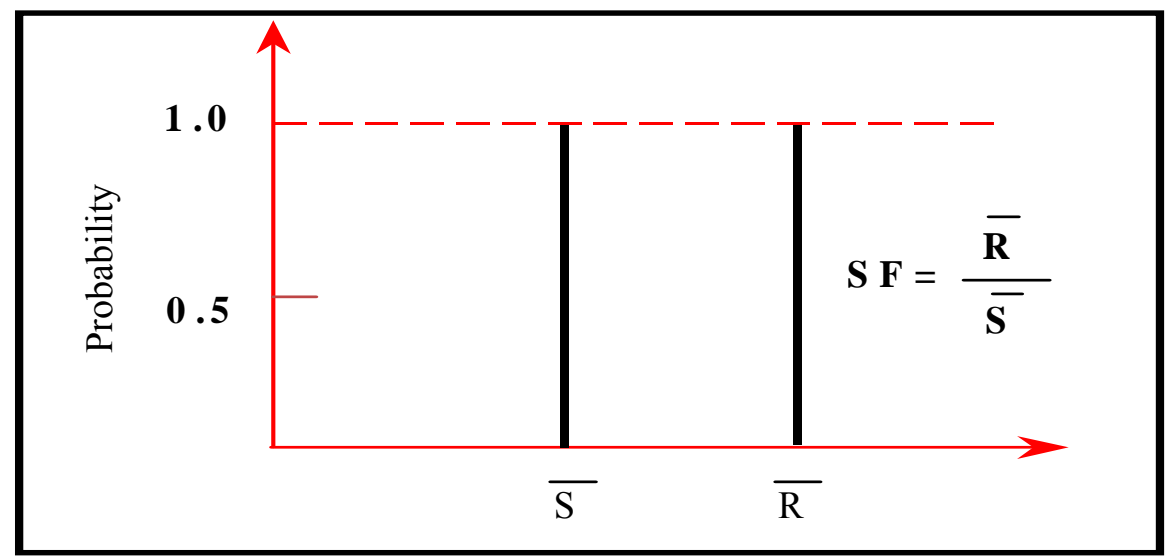

Figure 5.1 Central Safety Factor Method

It is obvious that this is only true for an ideal case. Very few underground mining conditions can meet this requirement due to a large variation both in coal/rock properties and mining-induced loads. If one designs a pillar and assesses its stability based on the SF only, a pillar with the SF of 1.01 has the same capacity as a pillar with a SF of 2.5 because both represent a $100 \%$ stable condition. Both pillars are $100 \%$ failure when the SF is below 1.0 , 
no matter whether it is 0.99 or 0.40 . Those statements actually do not agree with the mining practice. Therefore, using the central safety factor to measure structure stability, theoretically speaking, is only applicable to an ideal case and most likely not for the mine entry structure.

\subsubsection{Reliability Index for Safety Factor}

As shown in Eq. 5.1, the reliability is a complement of the portability of failure which is a function of the reliability index, $\beta$. One of the approaches to obtain the reliability index is from safety factor itself. It is defined as

$$
\beta=\frac{\overline{S F}-T_{l}}{S_{S F}}
$$

where $\mathrm{SF}$ and $\mathrm{S}_{\mathrm{SF}}$, respectively, denote the estimated mean and standard deviation of the safety factor. $\mathrm{T}_{l}$ is the nominal failure (limiting) value used in determining $\beta$. The reliability index, $\beta$ indicates the normalized distance, in terms of the standard deviation, between SF (i.e., best estimate of SF) and the nominal failure value. For example, $\beta=3$ means that the best estimate of SF is 3 standard deviations higher than the limiting value. The higher the $\beta$, the higher is the reliability of the structure under consideration. By using this approach, it is critical to know the limiting value used, since it has a great impact on the resulting reliability index. Eq. 5.3 shows the reliability index, $\beta$ varies in terms of the various limiting values, $\mathrm{T}_{l}$. Even under the same mean and standard deviations of $\mathrm{SF}$, the different selections of the limiting values can causes different results of the reliability 
indexes. In a deterministic analysis, a safety factor of larger than one is an acceptable limiting value mainly due to the uncertainty of the input parameters. But, in mining practices, no rational limiting value has been recommended since no relationship can be formulated between uncertainty of strength/stress and the limiting values. On the other hand, the use of the limiting value of larger than one seems to be redundant since the uncertainties are included in the probabilistic analysis.

\subsubsection{Probability of Low Safety Factor}

Instead of looking for the distance of the standard deviations of the best estimate of safety factor from the liming value, the probability of the computed safety factor being less than a limiting value, $T_{l}$ was the subjected of some investigators (McGuffey et al., 1982). It can be computed with the probability of a low safety factor, PLFS which is defined as

$$
P L S F=P\left[S F \leq T_{I}\right]=F_{F S}\left[T_{I}\right]=\int_{-\infty}^{T l} f_{S F}(x) d x
$$

where $\mathrm{F}_{\mathrm{FS}}$ is cumulative density function for $\mathrm{SF}, \mathrm{f}_{\mathrm{SF}}$ is $\mathrm{PDF}$ for $\mathrm{SF}$ and $\mathrm{x}$ is a dummy variable for integration. PLSF has also been called the "probability of failure". It should be noted that in using the PLFS parameter, just as in the use of $\beta$, one has to determine the limiting value, $\mathrm{T}_{l}$ first.

While the computation of $\beta$ is straightforward and can be done as a direct computation in the analysis, it will be necessary to incorporate statistical analysis software 
packages or manual computation using statistical tables to obtain PLFS. In the case of normal distribution, the use of statistical tables is fairly simple, but the task becomes more difficult when the other distribution is encountered. The normal, lognormal or other distributions may be assumed and the engineering judgment and experience may be needed to determine the ranges for the integration purpose.

\subsubsection{Statistical Safety Factor}

Another approach to obtain the reliability index is from the so called statistical safety factor which is defined to assess a structure stability based on a given reliability (Mischke, 1970). The statistical safety factor, $\mathrm{n}$ expresses the degree of safety level beyond the specified reliability, $\mathrm{P}_{\mathrm{s}}$ and is modified from Eq. 4.4 as

$$
k=\frac{\mu_{R}-n \mu_{s}}{\sqrt{\sigma_{R}^{2}+\sigma_{s}^{2}}}
$$

or

$$
n=\frac{1}{\mu_{S}}\left(\mu_{R}-k \sqrt{\sigma_{R}^{2}+\sigma s^{2}}\right)
$$

Note that this is not the same as the central safety factor. For any specified reliability $\mathrm{P}_{\mathrm{s}}$ is an unique number. It is not distributed. Once the mean and standard deviations of strength/stress and required reliability are given, one can determine the percentage margin 
of safety beyond the given reliability. For example, if $\mu_{s}=100,00 \mathrm{psi}, \mu_{R}=140,000 \mathrm{psi}$ $\sigma_{S}=7000, \sigma_{R}=6310 P_{s}=0.90$ (or $k=1.645$ ), then the statistical safety factor is

$$
n=\frac{1}{100,000}\left(140,000-1.645 \sqrt{(7,000)^{2}+(6,310)^{2}}=1.245\right.
$$

or, in other words, there is a 24.5 percent margin of safety beyond a reliability of 90 percent.

It is also clear that this definition of statistical safety factor is neither as rigorous nor as general as the central safety factor. Its use requires that both populations have normal distribution and that the statistics of these populations be known. However, it is interesting to note that if we specify a reliability $\mathrm{P}_{\mathrm{s}}=0.50$, then $\mathrm{k}=0$, and Eq. 5.7 becomes

$$
n=\frac{\mu_{R}}{\mu_{s}}=S F
$$

which is the same as the central safety factor.

\subsubsection{Capacity Demand Method}

In general, coal/rock properties and loads around a mine entry behave as a random variable. For example, Fig. 5.2 shows the coal strength distribution for a total of 130 coal samples tested in the laboratory. The mean strength is $3,210 \mathrm{psi}$ and the standard deviation is $800 \mathrm{psi}$ with a coefficient of variation of $25 \%$. The probability density function of the coal strength seems to follow the trend of a normal distribution. 


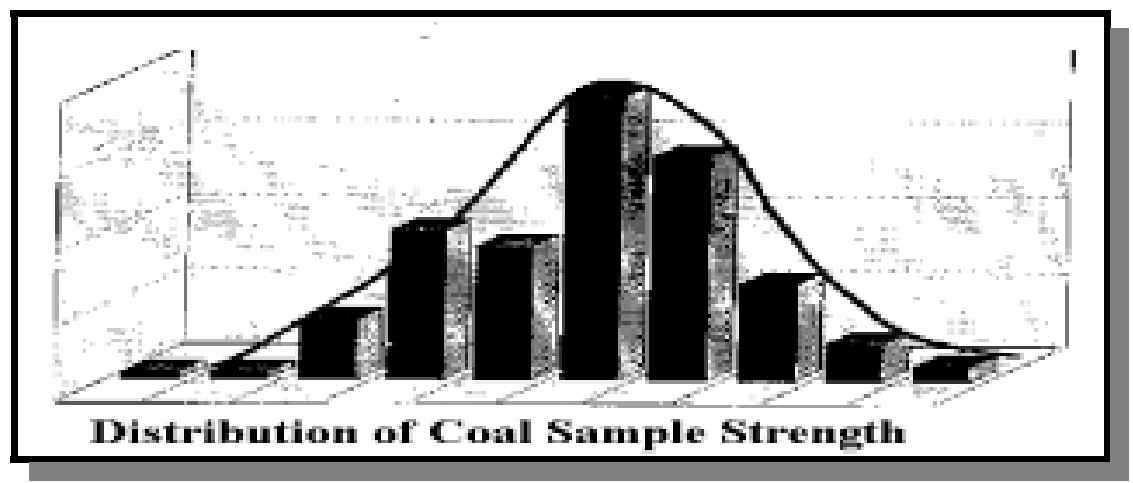

Figure 5. 2 Distribution of Coal Sample Strength

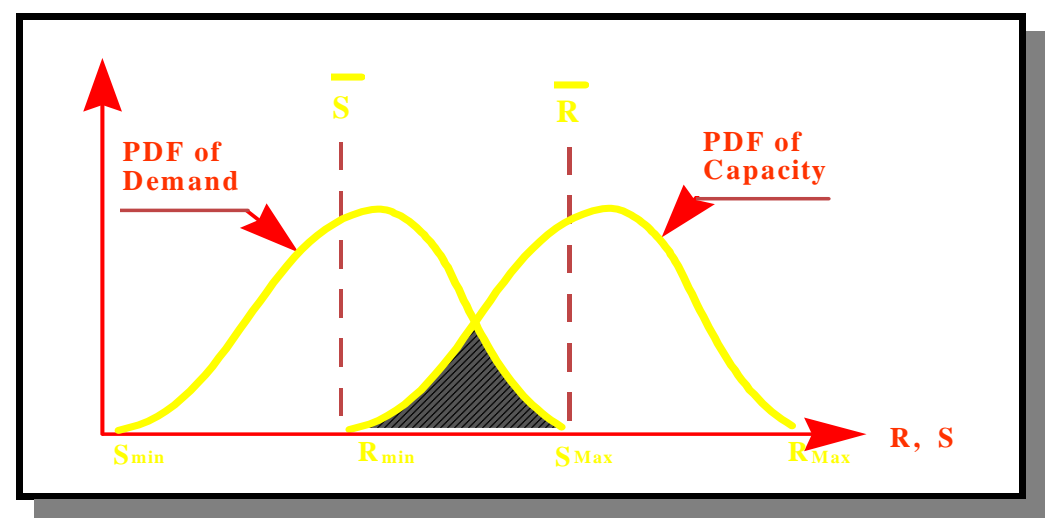

Figure 5.3 Capacity-Demand Method

To incorporate such variability into stability analysis of mine entry design, the capacity demand method, as shown in Fig. 5. 3, can be adopted. The reliability measurement, therefore, can be performed by the following expressions: 


$P=1-P_{f}$
$P_{f}=\int_{-\infty}^{\infty}\left[1-P_{s}\right] p_{R}(x) d x$
$P_{s}=\int_{-\infty}^{x} p_{s}(x) d x$

where $\mathrm{P}$ is the reliability; $\mathrm{P}_{\mathrm{f}}$ is the probability of failure; $\mathrm{p}_{\mathrm{s}}$ and $\mathrm{p}_{\mathrm{R}}$ are the probability distribution functions (PDF) of coal/rock strength and mining induced stress, respectively, and $\mathrm{P}_{\mathrm{S}}$ is the probability distribution function of stress. However, this concept, though well developed theoretically, has not been commonly followed in design practices on underground structures due to the lack of information on the density functions both $p_{s}$ and $p_{R}$, or even known $\mathrm{p}_{\mathrm{s}}$ and $\mathrm{p}_{\mathrm{R}}$ because their functions are too difficult to integrate. Therefore, by using this method, the standard probability density functions for both the coal/rock strength and stress induced by the mining activities are required. For certain cases, no solution can be obtained. 


\subsubsection{Safety Margin and Reliability Index (Safety Index) Method}

With this method, the failure function, which usually results from the use of a mechanical analysis method for the structure, needs to be defined first. In general, let $g\left(Z_{i}\right)$ denotes the failure function, then

$$
\begin{array}{ll}
M=g\left(Z_{i}\right)>0 & Z_{i} \in S S \\
M=g\left(Z_{i}\right)=0 & Z_{i} \in L S \\
M=g\left(Z_{i}\right)<0 & Z_{i} \in F S
\end{array}
$$

where M is safety margin and, SS is safe set, and FS is failure set. SS and FS are separated by LS, failure surface.

If failure function of the safety margin is defined with the limiting states, i.e., required strength $\leq$ design strength, then a convenient way of assessing this probability is to consider the difference between the capacity and demand functions, expressed as

$$
M=R-S
$$

Obviously, the safety margin is itself a random variable. As shown in Fig. 5.4, the probability of failure is associated with that portion of the distribution of safety margin wherein it became negative (shown shaded), that is, the portion in which 


$$
P(f)=P[(R-S) \leq 0]=P[M \leq 0]
$$

Since the shaded area is the probability of failure $p(f)$, we have

$$
M=R-S<=0
$$

To easily measure the probability of failure of the safety margin, the reliability index, $\kappa$ is defined by the expected values of safety margin, $\mathrm{E}[\mathrm{M}]$ divided by the uncertainty scale parameter, $\mathrm{D}[\mathrm{M}]$ as shown below (Cornll, 1969):

$$
\kappa=\frac{E[M]}{D[M]}
$$




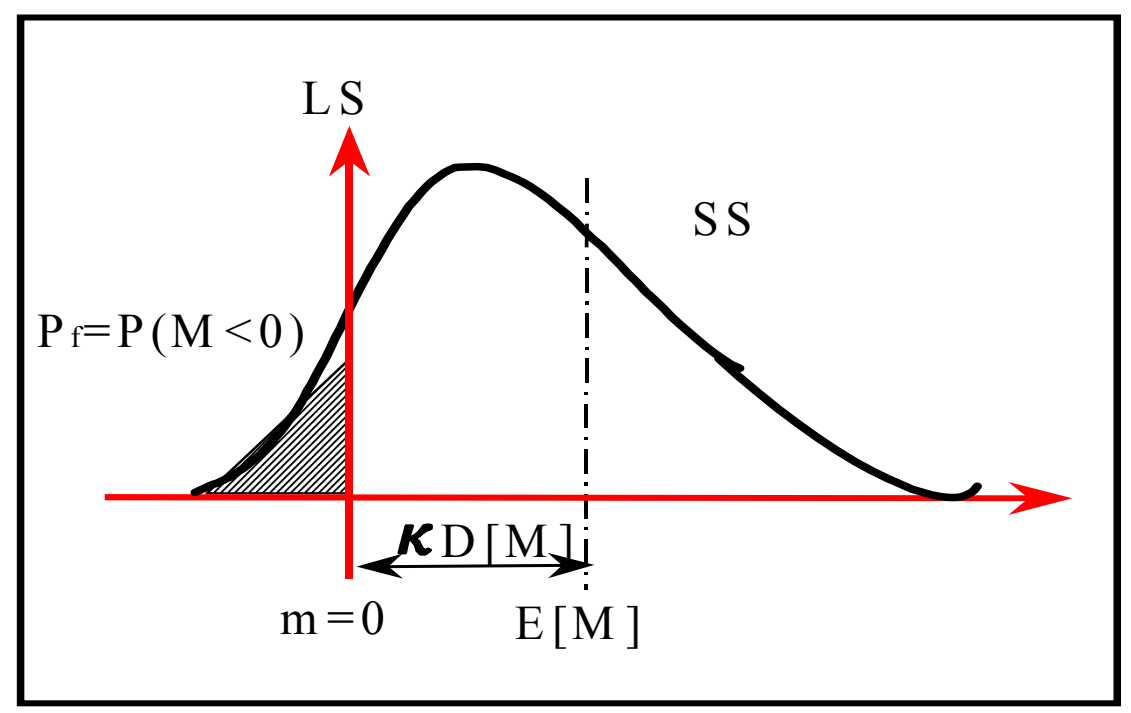

Figure 5.4 Geometrical Illustration of Reliability Index

Fig. 5.4 shows this definition geometrically. The failure surface is simply the line along $\mathrm{m}=0$. The idea behind the reliability index definition is that the distance from the location, $\mathrm{E}[\mathrm{M}]$ to the limit state surface provides a good measure of reliability. The distance is measured in units of the uncertainty scale parameter, $\mathrm{D}[\mathrm{M}]$.

Once the reliability index is known, the reliability of structure can be obtained by the equation as

$$
P=1-\left[\frac{1}{2}-\Phi(\kappa)\right]
$$




\subsection{Parameter Estimations}

The safety margin (or reliability index) method has been used in other engineering fields to measure a structure's reliability because it is easy to use and more reliable. The key is to determine the mean and standard deviation of the dependent variables. In general, the safety margin, $M$ assumed to be a dependent variable, is given by multivariables $X_{1}$, $\mathrm{X}_{2}, \ldots, \mathrm{X}_{\mathrm{k}}$ with their known expectations and standard deviations, say

$$
M=f\left(X_{1}, X_{2}, \ldots, X_{k}\right)
$$

where $X_{1}, X_{2}, \ldots, X_{k}$ are independent random variables in the failure function.

Several probability methods have been developed that yield measures of the distribution of functions of the random variables. These range from so-called exact methods that require computer-oriented numerical excursions to approximate procedures that can be accommodated by relatively simple algebraic calculations. Each system has its set of assumptions (including the exact methods) and its own group of advocates.

Briefly, the reliability measurement can be divided into three categories. One is called exact method which requires the probability distribution functions of all component variables to be known initially. Because of the complexity of the solution process, the unknown component distributions are usually assumed to be normal or lognormal, or even uniform. Numerical integration and Monte Carlo methods belong to this category. The second category, called the first-order, second-moment methods (FOSM), simplifies the 
implied functional relationship. The truncating of the Taylor Series expansion of the function forms the basis of these methods. As implied, inputs and outputs are expressed as expected values and standard deviations. The advantages of this category of solution stem from their simpler mathematical requirements and knowledge of moments rather than of complete distribution is required. The disadvantages are that the mathematical requirements, although simpler than those of exact methods, are generally not elementary. The third category, the point estimate method (PEM), is advocated here for reasons to be developed subsequently.

\subsubsection{Monte Carlo Simulation}

The Monte Carlo simulation method determines the mean and standard deviation of a function of random variables by performing repeated computations using randomly selected points estimated for the component variables. However, this simulation requires not only a high speed computer so that a large number of trials can be conducted but also an existing program to automatically make the repetitions and accumulation for a specified function. This may be very difficult to create for some complicated functions (Ang and Tang, 1975; 1984). The advantages of this methodology are that the complete probability distributions of the dependent random variables are obtained. The disadvantages are that the output may be no better than the (assumed) input and that considerable computer time is generally required. Also, each case must be treated separately. 


\subsubsection{Taylor Series Expansion (FOSM)}

This method is generally referred as the first-order, second-movement (FOSM) method. The Taylor series (FOSM) method requires the attainment and evaluation of derivatives. This effort ranges from being simple to cumbersome to impossible, such as, for the latter, when the function is given implicitly in the form of charts or graphs or finite element solution. When the variables $\mathrm{X}_{\mathrm{i}}$ are mutually independent with known means and standard deviations, the mean and standard deviation of the safety margin, $M$ can be determined by the following equations:

$$
\begin{gathered}
\mu_{M}=E[M]=f\left(X_{i}\right)+\frac{1}{2} \sum_{i=1}^{n}\left[\left(\frac{\partial^{2} M}{\partial X_{i}^{2}}\right)\left[\operatorname{Var}\left(X_{i}\right)\right]\right] \\
\sigma_{M}=\sqrt{\operatorname{Var}[M]}=\sqrt{\sum_{i=1}^{n}\left[\left(\frac{\partial M}{\partial X_{i}}\right)^{2}\left[\operatorname{Var}\left(X_{i}\right)\right]\right]}
\end{gathered}
$$

The advantages of this category of solution stem from their simpler mathematical requirements and knowledge of moments rather than of complete distribution is required. The disadvantages are that the mathematical requirements, although simpler than those of exact methods, are generally not elementary. The problem with this method is that a partial differentiation, performed on even simple functions, may result in complex expression. Furthermore, differentials of complex functions may not even exist.

\subsubsection{Moment Generation Function}


Moment generation function technique is another powerful method to find a distribution of function of several random variables (Hogg and Craig, 1995). It is particularly effective in certain instance if, for example, random variables are independent with known initial distributions. Once random variables are dependent, the distributions of function can be easily found when all random variables are linearly related. Otherwise, either the moment generation function doses not exist or the distribution function of the random variables is too difficult to find. Its mean and standard deviation, therefore, cannot be solved.

\subsubsection{Point-Estimate Method (PEM)}

Conceptually, the point estimate method is to estimate the expectation value and standard deviation with information concerning the central tendency and scatter of the variable. The ideal was initialized from an analogy between a probability distribution and a distributed vertical load on a horizontal rigid beam as shown in Figs. 5.5a and 5.5b .(Rosenblueth, 1975; 1981). Therefore, after information transformations, the expected value was the analog of the point of application of the equilibrate (of unit magnitude) or the center of loading. And the standard deviation was its radius of gyration. Depending on the numbers of the independent variables, the point estimates approach can be described as two point estimates methods, four point estimates method and generalized point estimates method, respectively. 


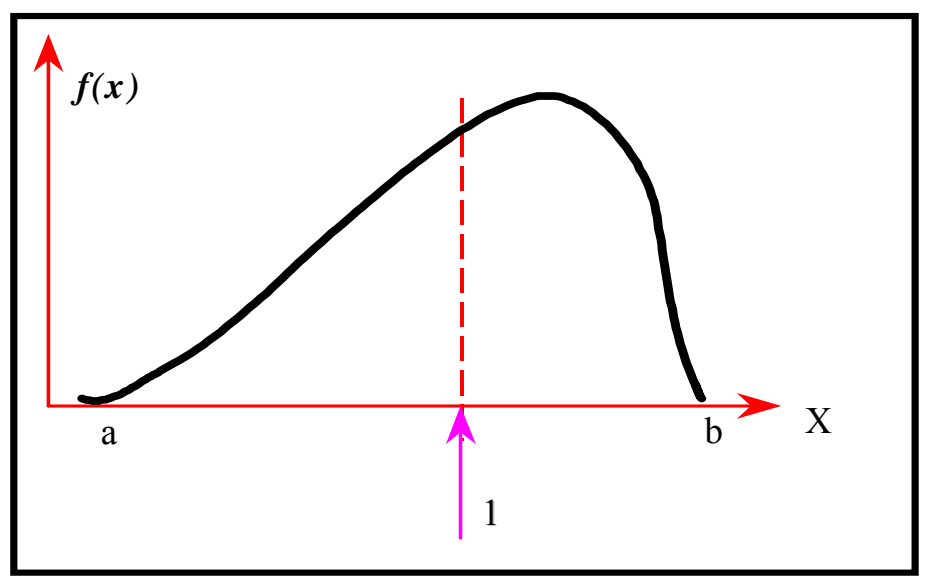

(a) Single support

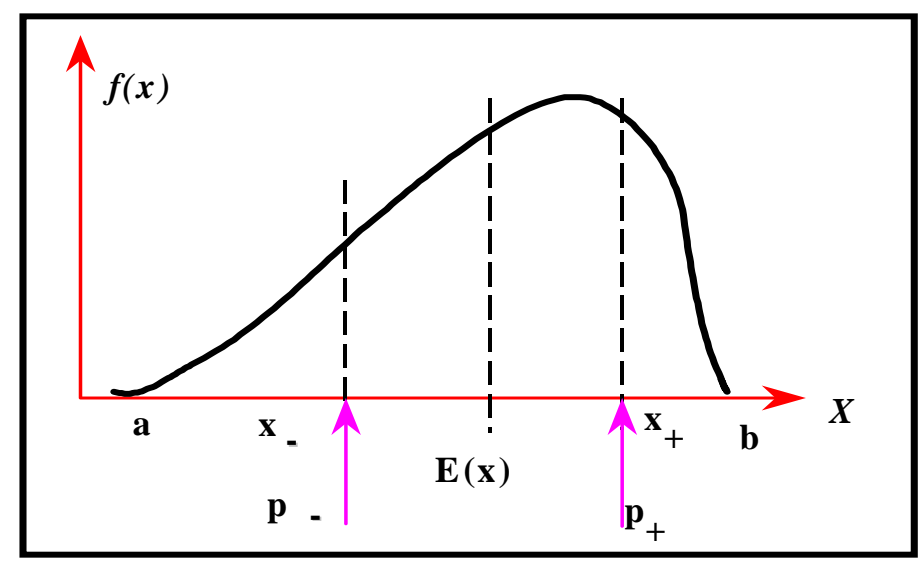

(b) Double supports

Figure 5.5 Representation of One Variable (Two Points) as Loading on Rigid Beam 


\subsubsection{Two Points Estimates}

Consider $\mathrm{y}=\mathrm{f}(\mathrm{x})$ to be the probability distribution of the single random variable, the information can be extracted from the analogy of a rigid beam supported on two reactions, $\mathrm{P}_{-}$acting at $\mathrm{x}=\mathrm{x}_{-}$and $\mathrm{P}_{+}$acting at $\mathrm{x}=\mathrm{x}_{+}$as shown in Fig. 5.5. The reaction $\mathrm{P}_{-}$and $\mathrm{P}_{+}$are said to be two-point estimate of the distribution of $\mathrm{f}(\mathrm{x})$. In other words, the continuous distribution is replaced by two discrete point estimates, $\mathrm{P}_{-}$and $\mathrm{P}_{+}$acting at $\mathrm{x}_{-}$and $\mathrm{x}_{+}$. Therefore, the moments, interpreted in common probalistic symbolism, specify the four equations with four unknowns.

$$
\begin{gathered}
P_{+}+P_{-}=1 \\
P_{+} x_{+}+P_{-} x_{-}=E[f(x)]=\bar{x} \\
P_{+}+\left(x_{+}-\bar{x}\right)^{2}+P_{-}\left(x_{-}-\bar{x}\right)^{2}=s[f(x)]^{2}=s^{2}[x] \\
P_{+}+\left(x_{+}-\bar{x}\right)^{3}+P_{-}\left(x_{-}-\bar{x}\right)^{3}=s[f(x)]^{2}=b(1) s^{3}[x]
\end{gathered}
$$

where $\mathrm{x}$ is the sample mean, $\sigma^{2}[\mathrm{x}]$ is the sample variance, and $\beta(1)$ is the sample coefficient of skewness for variable $\mathrm{x}$, and whole solution is listed as Equations in the following:

$$
\begin{gathered}
P_{+}=\frac{1}{2}\left[1 \pm \sqrt{1-\frac{1}{1+\left[\frac{\beta(1)}{2}\right]^{2}}}\right] \\
P_{-}=P_{+}=\frac{1}{2}
\end{gathered}
$$




$$
\begin{aligned}
& x+=\bar{x}+s[x] \sqrt{\frac{P_{-}}{P_{+}}} \\
& x_{-}=\bar{x}-\sigma[x] \sqrt{\frac{P_{+}}{P_{-}}}
\end{aligned}
$$

If $\mathrm{f}(\mathrm{x})$ is symmetrical where $\beta(1)=0$, then the equations above can be reduced to

$$
\begin{gathered}
P_{-}=1-P_{+} \\
x_{+}=\bar{x}+\sigma[x] \\
x_{-}=\bar{x}-\sigma[x]
\end{gathered}
$$

With the distribution $\mathrm{f}(\mathrm{x})$ approximated by the point estimate $\mathrm{P}_{+}$and $\mathrm{P}_{-}$, the information about the unknown distribution of $\mathrm{x}$ produces the two estimates of the $\mathrm{y}$ variate, $\mathrm{y}_{-}$and $\mathrm{y}_{+}$. That is, information about the $\mathrm{x}$ variate is transferred through the functional relationship between $\mathrm{x}$ and $\mathrm{y}(\mathrm{x})$ to provide the two values of $\mathrm{y}_{+}$and $\mathrm{y}_{-}$. The schematic representation of information transfer is shown in Fig. 5.6. The moments of $\mathrm{y}=\mathrm{f}(\mathrm{x})$ are:

$$
\begin{gathered}
E[y]=\bar{y}=P_{+} y_{+} P_{-} y_{-} \\
E\left[y^{2}\right]=P_{+} y_{+}{ }^{2} P_{-} y_{-}{ }^{2}
\end{gathered}
$$


or in general

$$
E\left[y^{m}\right]=P_{+} y_{+}^{m} P_{-} y_{-}^{m}
$$

Therefore, the variance of $\mathrm{y}=\mathrm{f}(\mathrm{x})$ can be expressed as an expectation as

$$
V[y]=E\left[(y-\bar{y})^{2}\right]=E\left[y^{2}\right]-\left(E[y]^{2}\right)
$$

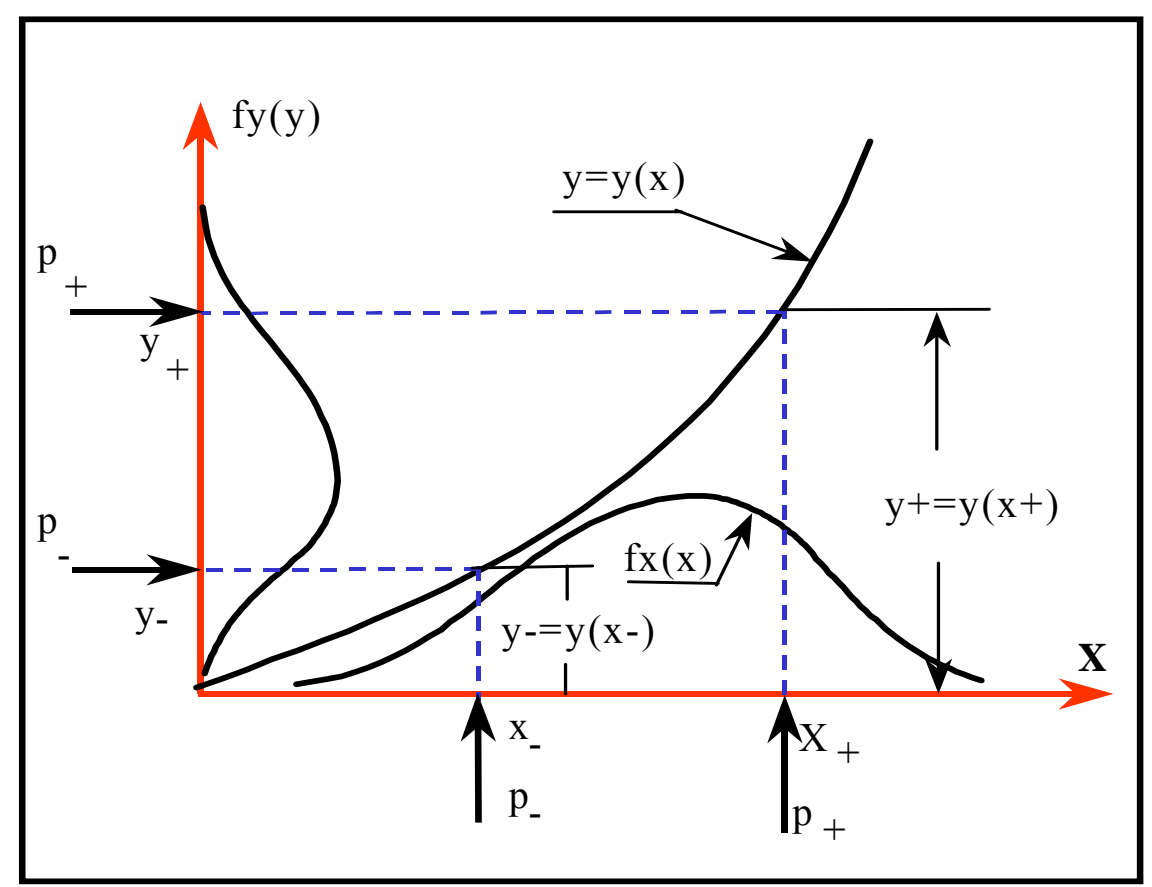

Figure 5.6 Illustration of Information Transfer 


\subsubsection{Four Point Estimate Method}

For two independent random variables, $\mathrm{y}=\mathrm{f}(\mathrm{x} 1, \mathrm{x} 2)$, the probability distribution is considered to be analogous to a distributed vertical load acting over a rigid plate, supported at four points $\mathrm{P}_{++}, \mathrm{P}_{+--}, \mathrm{P}_{-+}$and $\mathrm{P}_{--}$as shown in Fig. 5. 7. For this case the Mth moment of the functional relationship on $\mathrm{y}=\mathrm{f}(\mathrm{x} 1, \mathrm{x} 2)$ is

$$
E\left[y^{m}\right]=P_{++} y_{++}{ }^{m}+P_{+-} y_{+-}^{m}+P_{-+} y_{-+}^{m}+P_{--} y_{--}^{m}
$$

where

$$
\begin{gathered}
y \pm \pm=y\left(\bar{x}_{1} \pm \sigma\left[x_{1}\right], \bar{x}_{2} \pm \sigma\left[x_{2}\right]\right) \\
P_{++}=P_{--}=\frac{1+\rho}{4} \\
P_{+-}=P_{-+}=\frac{1-\rho}{4} \\
\bar{x}_{1}=E\left[x_{1}\right] \\
\bar{x}_{2}=E\left[x_{2}\right]
\end{gathered}
$$

In this equation $\rho$ is the correlation coefficient between $x_{1}$ and $x_{2}$. The influence of the correlation coefficient on the weighting factors is shown for a few cases in Fig. 5.8 . 


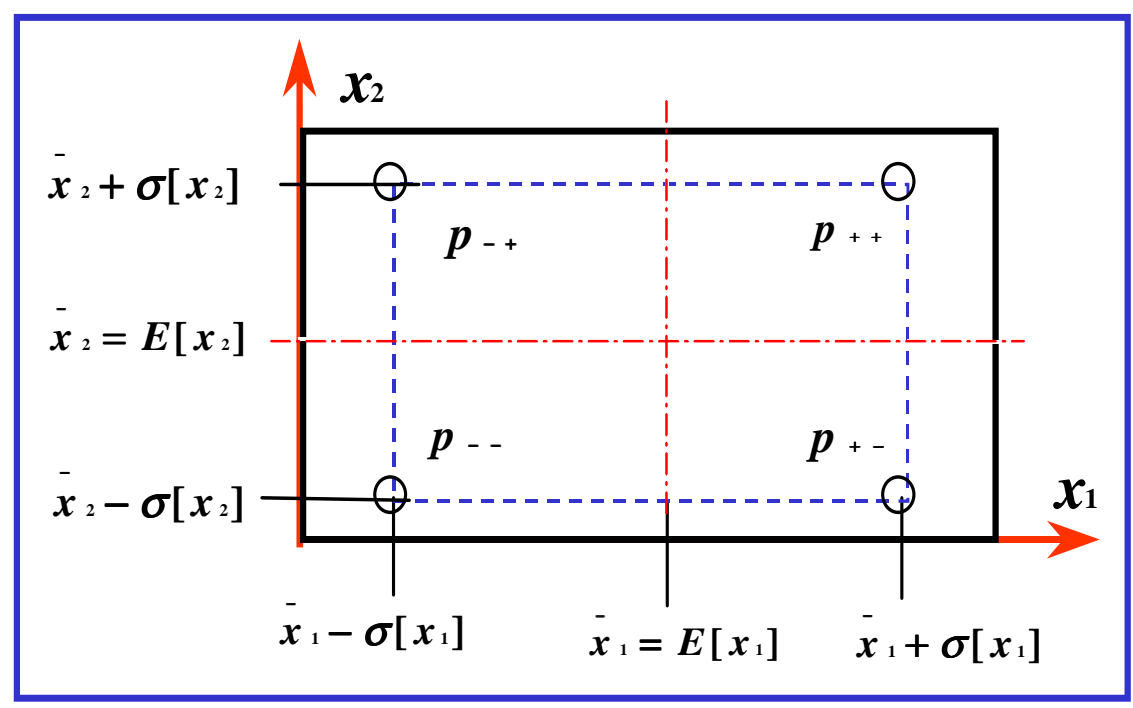

Figure 5.7 Representation of Two Variables (Four Points) as Loading on a Rigid Plate

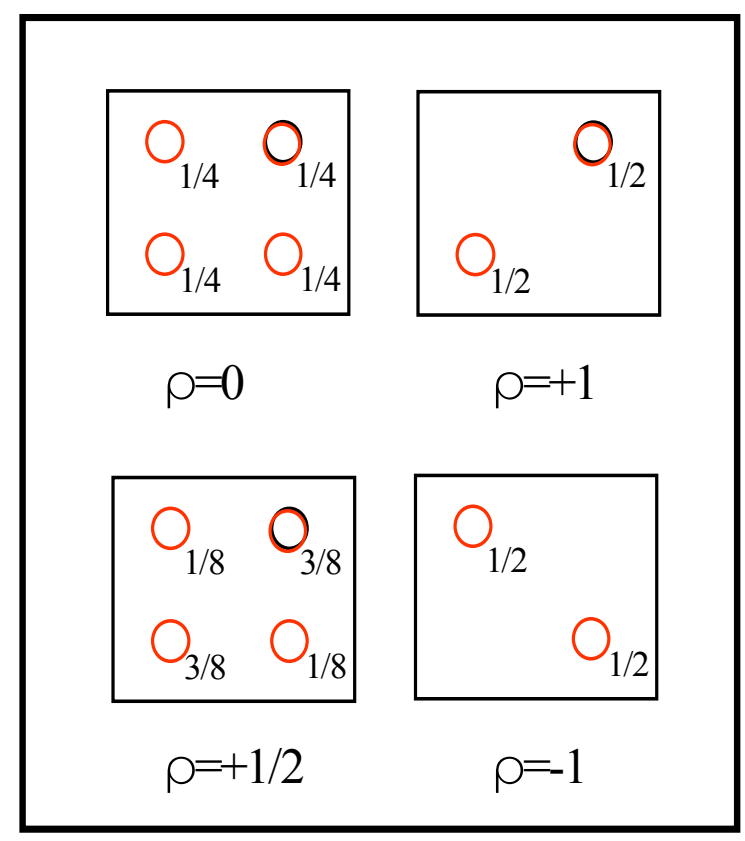

Figure 5.8 Influence of Correlation Coefficient on Weighting Factors 


\subsubsection{Generalized Point Estimates Method}

PEM can be extended for any number of independent random variables even though they are correlated each other. For a function of four correlated random variables, as an example, $y=f(x 1, x 2, x 3, x 4)$ or strength of pillar=f(uniaxial compressive strength, Young's modulus, Poisson ratio and ratio of roof stiffness to floor stiffness), the dependent random variable y (or pillar strength) can be expressed as follows:

$$
\begin{aligned}
E\left[y^{m}\right]= & P_{++++} y_{++++}{ }^{m}+P_{+++-} y_{+++-}{ }^{m}+P_{++--} y_{++--}{ }^{m}+\ldots \\
& +P_{---+} y_{---+}{ }^{m}+P_{----} y_{----}{ }^{m}
\end{aligned}
$$

where $\quad y \pm \pm \pm \pm=y\left(\bar{x}_{1} \pm \sigma\left[x_{1}\right], \bar{x}_{2} \pm \sigma\left[x_{2}\right], \bar{x}_{3} \pm \sigma\left[x_{3}\right], \bar{x}_{4} \pm \sigma\left[x_{4}\right]\right)$

$$
\begin{aligned}
& P_{++++}=P_{----}=\frac{1+\rho_{12}+\rho_{13}+\rho_{14}+\rho_{23}+\rho_{24}+\rho_{34}}{2^{4}} \\
& P_{+++-}=P_{--++}=\frac{1+\rho_{12}+\rho_{13}-\rho_{14}+\rho_{23}-\rho_{24}-\rho_{34}}{2^{4}} \\
& P_{++--}=P_{--++}=\frac{1+\rho_{12}-\rho_{13}-\rho_{14}+\rho_{23}-\rho_{24}+\rho_{34}}{2^{4}} \\
& P_{+---}=P_{-+++}=\frac{1-\rho_{12}-\rho_{13}-\rho_{14}+\rho_{23}+\rho_{24}+\rho_{34}}{2^{4}} \\
& P_{+--+}=P_{-++-}=\frac{1-\rho_{12}-\rho_{13}+\rho_{14}+\rho_{23}-\rho_{24}+\rho_{34}}{2^{4}}
\end{aligned}
$$




$$
\begin{gathered}
P_{+-+-}=P_{-+-+}=\frac{1-\rho_{12}+\rho_{13}-\rho_{14}-\rho_{23}+\rho_{24}-\rho_{34}}{2^{4}} \\
P_{+-++}=P_{-+--}=\frac{1-\rho_{12}+\rho_{13}+\rho_{14}-\rho_{23}-\rho_{24}+\rho_{34}}{2^{4}} \\
P_{++-+}=P_{--+-}=\frac{1+\rho_{12}-\rho_{13}+\rho_{14}-\rho_{23}+\rho_{24}-\rho_{34}}{2^{4}}
\end{gathered}
$$

where $\rho_{\mathrm{ij}}$ is the correlation coefficient of the random variables $x_{\mathrm{i}}$ and $\mathrm{x}_{\mathrm{j}}$. The sign of $\rho_{\mathrm{ij}}$ is determined by the sign of the multiplication of $\mathrm{ij}$. That is, $\mathrm{i}=(-), \mathrm{j}=(+)$ yields $\mathrm{ij}=(-)(+)=(-)$.

In general, for $\mathrm{N}$ independent random variables, there are $2^{\mathrm{N}}$ terms and $\mathrm{N}(\mathrm{N}-1) / 2$ correlation coefficients. The coefficient on the right-side of Eq. $5.27 \mathrm{is}(1 / 2)^{\mathrm{N}}$. For example as described above, when $\mathrm{N}=4$, a total of 16 terms is involved in Eq. 5.27 and 6 correlation coefficients are appeared in Eq. 5.28. Of course, when all the variables are uncorrelated, all the $\mathrm{P}$ terms become equal to $(1 / 2)^{4}=1 / 16$. A useful generator of the + 's and -'s for easy computation of terms is given in Fig. 5.9.

It is obvious that this method requires neither extensive computer capacity nor complex mathematical derivations for determination of a mean and standard deviation of a dependent random variable which is function of multiple random variables even though they are correlated each other. 


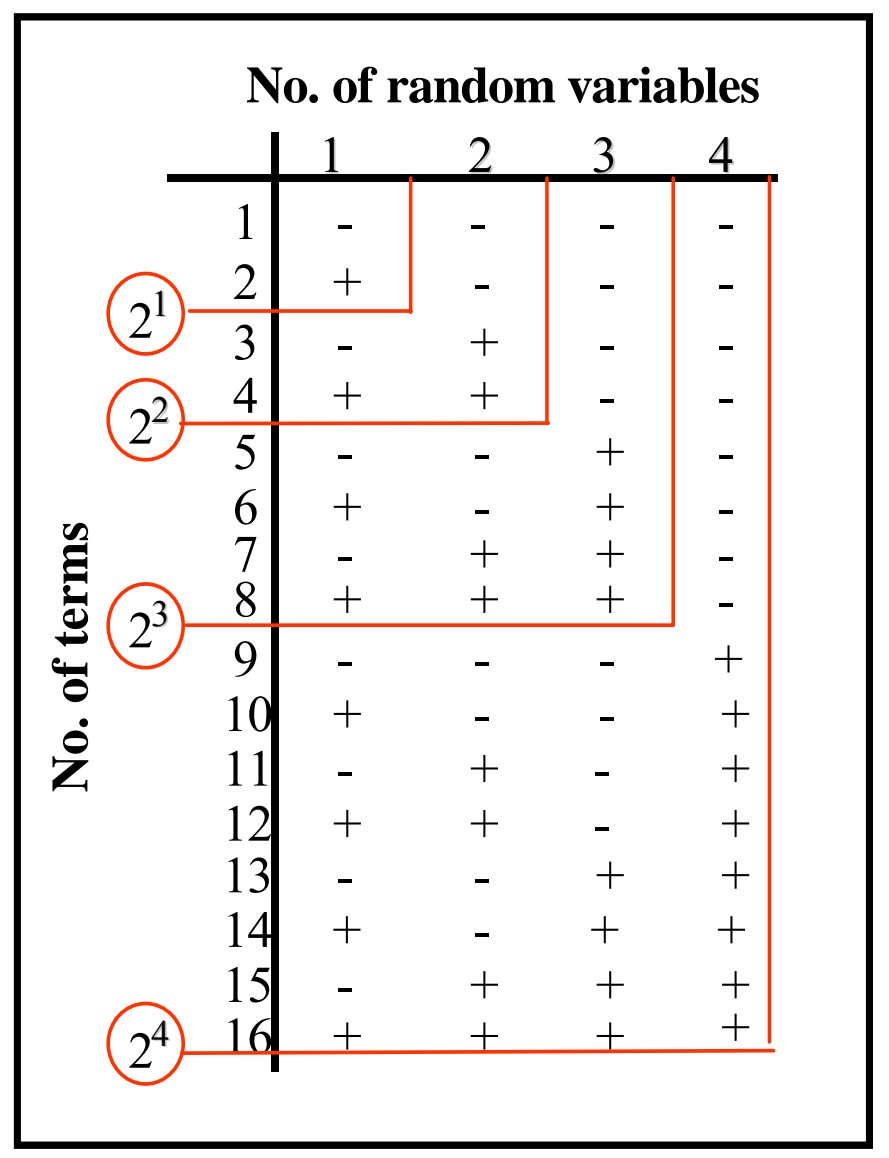

Figure 5.9 Generator Illustration for Determination of Number of Terms 


\subsection{PESM Method and Its General Procedure}

As described in the previous sections of this chapter, the selections of reliability measurement and parameter estimation are two key tasks to apply the reliability approach to the stability of mine entry design and evaluation. This section will formulate a reliability based new method called PESM method and briefly described the general procedure of PESM method.

\subsubsection{PESM Method}

For the sake of both safety requirement and mining environment, the point estimate method for parameter estimation and safety margin method for reliability measurement are conditionally merged together so that PESM (point estimate and safety margin) method as a reliability based new method is formulated for mining structure design and evaluation. For purpose of easy application, eight steps are briefly divided from the whole procedure of PESM method after taking the mining conditions into consideration. They are described in the next section.

\subsubsection{General Procedure of PESM Method}

The following eight steps serve as a guideline for using PESM method for mining entry design and evaluation. 
Step1 Set up the safety margin equation with "Strength Requirement" concept, which is equals to the difference between nominal strength (S) and stress (F) of structure. That is

$$
Y=S-F
$$

Step 2 Select a failure criterion which consists of methods for estimations of the nominal strength (S) and stress (F) of the structure.

$$
\begin{aligned}
& S=S\left(x_{1}, x_{2}, \ldots x_{n}\right) \\
& F=F\left(x_{1}, x_{2}, \ldots x_{m}\right)
\end{aligned}
$$

Where $\mathrm{x}_{\mathrm{k}}(\mathrm{k}=\mathrm{n}+\mathrm{m})$ are parameters (independent variables), and $\mathrm{n}$ and $\mathrm{m}$ are numbers of parameters which include in equations of the strength and stress calculations, respectively.

Step 3 Calculate the statistical parameters of mean $(E[x])$, standard deviation $(D[x])$, high limit $(H[x])$ and low limit $(L[x])$ for each independent variable. They are

$$
\begin{gathered}
E\left[x_{k}\right]=\frac{\sum x_{i}}{N} \\
D\left[x_{k}\right]=\sqrt{\frac{\sum x_{i}-E\left[x_{k}\right]^{2}}{N-1}}
\end{gathered}
$$




$$
\begin{aligned}
& H\left[x_{k}\right]=E\left[x_{k}\right]+D\left[x_{k}\right] \\
& L\left[x_{k}\right]=E\left[x_{k}\right]-D\left[x_{k}\right]
\end{aligned}
$$

Step 4 Estimate the coefficient of correlation $\left(\rho_{\mathrm{mn}}\right)$ between each pair of independent variables and weighting factor $(\mathrm{P})$. They are

$$
\begin{gathered}
\rho_{m n}=\frac{\sum\left(m_{i}-\bar{m}\right)\left(n_{i}-\bar{n}\right)}{\sqrt{\sum\left(m_{i}-\bar{m}\right)^{2}\left(n_{i}-\bar{n}\right)^{2}}} \\
P_{ \pm \pm \pm}=\frac{1 \pm r_{12^{ \pm}} r_{13^{ \pm}} r_{14^{ \pm}} r_{23^{ \pm}} r_{24^{ \pm}} r_{34}}{2^{4}}
\end{gathered}
$$

Step 5 Calculate the statistical parameters of mean $(E[Y])$, standard deviation $\mathrm{D}([\mathrm{Y}])$ and variance $\mathrm{V}[\mathrm{Y}]$ for safety margin $(\mathrm{Y})$

$$
\begin{aligned}
& E\left[y^{m}\right]=P_{++++} y_{++++}{ }^{m}+P_{++1-} y_{+++-}{ }^{m}+P_{++--} y_{++--}{ }^{m}+\ldots \\
& +P_{\ldots} \ldots+y_{-\ldots}{ }^{m}+P_{\ldots} \ldots y_{-\ldots}{ }^{m} \\
& y_{ \pm \pm \pm \pm}=y\left(\bar{x}_{1} \pm s\left[x_{1}\right], \bar{x}_{2} \pm s\left[x_{2}\right], \bar{x}_{3} \pm s\left[x_{3}\right], \bar{x}_{4} \pm s\left[x_{4}\right]\right) \\
& V[y]=E\left[(y-\bar{y})^{2}\right]=E\left[y^{2}\right]-\left(E[y]^{2}\right) \\
& D[y]=\sqrt{V[y]}
\end{aligned}
$$


where $\rho_{\mathrm{ij}}$ is the correlation coefficient between the random variables $\mathrm{x}_{\mathrm{i}}$ and $\mathrm{x}_{\mathrm{j}}$.

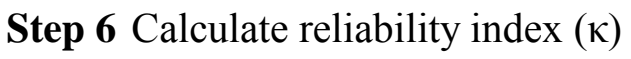

$$
\kappa=\frac{E[y]}{D[y]}
$$

Step 7 Calculate the reliability of structure

$$
R=1-R_{f}=1-\left[\frac{1}{2}-\varphi(\kappa)\right]
$$

Where $\varphi$ is the Laplace function.

Step 8 Make decision after comparing to target reliability

If the calculated the reliability is larger than the target reliability as described in next section, the structure is considered as stable. Otherwise, it is potentially unstable.

\subsection{Target Reliability of Mine Entry}

In the deterministic approaches to design, the acceptable safety factors have been set to which computed values are compared. The stability assessments accepted or rejected depending on whether the computed safety factor is within the acceptable value or not. Due to the definition of safety factor commonly used in mining structure design, even when a 
conservative number of safety factor is used, the degree of stability is still unknown. In practice, both the acceptable and computed safety factors are adjusted based on entirely on empiricism. Uncertainties which aries from variations in loads and material physical properties, dimensions, natural and man-made hazards, insufficient knowledge, and human error in design and constructions cannot be incorporated within the deterministic approaches of design.

Advances in structure reliability theory and probabilistic methods for analyzing uncertainty and setting performance criteria for design have accompanied the development of limit states design as an engineering field of endeavor so that designed structure can be approached quantifying adequacy, optimized design and uniform reliability. In the reliability design, the issue as to how much risk (or target reliability) is acceptable is central. The determination of the target reliability is perhaps another difficult task for many practicing engineering due to involving both the economic and safety aspects of the consequences of failure. This issue is beyond the major scope of this research and a further study is needed for detail consideration. Here only some information and conceptual model for determining a target reliability regarding mining entry are provided. Although no any regulations or published papers have been found to address the target reliability issue on underground coal mining structure design, the acceptable risks levels do establish in metal mines and civil engineering fields, such as for raise bored shafts (McCracken and Stacey, 1989) and slopes and dams (Grosschalk, 1994) as shown in Tables 5.1 and 5.2, respectively. 
Table 5.1 Acceptable Risk Levels for Various Raised-bored Shafts

\begin{tabular}{l|c|c|c}
\hline \multicolumn{1}{c|}{ Excavation } & $\begin{array}{c}\text { Service life } \\
\text { (years) }\end{array}$ & \multicolumn{2}{|c}{$\begin{array}{c}\text { Acceptable Risk Level } \\
\text { R (\%) }\end{array}$} \\
\hline $\begin{array}{l}\text { 1. Unlined hoisting } \\
\text { shaft }\end{array}$ & $>15$ & 99 & 0.01 \\
2. Ventilation shaft & 10 & 95 & 0.05 \\
3. Ore pass & $>2$ & 85 & 0.15 \\
4. Ore pass & 1 & 75 & 0.25 \\
\hline
\end{tabular}

Table 5.2 Suggested Acceptable Risks Levels for Cases Involving Human Lives

\begin{tabular}{l|c|c}
\hline \multicolumn{1}{c|}{ Source } & Event & Annual P(f) \\
\hline 1. Guide for dams & dams & $0.001-0.000033$ \\
& land use and nuclear power & $<=0.00001$ \\
2. Health and safety executive & dams & $<=0.000001$ \\
$\begin{array}{l}\text { 3. ICOLD Chairman-Comm. } \\
\text { on dam safety }\end{array}$ & & \\
\hline
\end{tabular}

What is the target reliability for mining entry design and what fatality rates are acceptable in underground coal mining? Again this is also an area that has been ignored over the years. The annual figures of fatalities and accidents are given from mining establishments and other governmental agencies will remain meaningless unless we are able to establish the target reliability in this field. Although the establishment of the target reliability on mine entry design is beyond the scope of this research, it is instructive to note 
that it can be modified from the following equation developed by the Construction Industry Research and Information Association - CIRIA (Suorineni and Dusseault, 1995).

$$
P_{T}=1-P_{f}^{\prime}=1-\frac{10^{-4}}{N_{r}} k_{s} N_{d}
$$

where $\mathrm{R}_{\mathrm{T}}$ is target reliability; $\mathrm{P}_{\mathrm{f}}$ ' is acceptable probability of failure during design life; $\mathrm{N}_{\mathrm{r}}$ is average number of miners at risk entry during design life; $\mathrm{N}_{\mathrm{d}}$ is design life for mining entries and $\mathrm{k}_{\mathrm{s}}$ is social criterion factor depending on the type of mining entries.

Conceptually, this modified approach on the estimation of the mining entry target reliability may be applicable as soon as the social criterion factor can be established in terms of various functions of different mining entry. Table 5.3 gives values of $\mathrm{k}_{\mathrm{s}}$ for various structures by CIRIA.

Table 5.3 Social Criterion Factor $\left(\mathrm{k}_{\mathrm{s}}\right)$ for Various Structures

\begin{tabular}{l|c}
\hline \multicolumn{1}{c|}{ Nature of Structure } & $\mathrm{k}_{\mathrm{s}}$ \\
\hline 1. Places of public assembly, Dams & 0.005 \\
2. Domestic, Office or trade and industry & 0.05 \\
3. Bridge & 0.5 \\
4. Towers, Masts, Offshore structure & 5.0 \\
\hline
\end{tabular}

In design of non-entry excavations, the probabilities of failure of 0.05 or more will be reasonable ranges while for entries involving 6-10 people, and probability of failure of 
0.001 will be reasonable. 


\section{CHAPTER 6}

\section{PESM APPLICATIONS AND COMPARISONS}

Design of mining entry and its stability evaluation is a key issue on ground control for underground mines in both room-and-pillar and longwall mines. Regardless of the discrepancies in the assumptions and methodologies for mine entry design by the various conventional methods, they have one thing in common, i.e. to answer the question whether the newly designed entry or the existing entry is stable? In order to reach a more rational answer by comparing the results from both the conventional and the newly developed methods (PESM), two case studies are illustrated here. One is for mine entry stability on room- and- pillar mining, and the other for pillar stability in longwall mining. Eight steps are also shown when PESM method is used, and the following three aspects, i.e., input consideration, stability computation and result interpretation are emphasized throughout those two case studies.

\subsection{Mine Entry Stability - Case 1}

Case 1 illustrated here is to show the procedures and effectiveness for both the conventional SF and PESM methods for stability evaluation of a mine entry in a room-andpillar mine where the roof, pillar and floor are considered as a whole structure for evaluation. 
To simplify this demonstration, stress variation is assumed to be zero. However, if this information is available, the effects of stress variation can be considered in the reliability computation as shown in the previous chapter.

Assuming a mine entry system in a room-and-pillar mine is $500 \mathrm{ft}$. deep. Pillars are $30 \mathrm{ft} \times 40 \mathrm{ft}$ and the entry is $18 \mathrm{ft}$ wide. The Pittsburgh seam is $7 \mathrm{ft}$. high. Both the roof and floor are shales. The coal/rock properties and in-situ stresses are listed in Table 6.1. The questions are: "Is this entry stable ?" and if so "How stable is the entry ?" To answer those questions, both the conventional SF and PESM methods for the entry stability analysis are conducted for purpose of comparison.

\subsubsection{Evaluation of Mine Entry Stability with SF Method}

Basically, the SF method cannot evaluate the entry stability as a whole. Rather, it evaluates each component (i.e., roof, pillar, and floor) individually. In addition, in the SF calculations, a deterministic value (or mean) for each independent variable as shown in Table 6.1 is used.

\subsubsection{For roof stability}

Assuming the Coulomb failure criterion is used, the SF for the roof can be determined by the following formula: 


$$
\begin{gathered}
S F=\frac{R_{r s}+q \sigma_{r \min }}{\sigma_{r \max }} \\
q=\frac{1+\sin \beta_{r}}{1-\sin \beta_{r}}
\end{gathered}
$$

Then, the SF for the roof can be obtained as shown in Table 6.2.

Table 6.1 Coal/rock Properties and Predetermined Stresses Around Mine Entry

\begin{tabular}{c|c|c|c}
\hline $\begin{array}{c}\text { Components of } \\
\text { Entry System }\end{array}$ & $\begin{array}{c}\text { Roof } \\
(18 \mathrm{ft})\end{array}$ & $\begin{array}{c}\text { Pillar } \\
(30 \mathrm{ftx} 40 \mathrm{ft})\end{array}$ & Floor \\
\hline Rock Type & Shale & Pitt. Seam & Shale \\
\hline
\end{tabular}

Uniaxial Compressive Strength (psi)

\begin{tabular}{l|l|c|c}
\hline $\begin{array}{l}\text { Mean } \\
\text { Standard Deviation }\end{array}$ & $\begin{array}{l}\mathrm{R}_{\mathrm{rs}}=4,500 \\
\mathrm{D}_{\mathrm{Rrs}}=1,500\end{array}$ & $\begin{array}{c}\mathrm{R}_{\mathrm{ps}}=3,210 \\
\mathrm{D}_{\mathrm{Rps}}=800\end{array}$ & \\
\hline \multicolumn{4}{c}{ Internal Friction Angle $\left(^{\mathrm{O}}\right)$} \\
\hline Mean & $\beta_{\mathrm{r}}=30$ & $\beta_{\mathrm{p}}=27$ & \\
Standard Deviation & $\mathrm{D}_{\beta \mathrm{r}}=3$ & $\mathrm{D}_{\beta \mathrm{p}}=5$ & \\
\hline
\end{tabular}

Cohesive Strength (psi)

\begin{tabular}{l|l|l|l}
\hline Mean & & & for im. floor \\
Standard Deviation & & & $\mathrm{R}_{\mathrm{fc}(\mathrm{i})}=1250$ \\
& & $\mathrm{D}_{\mathrm{pcc}(\mathrm{i})}=626$ \\
\hline
\end{tabular}

Modified Bearing Capacity Factor

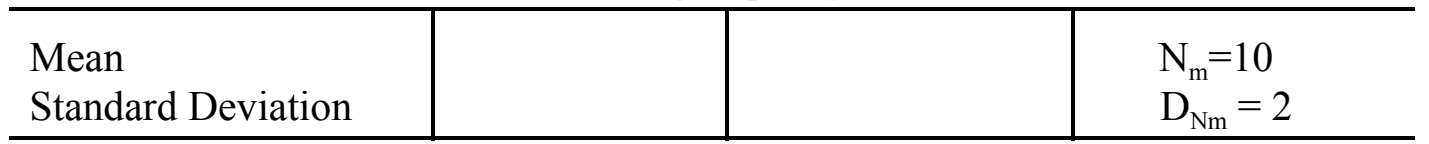

Stress Conditions (psi)

\begin{tabular}{l|l|l|l}
\hline & $\begin{array}{l}\sigma_{\text {rmax }}=1,050 \\
\sigma_{\text {rmin }}=150\end{array}$ & $\sigma_{\mathrm{p}}=1,276$ & $\sigma_{\mathrm{f}}=1,350$ \\
\hline
\end{tabular}


Table 6.2 Corresponding SF with SRF

\begin{tabular}{c|c}
\hline $\begin{array}{c}\text { Safety Factor } \\
\text { (SF) }\end{array}$ & $\begin{array}{c}\text { Strength Reduction } \\
\text { Factor (SRF) }\end{array}$ \\
\hline 2.57 & 2 \\
\hline 1.86 & 3 \\
\hline 1.50 & 4 \\
\hline
\end{tabular}

where SRF is the strength reduction factor. If the stability of roof is evaluated based on these results, it will lead to different conclusions depending on individual experiences.

\subsubsection{For pillar stability}

If the coal pillar strength, $\mathrm{R}_{\mathrm{p}}$ is estimated by the Bieniawski formula, the SF of pillar is calculated as

$$
\begin{gathered}
R_{p}=930\left(0.64+0.36 x \frac{W}{h}\right)=2,030 \\
S F=\frac{R_{p}}{\sigma_{p}}=1.59
\end{gathered}
$$

The SF of this pillar is below the average value of 1.73 suggested by Bieniawski. Notice that the scale down coal strength of 930 psi is used here. If it has certain variation like 950 psi \pm 150 psi as recommended by Su and Hasenfus (1996), it becomes difficult to pick a proper SF value and evaluate the pillar stability. 


\subsubsection{For floor stability}

Assuming the floor bearing capacity is estimated by one of the foundation engineering method as

$$
q_{f}=R_{f c} \times N_{m}
$$

where $R_{f c}$ is the cohesive strength of the weak layer, and $N_{m}$ is the modified bearing capacity reduction factor which is a function of the internal friction angle, $\beta_{\mathrm{f}}$ as well as the pillar size $\mathrm{W}$ and $\mathrm{L}$. If the cohesive strength reduction factor is taken as $50 \%$, the $\mathrm{SF}$ is about 1.1 , which might be interpreted as that the floor is unstable.

Obviously, with the SF method stability evaluation for each component depends mainly on experiences when choosing the "right" values of the strength reduction factor and SF. This could lead to human error if the relationship between the uncertainty of strength/stress and reduction factor/SF is not established. The safety level of confidence for each component of mine entry cannot be fully conveyed by the deterministic numbers of the SF.

\subsubsection{Evaluation of Mine Entry Stability with PESM Method}

By using the PESM method, the reliability of each component (i.e., roof, pillar, and floor) can be evaluated. The main results of the reliability calculations for individual 
component are shown here. The variations of coal/rock properties, as listed in Table 6.1, are taken into account during the reliability calculations. The whole procedure for evaluating stability of the roof is described in details by following the general eight steps of PESM method. However, those eight steps are simplyfied for reliability calculation on the pillar and floor.

\subsubsection{For Roof Reliability}

Step 1 Set up Safety Margin Equation

$$
M_{R}=R-F
$$

Step 2 Select Failure Criterion

Assuming the Coulomb failure criterion is used as the failure function for the stability of the roof assessment. There are two indpedent parameters, the uniaxial compressive strength, $\mathrm{R}_{\mathrm{rs}}$ and internal friction angle, $\beta_{\mathrm{r}}$ that exhibit certain variations assuming the stresses are constants for this case. Therefore, the safety margin for the roof is

$$
M_{R}=\left(R_{r s}+q \sigma_{r \min }\right)-\sigma_{r \max }
$$

Step 3 Calculate the Statistical Parameters for Each Independent Variable

Table 6.3 show the calculated statistic parameters for the uniaxial compressive strength, $\mathrm{R}_{\mathrm{rs}}$ and internal friction angle, $\beta_{\mathrm{r}}$. 
Table 6.3 Calculated Statistical Parameters for Independent Variables of Roof

\begin{tabular}{c|c|c|c|c}
\hline Parameter $(\mathrm{x})$ & $\mathrm{E}[\mathrm{x}]$ & $\mathrm{D}[\mathrm{x}]$ & $\mathrm{x}_{+}$ & $\mathrm{x}_{-}$ \\
\hline $\mathrm{R}_{\mathrm{rs}}$ & 4,500 & 1,500 & 6,000 & 3,000 \\
\hline$\beta_{\mathrm{r}}$ & 30 & 3 & 33 & 27 \\
\hline
\end{tabular}

Step 4 Estimate the Coefficient of Correlation and Weighting Factor

Assuming the correlation coefficient, $\rho$, between the uniaxial compressive strength, $\mathrm{R}_{\mathrm{rs}}$ and internal friction angle, $\beta_{\mathrm{r}}$ is 0.5 . Then, the weighting wight factor $\mathrm{P}_{\mathrm{ij}}$ can be calculated as

$$
\begin{aligned}
& P_{++}=P_{--}=\frac{1}{4} x(1+\rho)=0.375 \\
& P_{+-}=P_{-+}=\frac{1}{4} x(1-\rho)=0.125
\end{aligned}
$$

Step 5 Calculate the Statistical Parameters on Safety Margin

Table 6.4 shows the calculation process in this step.

Table 6.4a Initial Process for Roof Reliability Calculation

\begin{tabular}{c|c|c|r|c|c}
\hline & \multicolumn{1}{|c|}{$\mathrm{Y}$} & $\mathrm{P}$ & \multicolumn{1}{c|}{$\mathrm{YxP}$} & $\mathrm{Y}^{2}$ & $\mathrm{Y}^{2} \mathrm{xP}$ \\
\hline $\mathrm{Y}++$ & 5,459 & 0.375 & 2,047 & $2.98 \times 10^{7}$ & $1.12 \times 10^{7}$ \\
\hline $\mathrm{Y}+-$ & 5,349 & 0.125 & 669 & $2.86 \times 10^{7}$ & $3.58 \times 10^{6}$ \\
\hline $\mathrm{Y}-+$ & 2,458 & 0.125 & 307 & $0.642 \times 10^{7}$ & $6.04 \times 10^{6}$ \\
\hline $\mathrm{Y}--$ & 2,349 & 0.375 & 881 & $0.55 \times 10^{7}$ & $5.52 \times 10^{6}$ \\
\hline
\end{tabular}


Table $6.4 \mathrm{~b}$ Results of Step 5 Computation

\begin{tabular}{c|c}
\hline Parameter & Result \\
\hline $\mathrm{E}\left[\mathrm{M}_{\mathrm{R}}\right]$ & 3,904 \\
\hline $\mathrm{E}\left[\mathrm{M}_{\mathrm{R}}{ }^{2}\right]$ & $1.75 \times 10^{7}$ \\
\hline $\operatorname{Var}\left[\mathrm{M}_{\mathrm{R}}\right]$ & $2.3 \times 10^{6}$ \\
\hline $\mathrm{D}\left[\mathrm{M}_{\mathrm{R}}\right]$ & 1,517 \\
\hline
\end{tabular}

Step 6 Calculate the Reliability Index

$$
\kappa=\frac{E\left[M_{R}\right]}{E\left[\sigma_{M_{R}}\right]}=\frac{3904}{1517}=2.573
$$

Step 7 Calculate the Reliability of Structure

$$
P_{f}=\frac{1}{2}-\Phi(2.573)=0.0051
$$

$$
P=99.49 \%
$$

Step 8 Make Decision by Comparing the Target Reliability

Assuming the target reliability for the roof is $97 \%$, the result indicates that the roof is in the stable condition since the calculated reliability of the roof is higher than the target reliability. 
6.1.2.2 For pillar reliability: Two methods on the pillar stability analysis are conducted using the reliability method.

Method 1. Calculate the probability of the pillar SF being less than 1.3 if the coefficient of variation of the scaled down coal strength in the Bieniawski equation is $20 \%$.

Table 6.5 Calculated Statistics for Independent Variable of Pillar (Method 1)

\begin{tabular}{c|c|c|c|c}
\hline Parameter (x) & $\mathrm{E}[\mathrm{x}]$ & $\mathrm{CV}(\%)$ & $\mathrm{x}_{+}$ & $\mathrm{x}_{-}$ \\
\hline $\mathrm{R}_{\mathrm{ps}}$ & 930 & 20 & 1,116 & 744 \\
\hline
\end{tabular}

Table 6.6 Results from Step 5 Computation (Method 1)

\begin{tabular}{c|c}
\hline Parameter & Result \\
\hline$[\mathrm{SF}]$ & 1.591 \\
\hline $\mathrm{E}\left[\mathrm{SF}^{2}\right]$ & 2.612 \\
\hline $\operatorname{Var}[\mathrm{SF}]$ & 0.081 \\
\hline $\mathrm{D}[\mathrm{SF}]$ & 0.284 \\
\hline
\end{tabular}

$$
P_{f}(S F<1.3)=\Phi\left(\frac{1.3-1.591}{0.2844}\right)=15.5 \%
$$

The probability of failure for this case is about $16 \%$ which is too high to be acceptable. However, why should the critical (limiting) SF be 1.3 ? A different probability 
of failure will be obtained if another number of critical SF is chosen.

Method 2. Let the safety margin of pillar be $\mathrm{M}_{\mathrm{p}}$, The safety margin is

$$
M_{P}=R_{p s}-\sigma_{p}
$$

The calculated statistics for the independent variables of the pillar and the intermediate results for pillar reliability computation are shown in Tables 6.7 and 6.8 , respectively.

Table 6.7 Calculated Statistics for Independent Variables of Pillar (Method 2)

\begin{tabular}{c|c|c|c|c}
\hline Parameter $(\mathrm{x})$ & $\mathrm{E}[\mathrm{x}]$ & $\mathrm{D}[\mathrm{x}]$ & $\mathrm{x}_{+}$ & $\mathrm{x}_{-}$ \\
\hline $\mathrm{R}_{\mathrm{ps}}$ & 3,210 & 800 & 4,010 & 2,410 \\
\hline
\end{tabular}

Table 6.8 Results form Step 5 Computation

(Method 2)

\begin{tabular}{c|c}
\hline Parameter & Result \\
\hline$E\left[\mathrm{M}_{\mathrm{P}}\right]$ & 1,934 \\
\hline $\mathrm{E}\left[\mathrm{M}_{\mathrm{P}}{ }^{2}\right]$ & $4.38 \times 10^{6}$ \\
\hline $\operatorname{Var}\left[\mathrm{M}_{\mathrm{P}}\right]$ & $0.64 \times 10^{6}$ \\
\hline $\mathrm{D}\left[\mathrm{M}_{\mathrm{P}}\right]$ & 800 \\
\hline
\end{tabular}

$$
\kappa=\frac{E\left[M_{P}\right]}{E\left[\sigma_{M_{P}}\right]}=\frac{1934}{800}=2.42
$$




$$
P_{f}=\frac{1}{2}-\Phi(2.42)=0.80 \%
$$

$$
P=99.2 \%
$$

The results indicate the pillar is stable since the calculated reliability is higher than $97 \%$ which is assumed as the target reliability for the pillar.

6.1.2.3 For floor reliability: Variations due to the cohesive strength, $\mathrm{R}_{\mathrm{fC}}$ of the weaker layer (i.e., immediate floor) and modified bearing capacity factor, $\mathrm{N}_{\mathrm{m}}$ is considered for the floor reliability determination. The correlation coefficient between $\mathrm{R}_{\mathrm{fC}}$ and $\mathrm{N}_{\mathrm{m}}$ is assumed to be 0.5 . The safety margin of floor, $\mathrm{M}_{\mathrm{F}}$ and the floor reliability are calculated as

$$
M_{F}=R_{f c}-\sigma_{V}
$$

Table 6.9 Calculated Statistics for Independent Variables of Floor

\begin{tabular}{c|c|c|c|c}
\hline Parameter $(\mathrm{x})$ & $\mathrm{E}[\mathrm{x}]$ & $\mathrm{CV}(\%)$ & $\mathrm{x}_{+}$ & $\mathrm{x}_{-}$ \\
\hline $\mathrm{R}_{\mathrm{rfs}}$ & 1,250 & 50 & 1,878 & 626 \\
\hline$\beta_{\mathrm{m}}$ & 10 & 20 & 12 & 8 \\
\hline
\end{tabular}


Table 6.10 Results from Step5 Computation

\begin{tabular}{c|c}
\hline Parameter & Result \\
\hline $\mathrm{E}\left[\mathrm{M}_{\mathrm{F}}\right]$ & 10,640 \\
\hline $\mathrm{E}\left[\mathrm{M}_{\mathrm{F}}^{2}\right]$ & $146.77 \times 10^{6}$ \\
\hline $\operatorname{Var}\left[\mathrm{M}_{\mathrm{F}}\right]$ & $33.56 \times 10^{6}$ \\
\hline $\mathrm{D}\left[\mathrm{M}_{\mathrm{F}}\right]$ & 5,793 \\
\hline
\end{tabular}

$$
\begin{gathered}
\kappa=\frac{E\left[M_{F}\right]}{E\left[\sigma_{M_{F}}\right]}=\frac{10,640}{5,793}=1.84 \\
P_{f}=\frac{1}{2}-\Phi(1.84)=3.2 \%
\end{gathered}
$$

$$
P=96.8 \%
$$

It can be concluded that the floor is also stable since the calculated reliability of the floor is close to the target reliability of $97 \%$.

\subsubsection{Stability Comparison on Mine Entry}

By using the conventional method, the stability of the roof, pillar and floor are assessed by values of the calculated SF as compared to the limited values of SF. Under this condition, the selection of a critical SF is a difficult task since it is totally controlled by previous experience rather than scientific rationalization. Of course, for the calculated SF, 
there are even more questions about it as mentioned in the previous chapters. If one cannot explain quantitatively and qualitatively the reasons and degrees of structure stability with SFs (both the selected critical SF and the calculated SF), the outcomes from using the conventional SF method for stability of mine entry design are questionable. It will become worse when multiple solutions of SFs exist and discrepancies among those arguments cannot be resolved since no scientific and regulatory rules can be followed to adjudge which one is more reliable under this condition. With the results of the reliability method, it can measure how faraway the current stability condition of the structure is from the target (or acceptable) reliability. The reliability results indicate how much risk will be with confidence. Since it includes the variations of the coal/rock properties, one can state that any component of the mine entry with $97 \%$ reliability is more stable than that with $95 \%$ reliability even though they are locate in different sites. But the statement that any component of the mine entry has a SF of 2.2 is more stable than that with SF of 1.8 is not always true even for the different components of the same entry..

Overall, the results of using reliability assessment as shown in Table 6.11 are much easier to make decision on the stability of each component of the mine entry as soon as the target reliability is established. For this project, if $97 \%$ is the target reliability, the following conclusions can be obtained: (1) the floor is almost close to an optimum design; (2) the pillar is over-designed and pillar size can be reduced; (3) the roof is under-designed and its probability of failure is $27 \%$ more than the acceptable one. The stability order for the mine entry components can be compared as shown in Table 6.12. It may be expected the roof 
will be failure first in this entry. However, by using SF assessment as shown in Table 6.11, more information other than SF is required to make final decision. For example, strength reduction factor and critical SF should be predetermined which may have many discrepancies from different experiences and sites. Those parameters cannot be unique determined. Therefore, the decision making by the results of SF only is always debated due to much disagreement of different expertise. Also, we may conclude with SF, for example, the floor is stable since it is great than 1.0. But how much risk it will be ? No stability order can be compared among the components of the mining entry as show in Table 6. 12, since no uniform critical SF can be established under the conventional SF method.

Table 6.11 Stability of Evaluation of Entry Components Using SF and Reliability Methods

\begin{tabular}{l|c|c|c}
\hline \multirow{2}{*}{} & \multicolumn{3}{|c}{ Component's Stability of Mine Entry } \\
\cline { 2 - 4 } & Roof & Pillar & Floor \\
\hline SF & 1.86 & 1.59 & 1.10 \\
Critical SF* & $>1.0$ & 1.75 & $>1.0$ \\
Stable or Not Stable? & Stable & No/Yes (?) & No/Yes (?) \\
\hline Reliability (\%) & 99.49 & 99.2 & 96.8 \\
Target Reliability (\%)** & 97 & 97 & 97 \\
Stable or Not Stable ? & Yes & Yes & Yes \\
\hline
\end{tabular}

Notes:

* Assumed critical SFs; and

** Assumed target reliability. 
Table 6.12 Comparison of Stability Order Using SF and Reliability Methods

\begin{tabular}{l|c}
\hline \multicolumn{1}{c|}{ Method } & Stability Order among Components of Mine Entry \\
\hline SF & NA* $^{*}$ or Roof $>$ Pillar $>$ Floor) \\
\hline Reliability & Roof $>$ Pillar $>$ Floor \\
\hline
\end{tabular}

Note:

* Not applicable.

\subsection{Longwall Pillar Stability - Case 2}

This case study is to evaluate the pillar stability in a longwall mining. The variations in both strength and stress of the pillar are taken into consideration by using the PESM method. Three types of stresses are simulated by FE modeling when the coal/rock properties, as input parameters, are assumed as non-constant variables. Two failure criteria are selected using both SF and PESM methods for purpose of comparison.

It assumes that the width and length of the longwall panel are $750 \mathrm{ft}$ and 1,200 ft, respectively, and overburden depth is $800 \mathrm{ft}$ deep. The three entry system is used with $20 \mathrm{ft}$ wide entry during the development stage. The pillar size is $100 \mathrm{ft}$ long, $80 \mathrm{ft}$ wide and $7 \mathrm{ft}$ high as shown in Figure 6.1. 


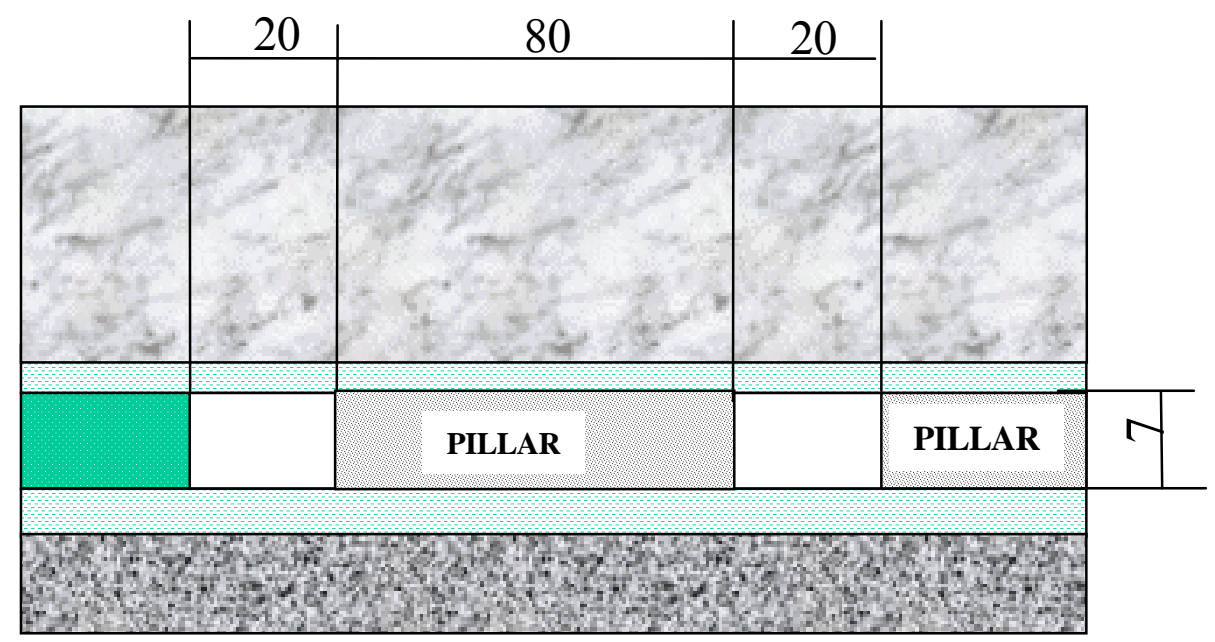

(a)

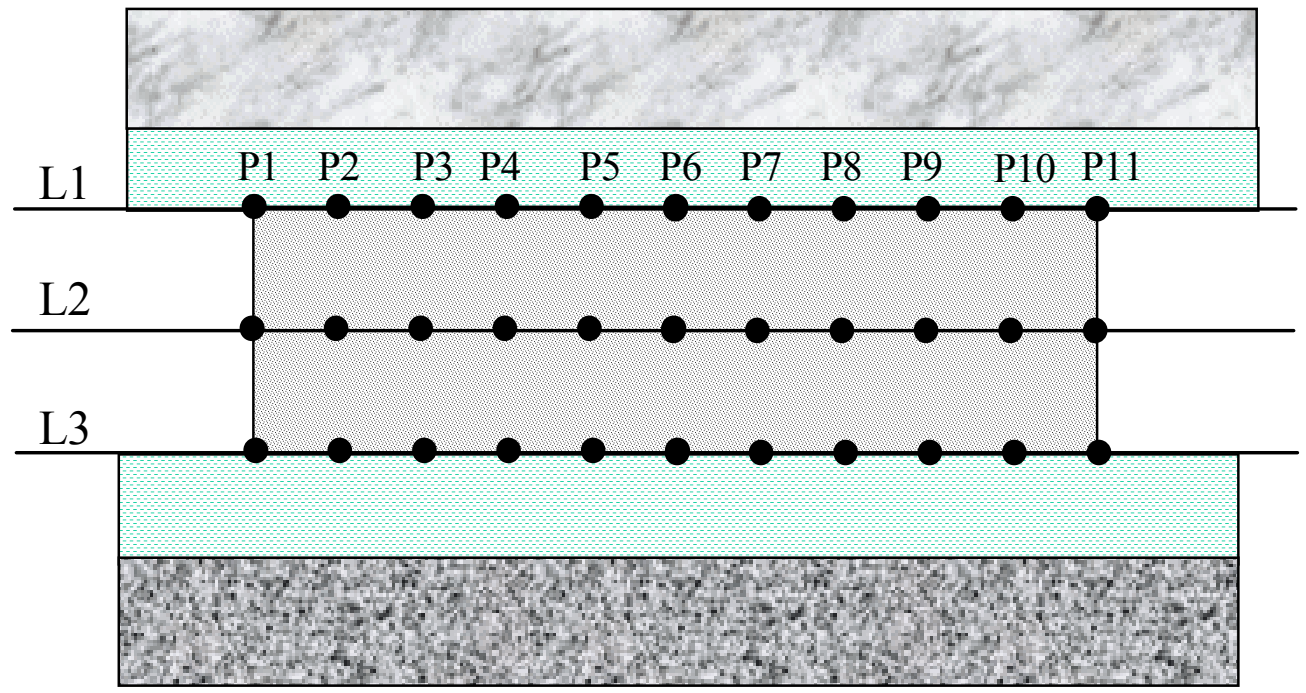

(b)

Figure 6.1 Layout of Longwall Pillar 


\subsubsection{FE Modeling}

To evaluate the stresses variations due to the uncertainties of the coal/rock properties, three levels of Young modules from the roof, coal seam and floor are used as shown in Table 6.13. To cover possible combination, twenty seven 3-D FE models are constructed with $3 \times 3$ orthogonal experimental design when all other geological and geometrical conditions for the mine entry are hold constants.

Table 6.13 Young's Modules Using for Construction of 27 FE Models

\begin{tabular}{l|c|c|c}
\hline & \multicolumn{3}{|c}{ Young's Modules (x10^6 $\mathrm{psi})$} \\
\hline & Roof & Coal Seam & Floor \\
\hline Level 1 & 20 & 0.20 & 0.2 \\
\hline Level 2 & 40 & 0.40 & 0.4 \\
\hline Level 3 & 60 & 0.60 & 0.6 \\
\hline
\end{tabular}


Figure $6.1 \mathrm{a}$ and $6.1 \mathrm{~b}$ show the partial cross section of the element arrangement in the FE modeling. Three types of stresses (i.e. Von Misses stress, minimum and maximum principal stresses) are simulated along both the height direction with 3 lines (i.e., roof line, center line and floor line through the pillar) and the width direction with 11 points (i.e. P1, P2...P11).

\subsubsection{Modeling Results}

Figure 6.2 illustrates a frequency plot from all modeling results. It includes outcomes from the three types of stresses at each element. The horizontal axis indicates the scale of stress level. The vertical axis shows the numbers of count. It can be observed from the plot that there is no distribution trend for the three types of stresses. However, it seems that the magnitude of the Von Misses (VON_M) stress is between the minimum (MIN_P) and maximum (MAX_P) principal stress. Both the Von Misses and maximum principal stress have the larger range than that of the minium principal stresses. 


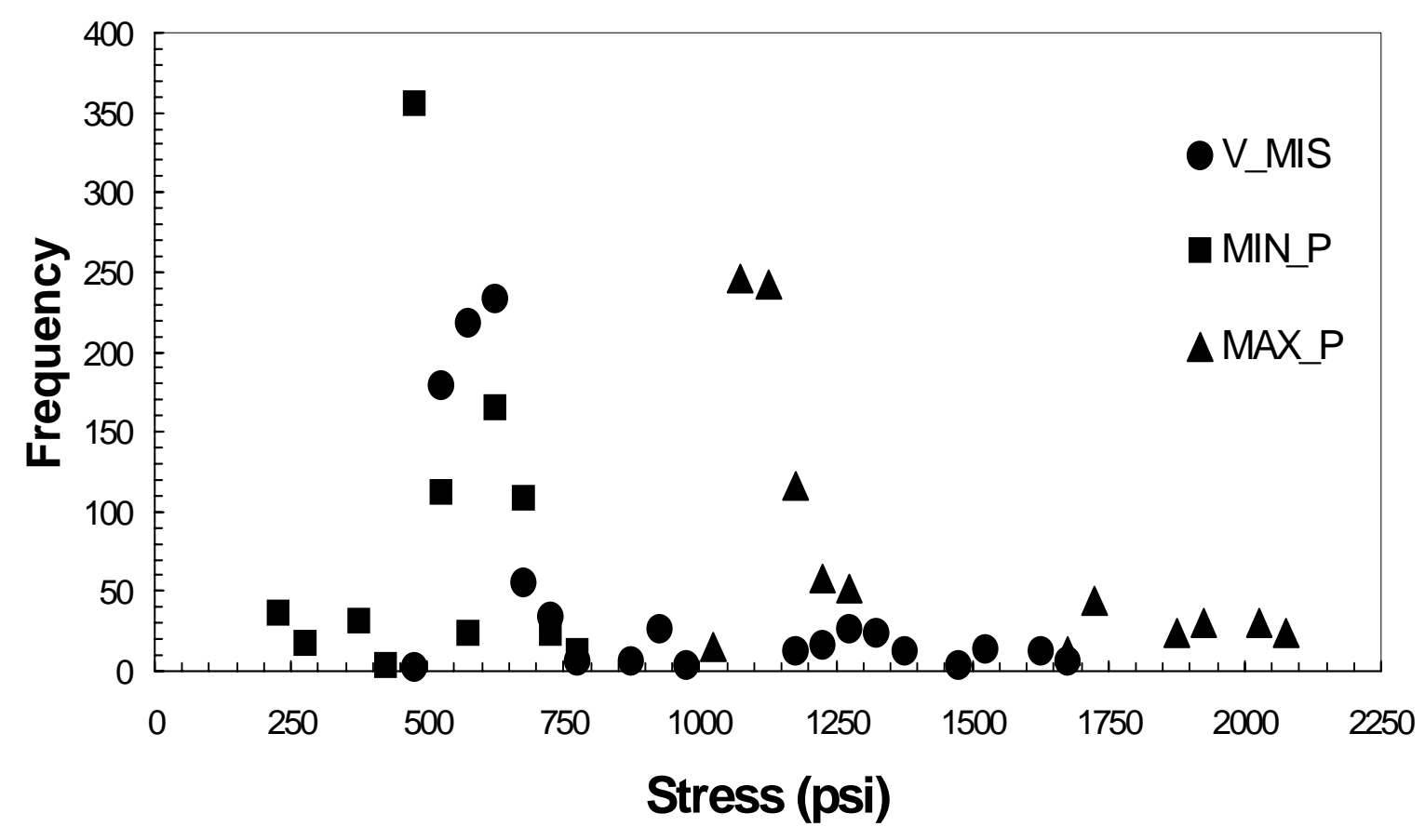

Figure 6.2 Frequency of Three Types of Stresses

Figure 6.3 shows the comparison of the statistical results in the form of SM and MM. SM means the modeling results come from only using the average Young's modulus (Level2) or single model, while MM means that the modeling results come from the multiple models, where all 27 modeling results are used. The horizontal axis indicates the three types of stresses in all figures. The results from Figure $6.3 \mathrm{~b}, 6.3 \mathrm{c}$ and $6.3 \mathrm{~d}$ show that the differences of the stress means, standard deviations and coefficient (CV) of variations between SM andMM are very small for each type of stress, even though the difference for sample sizes used for SM and MM are very large as shown in Figure 6.3a. However, The standard deviations of three types of 


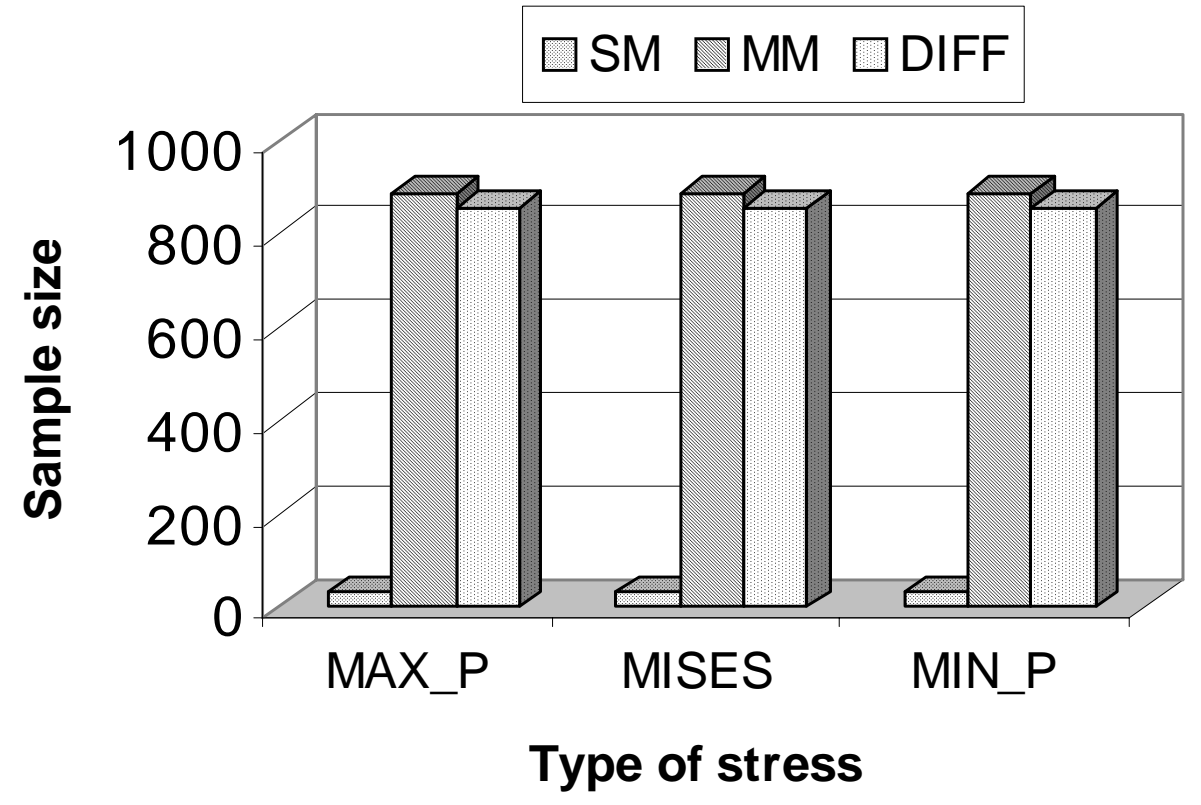

(a)

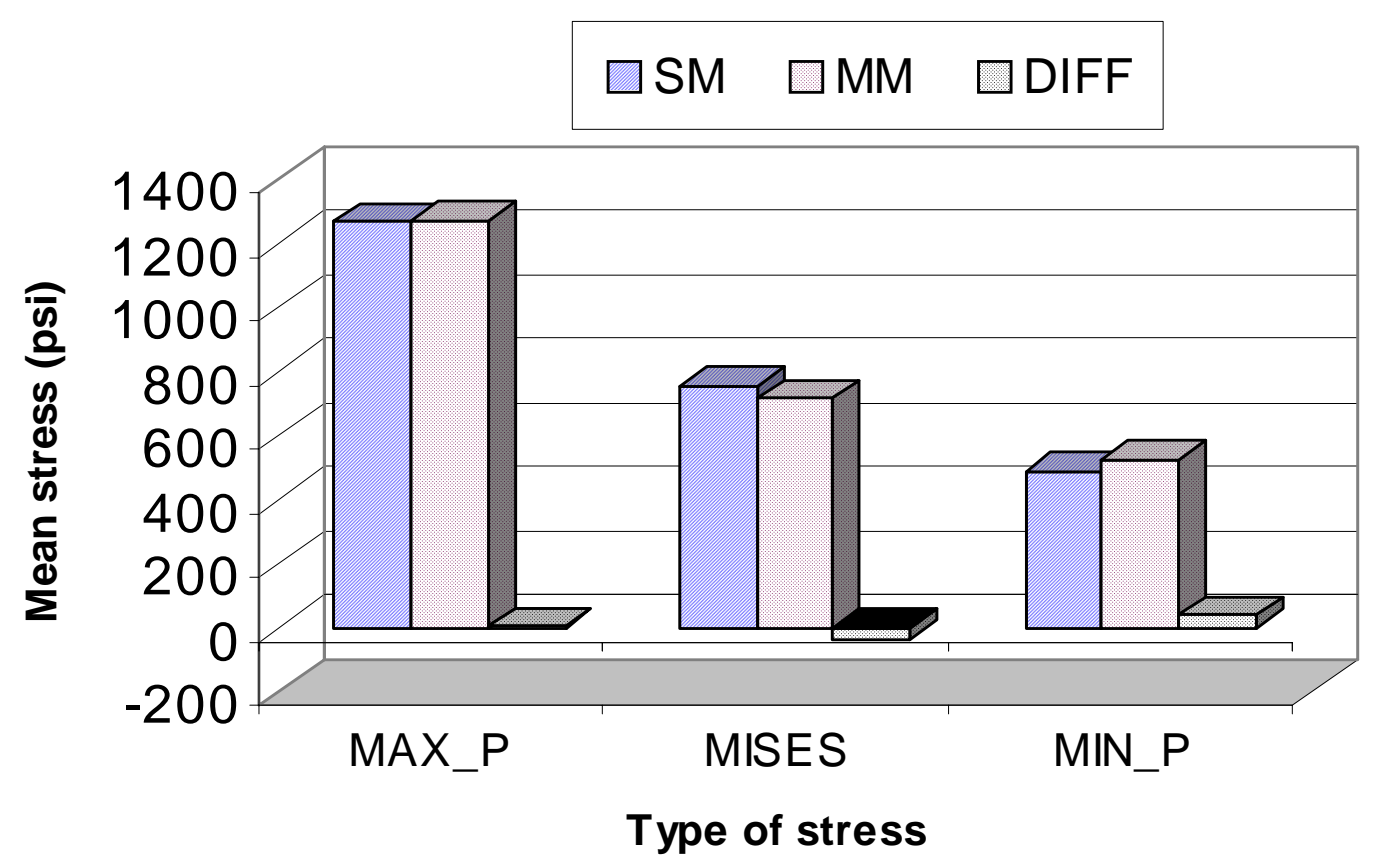

(b) 


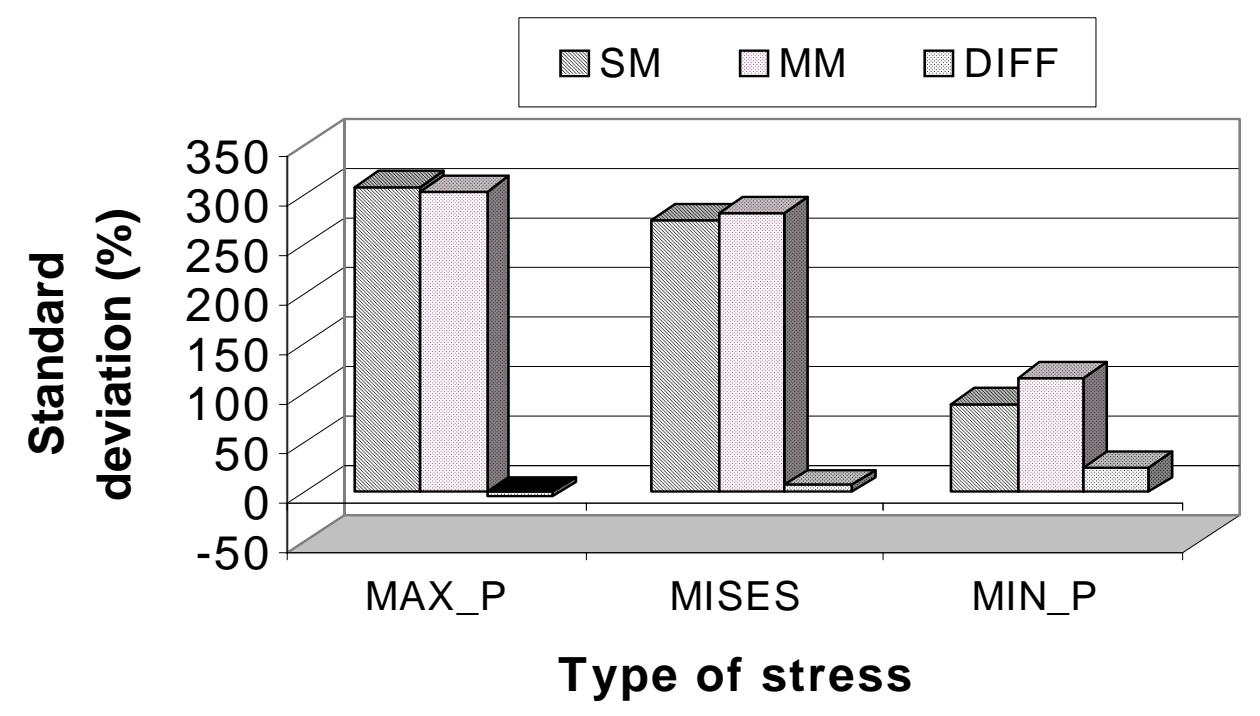

(c)

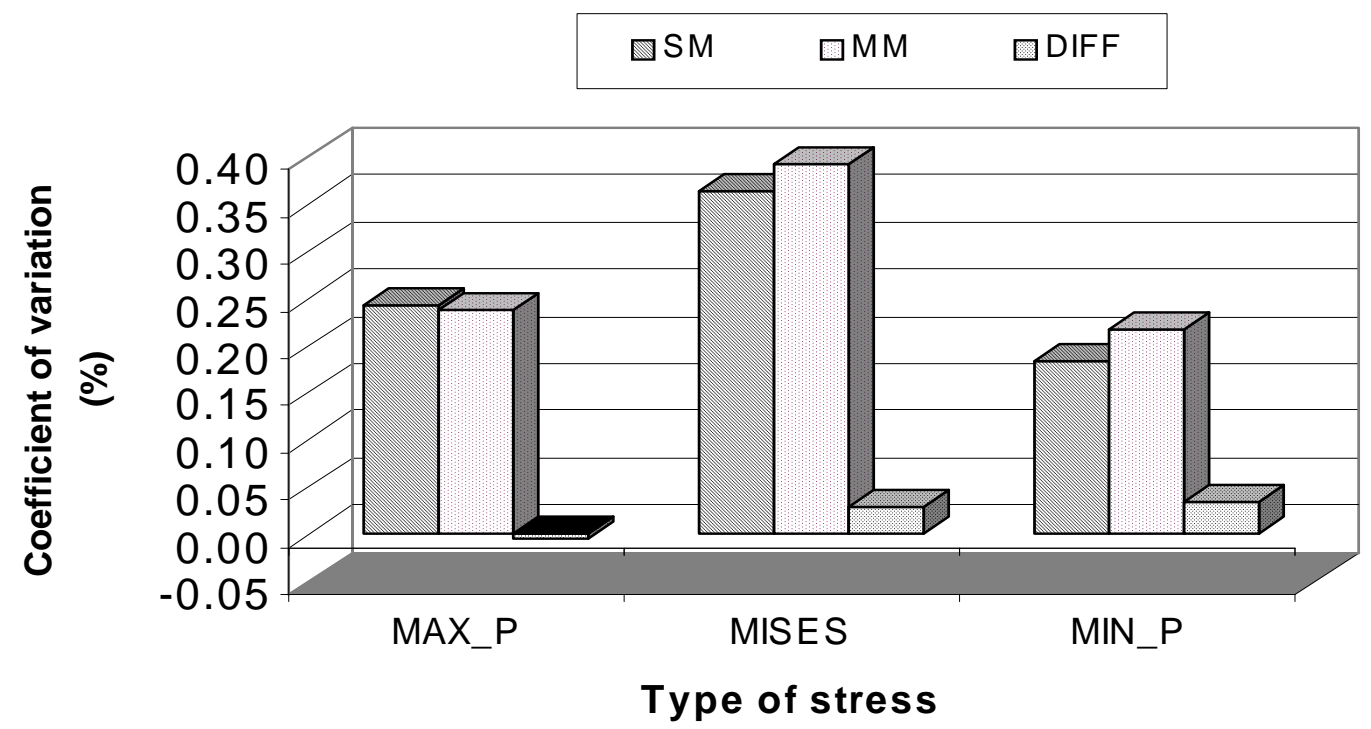

(d)

Figure 6.3 Comparison of Stresses Statistics on SM and MM 
stresses are the considerable larger. The coefficient of variations for all three are very large as shown in Figure 6.3a. However, The standard deviations of three types of stresses are the considerable larger. The coefficient of variations for all three types of stresses are above $20 \%$. The CV of Von-mises stresses for both SM and MM are more than 35\%. These indicate that the Von Mises stresses have a larger degree of spread from the their means than that of minimum and maximum principal stresses.

Figure 6.4 shows stresses distribution across the pillar with one of 27 models (model-8). Three types of stresses are presented, separately, along both the vertical (along the pillar height with 3 lines) and horizontal (along the pillar width with 11 points) directions. It can be observed that the variations of the Von Misses and maximum principal stresses appear to have less variation along the pillar height direction since the stresses between L1, L2 and L3 have the similar trend. The minium principal stresses, however, show quite bigger diverse distribution among the 3 lines. The stress along the pillar width direction seems to changes considerably, especially near the pillar edges (e.g. P1, P2, P10 and P11). The results suggest that the statistical parameters may need to be calculated in terms of the different locations rather than on the entire pillar. 


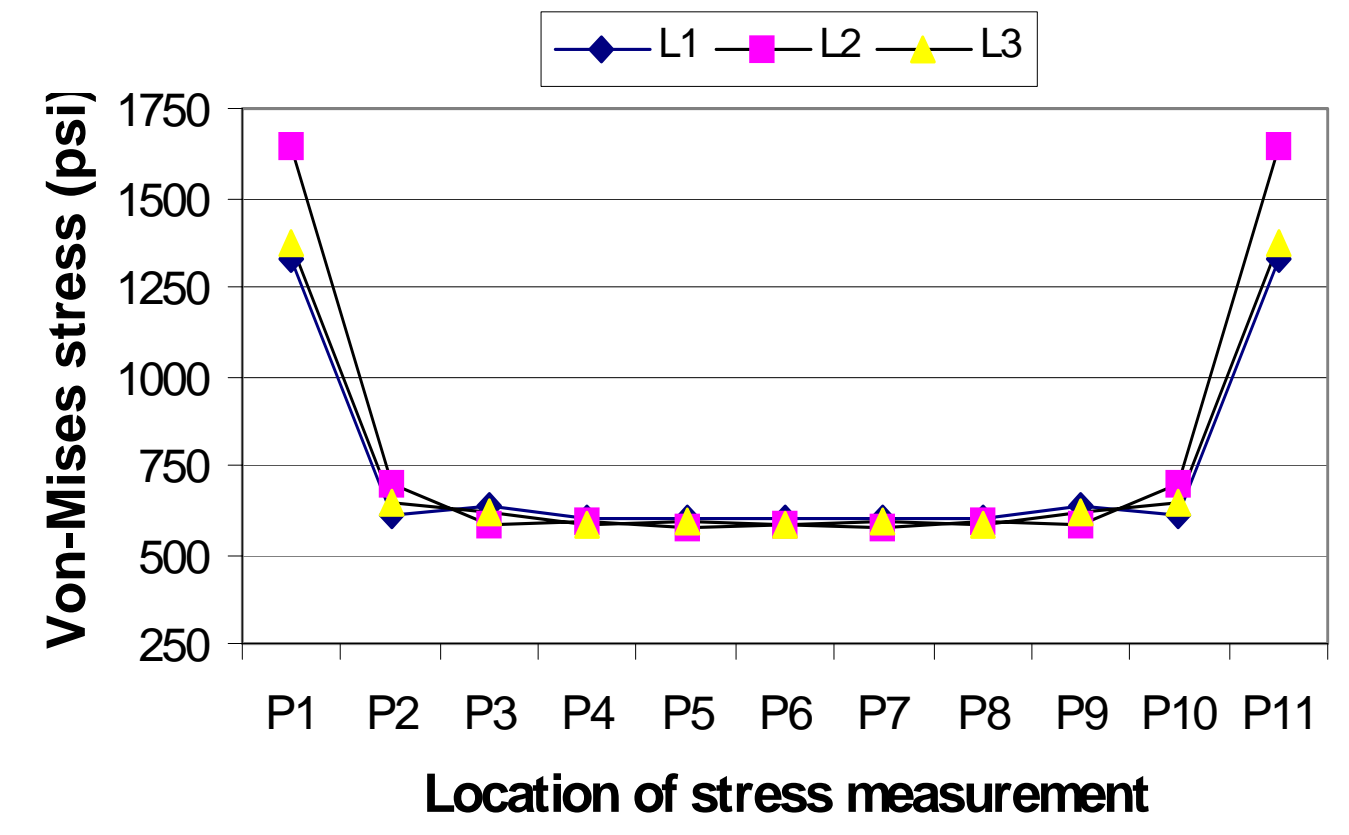

(a)

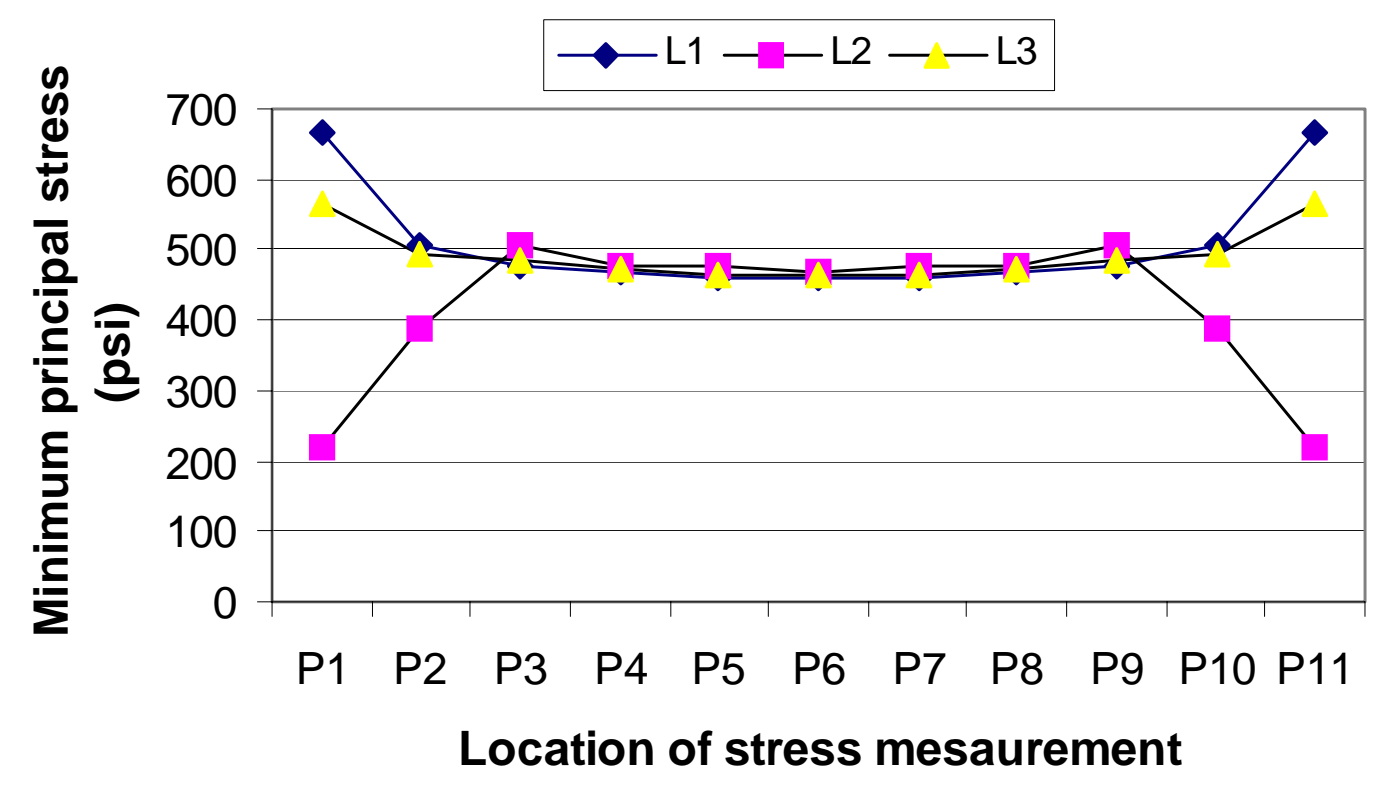

(b) 


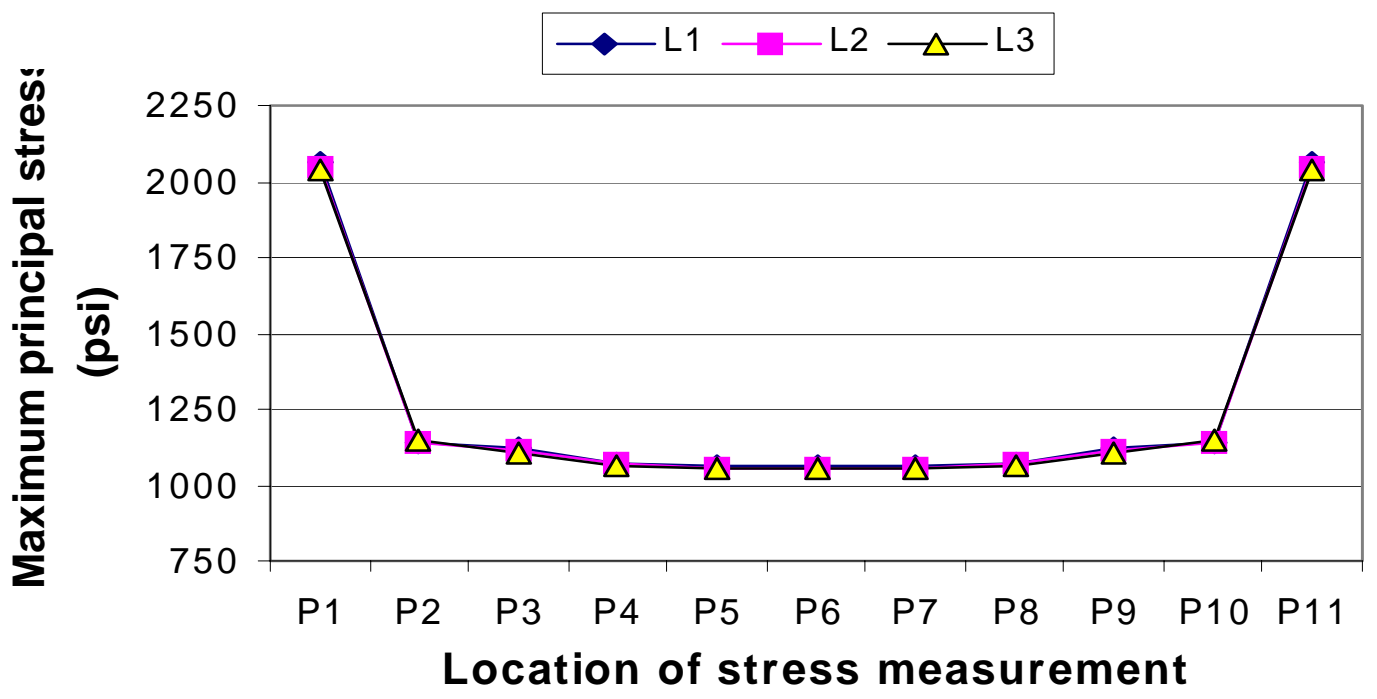

(c)

Figure 6.4 Stress Distribution for Model 8

Figure 6.5 is prepared to compare the sample sizes, mean and STD of the three types of stresses for all 14 groups. The detail classifications of the group along the horizontal axis are listed as follows:

$$
\text { XX_YY_ZZ }
$$

$\mathrm{XX}$ indicates the modeling type in that group.

$$
\begin{aligned}
& \text { SM } \quad \text { - for single model } \\
& \text { MM - for multiple models }
\end{aligned}
$$

YY indicates the line(s) included in that group. For example,

$$
\text { L1 - only elements along L1 are included }
$$


3L - elements along all three lines are included

$\mathrm{ZZ}$ indicates element(s) which are included in that group. For example,

P1 - only first element is included

3P - all elements are included

MM_L2_3P, for example, means that the statistical parameters are calculated from the output of the multiple models (MM) but including all points (3P) at center line (L2). MM_3L_3P refers to results from multiple model including all points in all 3 lines. The results from Figure 6.5 indicate that stress means and STDs are very close when they are compared along the pillar height (i.e. between L1, L2 and L3) direction, and is also reaching the results from the reference for both MM and SM. Along the pillar width direction, all three types of stresses are quite different from that in the pillar rib (i.e. at P1), especially along the central line (L2). Although the stress magnitude at P1 seem to be very close between SM and MM, no standard deviation can be calculated from SM. The results from those figures also suggest that the dispersion of stresses about the means is larger from one group to another if the group consists of more elements. Therefore, the variations for pillar strength and stress begins to show up when MM is considered, as opposed to single element single point in SM where there is no coefficient of variation. Those facts should be taken into consideration in the stability of pillar design and evaluation. 


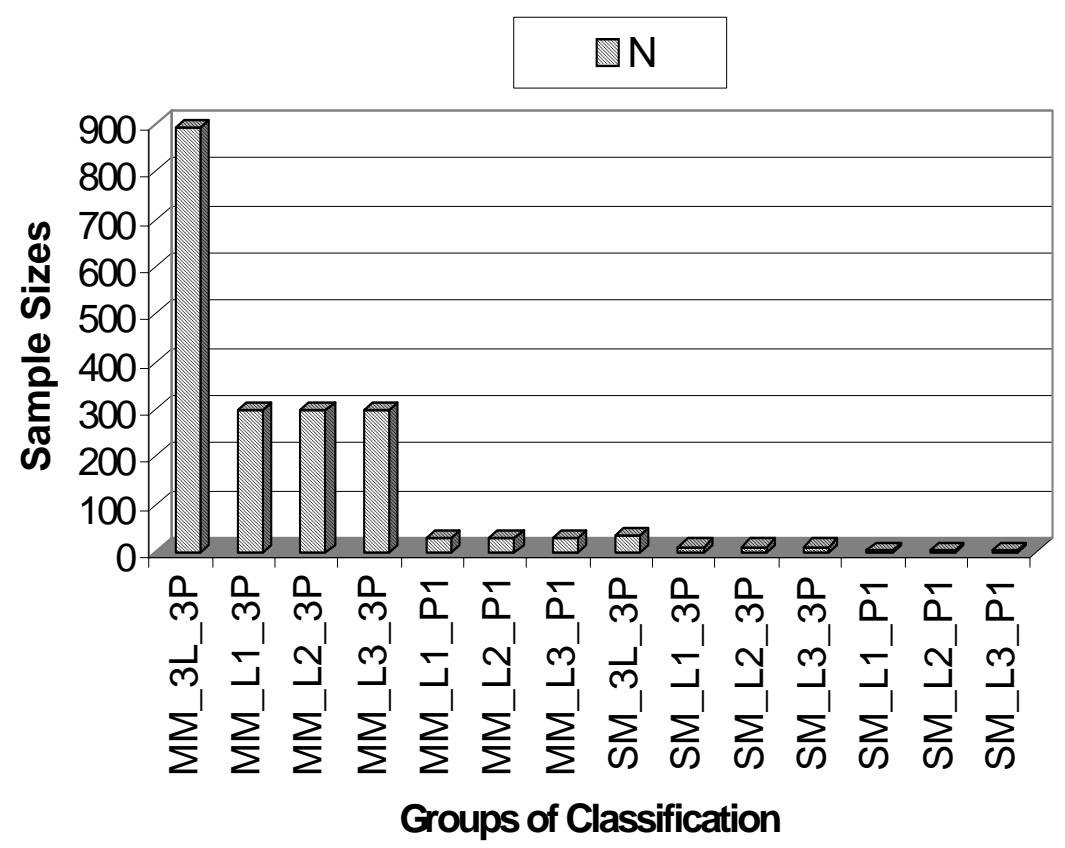

(a)

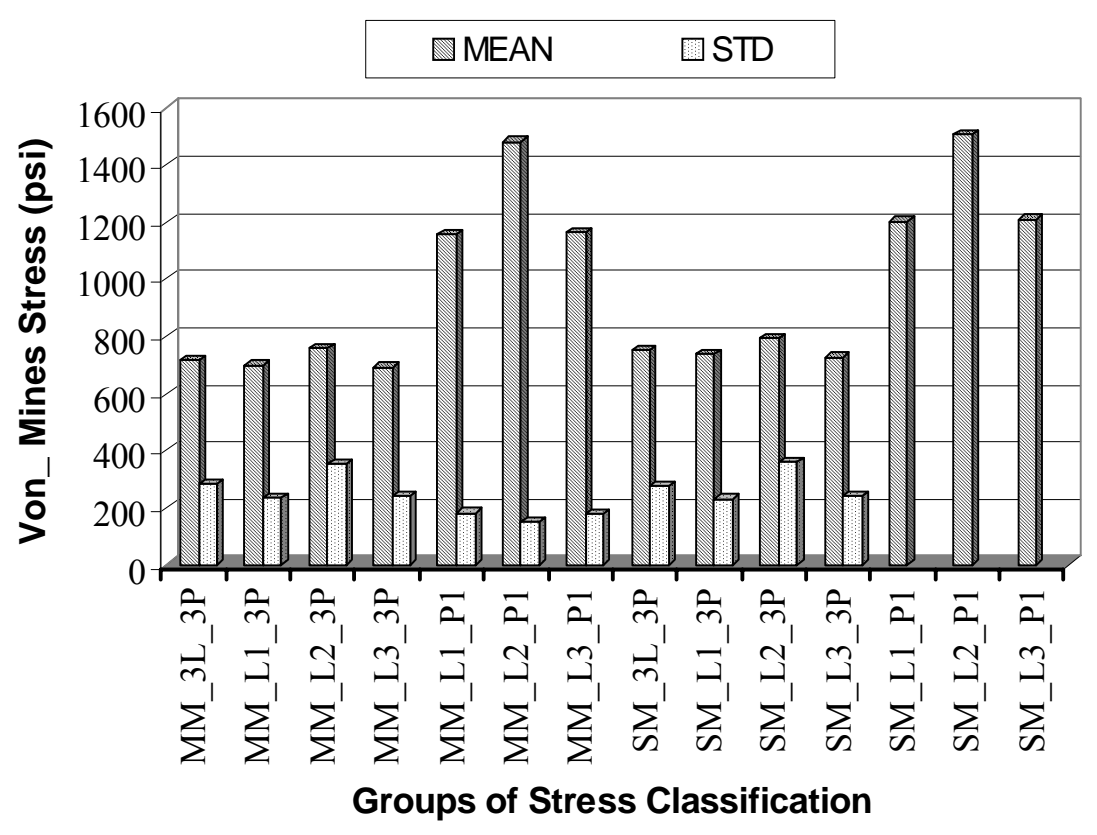

(b) 


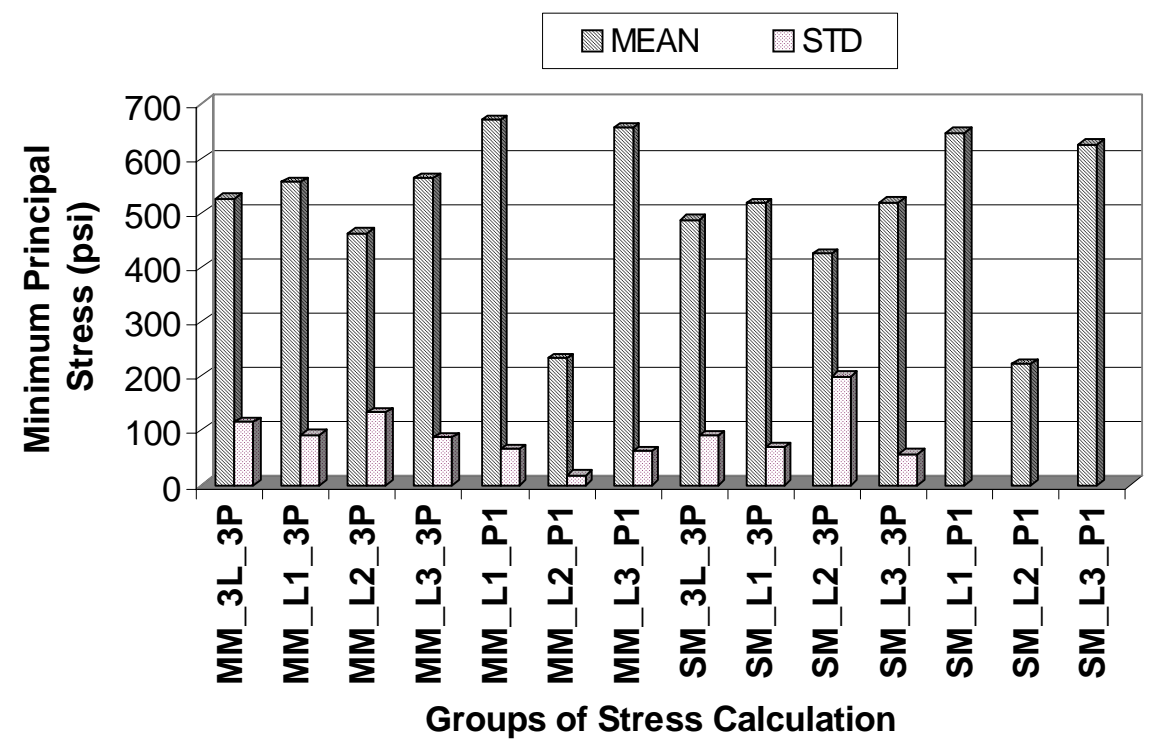

(c)

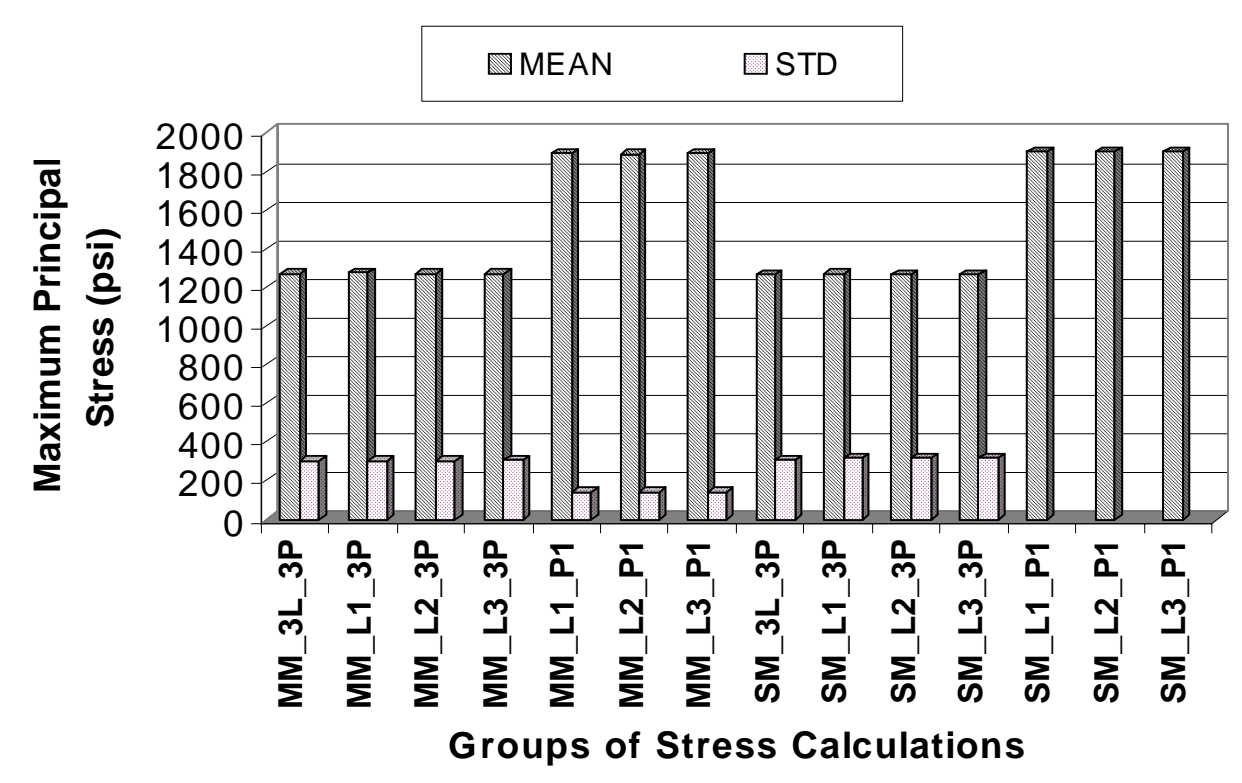

(d)

Figure 6.5 Stresses Statistics for All Groups 


\subsubsection{SF Based Analysis on Pillar Stability}

In general, the commonly used SF methods is based on a deterministic analysis. It is defined as the ratio of mean strength $(\mathrm{E}[\mathrm{S}])$ to mean stress $(\mathrm{E}[\mathrm{F}])$ of a structure although the mean strength and mean stress may be determined in different ways using varying failure criteria under varying mining environments.

$$
S F=\frac{E[S]}{E[F]}=\frac{\bar{S}}{\bar{F}}
$$

a. If the Coulomb failure criterion is used, then

$$
\begin{gathered}
S F=\frac{t \sigma_{c}+q \sigma_{3}}{\sigma_{1}} \\
q=\frac{1+\sin \alpha}{1-\sin \alpha}
\end{gathered}
$$

Where $t$ is strength reduction factor; $\sigma_{\mathrm{c}}$ is uniaxial compressive strength, psi; $\alpha$ is internal frictional angle; $\sigma_{1}$ and $\sigma_{3}$ are the maximum and minimum principal stresses, psi, respectively. 
b. If the Von-Mises failure criterion is used, then

$$
S F=\frac{\sigma_{v o n}}{t \sigma_{c}}
$$

where $\sigma_{\mathrm{von}}$ is the Von-Mises stress, psi.

As described before, SF is a function of both pillar strength and stress. However, depending on the failure criteria, the strength and stress calculations vary because different parameters are used in the strength and stress estimations. Since there are several parameters in the equations, the determination of their impact on SF uncertainty of all these parameters is very involved. Therefore, as example, only a single parameter, strength reduction factor $(\mathrm{t})$, is analyzed using the Coulomb and Von Mises failure criteria while all other parameters are hold constant. Figure 6.6 shows the effects on SF due to different strength reduction factors for various groups under both the Coulomb (C_FC) and Von Misses failure criteria (V_FC). Note the central rib of the pillar (i.e MM_L2_P1 or SM_L2_P1) is in unstable condition if $\mathrm{t}>=3$ but it is difficult to determine if it is in stable or failure condition when $\mathrm{t}$ equals 2. Figure 6.7 shows the summary statistics for the results of SFs. It shows that in each group, SFs are different when different failure criteria are used. The SF from using the Coulomb failure criterion is always higher than that from using the Von Misses failure criterion. The higher is the $\mathrm{t}$, the larger is the difference of SF. 


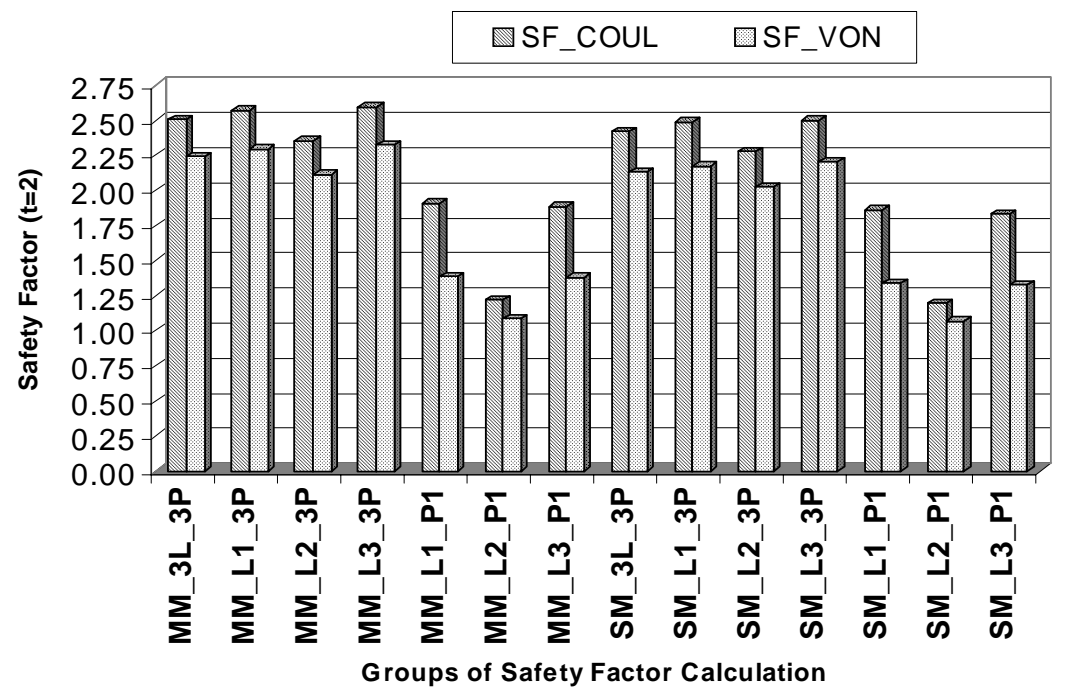

(a)

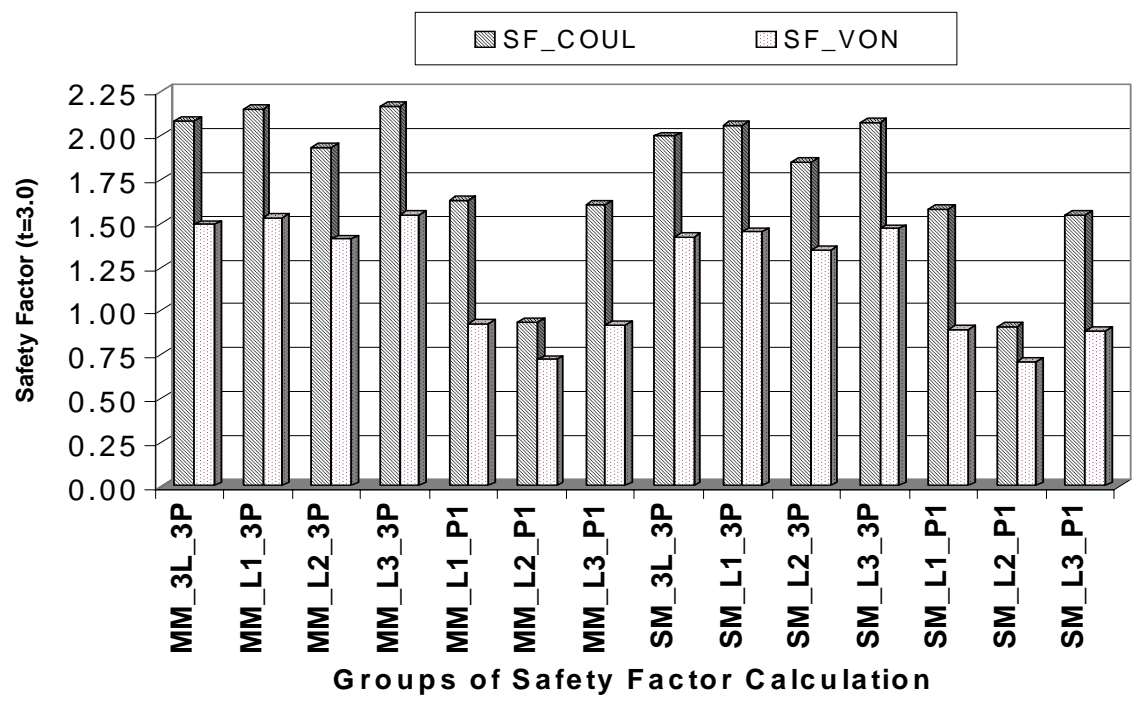

(b)

Figure 6.6 SF vs. Strength Reduction Factor 


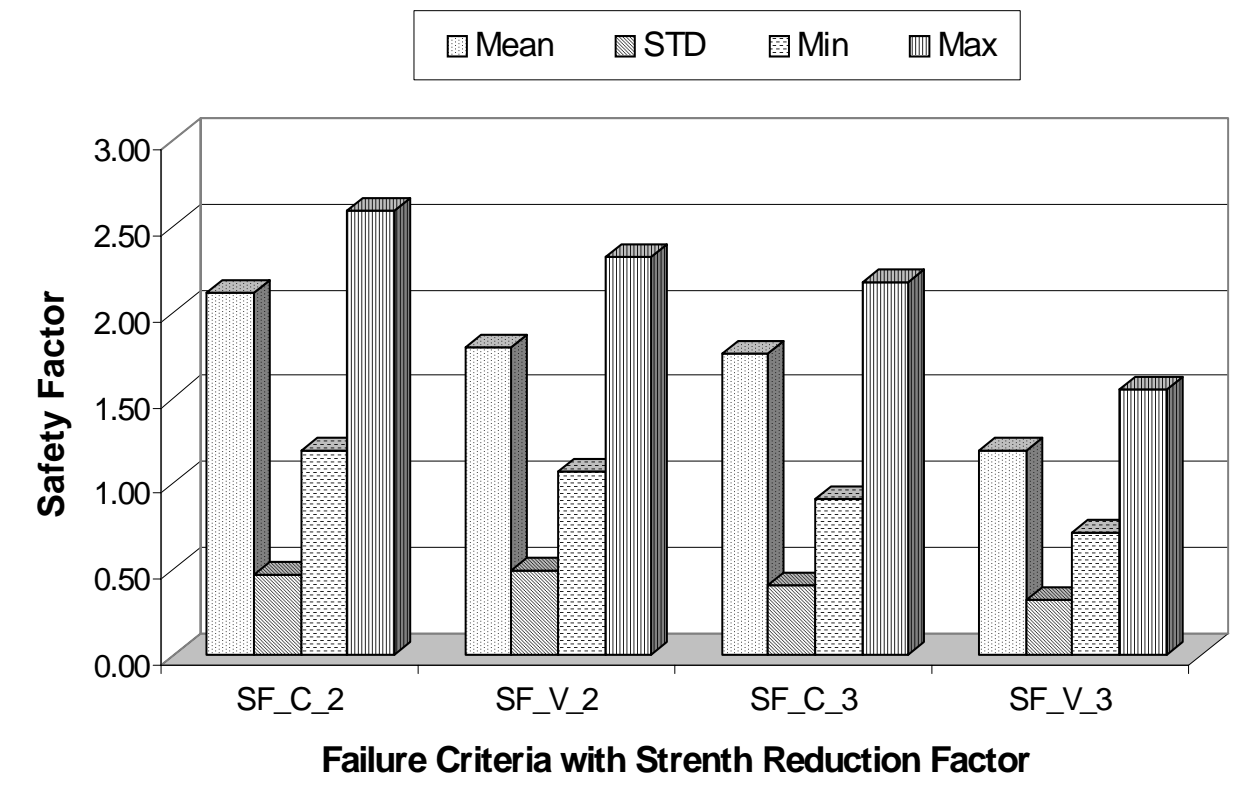

Figure 6.7 Summary Statistics on SF

Figure 6.8 shows the comparison of relationship between strength rduction (\%) and SF change when different failure criteria are used. As an example, Figure 6.9 illustrates the SF changes for two groups (i.e. MM_3L_3P and MM_2L_P1) using both failure criteria. It indicates that changes in SF is not only affected by failure criteria but also by strength reduction factor. 


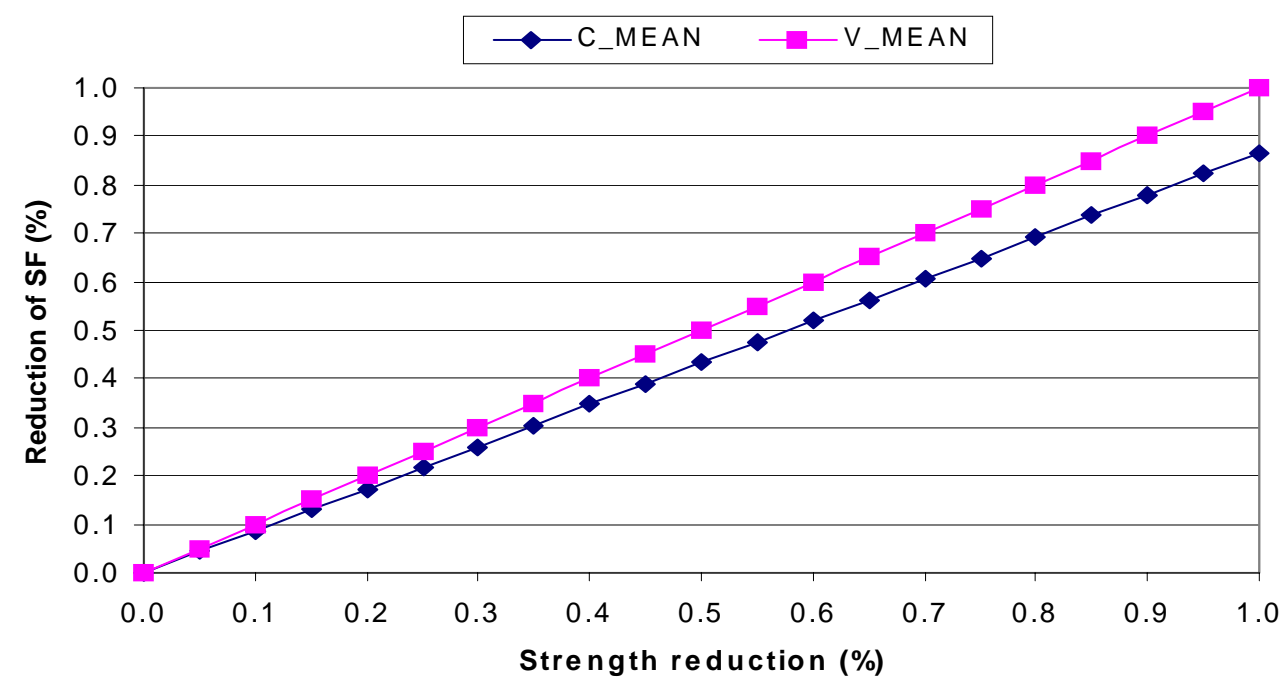

Figure 6.8 SF Reduction vs. Strength Reduction

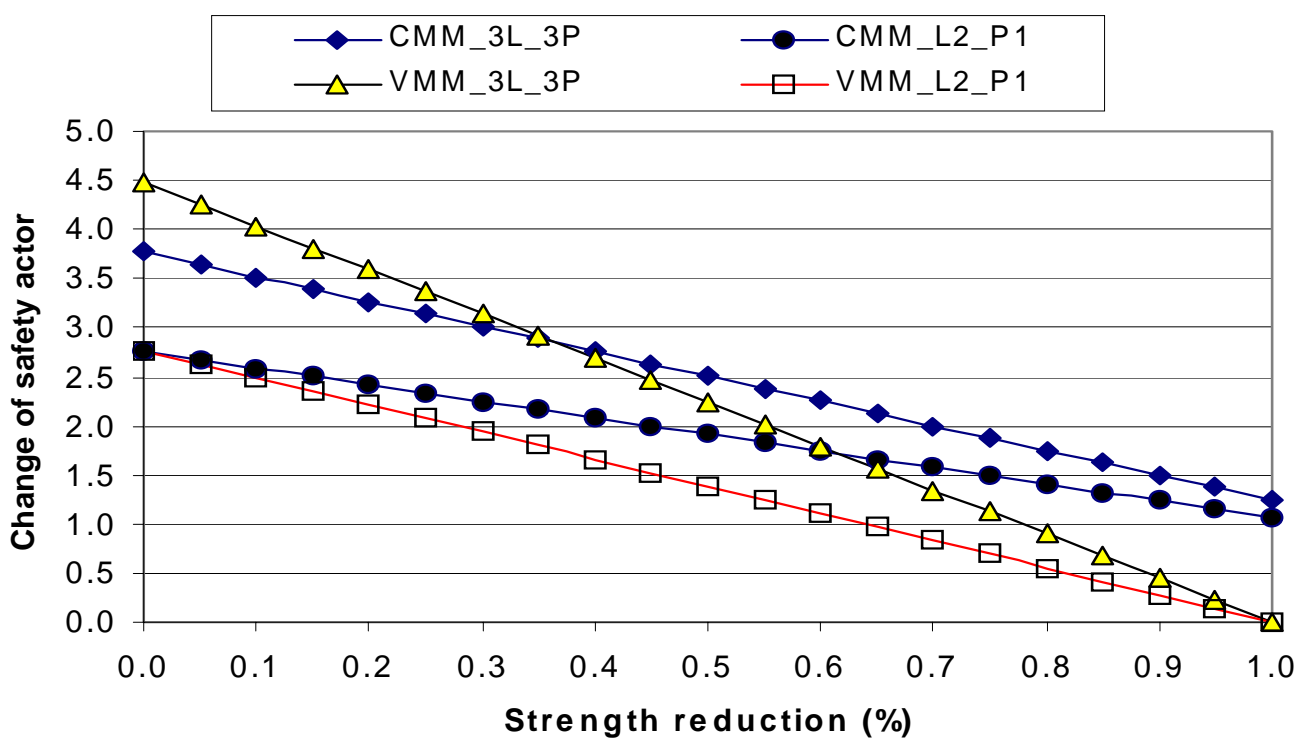

Figure 6.9 Strength Reduction Factor vs. Change in SF 


\subsubsection{PESM Based Assessment on Pillar Stability}

Although the stress variation in underground mine structures are significant shown in Section 6.2.2, the SF method can not consider those uncertainity in the design process for pillar stability. But using the PESM method, the variations of both strength and stress can be taken into consideration. The following example shows the procedure of using the PESM method. The step by step calculations for one group (i.e. MM_3L_3P) is described according to the general procedure described in Section 5.4.2 in the previous chapter. More detain calculation is attached in Appendix for this example. The same process can be applied for other groups or using other failure criteria.

Step 1 Set up the safety margin

$$
Y=S-F
$$

Step 2 Select the failure criterion

If the Coulomb failure criterion is selected in this case study, then pillar strength and stress are estimated as follows:

$$
\begin{gathered}
S=\sigma_{c}+q \sigma_{3} \\
F=\sigma_{1}
\end{gathered}
$$


Here $n$ is 3 and $m$ is 1 . Thus a total of 4 independent variables $(k=n+m=4)$ are included.

Step 3 Calculate the statistical parameters for each individual variable

Table 6.14 Calculated Statistics for Individual Variable of Pillar

\begin{tabular}{c|c|c|c|c}
\hline & $\boldsymbol{\sigma}_{\mathrm{c}}$ & $\boldsymbol{\alpha}$ & $\boldsymbol{\sigma}_{\mathbf{3}}$ & $\boldsymbol{\sigma}_{\mathbf{1}}$ \\
\hline & $(\mathbf{p s i})$ & (degree) & (psi) & (psi) \\
\hline $\mathrm{E}[\mathrm{X}]$ & 3210 & 30 & 527 & 1271 \\
\hline $\mathrm{D}[\mathrm{X}]$ & 850 & 3 & 115 & 303 \\
\hline $\mathrm{H}[\mathrm{X}]$ & 4060 & 33 & 642 & 1574 \\
\hline $\mathrm{L}[\mathrm{X}]$ & 2360 & 27 & 412 & 968 \\
\hline
\end{tabular}

Step 4 Estimate the coefficient of correlation and weighting Factor

It is assumed that there are no correlations among those four variables. Therefore, the weighting factor will be

$$
P=\frac{1}{2^{k}}=\frac{1}{16}
$$

Step 5 Calculated the statistical parameters for safety margin $\mathrm{Y}[\mathrm{x}]$

The following two tables are used to show the results from process of Step 5 for calculation each statistical parameter on the safety margin.. 
Table 6.15 Results from Step 5 Computation

\begin{tabular}{c|c|c|c|c|c}
\hline & $\mathbf{Y}$ & $\mathbf{P}$ & $\mathbf{Y x P}$ & $\mathbf{Y}^{2}$ & $\mathbf{Y}^{2} \mathbf{x}$ \\
\hline $\mathrm{Y}++++$ & 4663 & 0.0625 & 291 & $2.17 \times 10^{7}$ & $1.36 \times 10^{6}$ \\
\hline $\mathrm{Y}+++-$ & 5268 & 0.0625 & 330 & $2.77 \times 10^{7}$ & $1.73 \times 10^{6}$ \\
\hline $\mathrm{Y}++--$ & 4489 & 0.0625 & 281 & $2.01 \times 10^{7}$ & $1.26 \times 10^{6}$ \\
\hline $\mathrm{Y}+---$ & 4189 & 0.0625 & 262 & $1.75 \times 10^{7}$ & $1.09 \times 10^{6}$ \\
\hline $\mathrm{Y}+--+$ & 3582 & 0.0625 & 224 & $1.28 \times 10^{7}$ & $8.0 \times 10^{5}$ \\
\hline $\mathrm{Y}+-+-$ & 4799 & 0.0625 & 300 & $2.30 \times 10^{7}$ & $1.44 \times 10^{6}$ \\
\hline $\mathrm{Y}+-++$ & 4194 & 0.0625 & 262 & $1.76 \times 10^{7}$ & $1.10 \times 10^{6}$ \\
\hline $\mathrm{Y}++-+$ & 3883 & 0.0625 & 424 & $1.51 \times 10^{7}$ & $0.94 \times 10^{6}$ \\
\hline $\mathrm{Y}----$ & 2789 & 0.0625 & 174 & $7.77 \times 10^{6}$ & $4.86 \times 10^{5}$ \\
\hline $\mathrm{Y}---+$ & 1882 & 0.0625 & 118 & $3.54 \times 10^{6}$ & $2.21 \times 10^{5}$ \\
\hline $\mathrm{Y}--++$ & 2494 & 0.0625 & 156 & $6.22 \times 10^{6}$ & $3.89 \times 10^{5}$ \\
\hline $\mathrm{Y}-+++$ & 2963 & 0.0625 & 185 & $8.78 \times 10^{6}$ & $5.49 \times 10^{5}$ \\
\hline $\mathrm{Y}-++-$ & 3954 & 0.0625 & 247 & $1.56 \times 10^{7}$ & $0.98 \times 10^{6}$ \\
\hline $\mathrm{Y}-+-+$ & 2183 & 0.0625 & 136 & $4.76 \times 10^{6}$ & $2.98 \times 10^{5}$ \\
\hline $\mathrm{Y}-+--$ & 2789 & 0.0625 & 174 & $7.79 \times 10^{6}$ & $4.87 \times 10^{5}$ \\
\hline $\mathrm{Y}--+-$ & 3100 & 0.0625 & 194 & $9.61 \times 10^{6}$ & $6.01 \times 10^{5}$ \\
\hline & & & &
\end{tabular}

Table 6.16 Statistical Parameters of Safety Margin

\begin{tabular}{c}
\hline$E[Y]=3564$ \\
\hline$E\left[Y^{\wedge} 2\right]=1.37 \times 10^{7}$ \\
\hline$V[Y]=1.0 \times 10^{6}$ \\
\hline$D[Y]=1000$ \\
\hline
\end{tabular}


Step 6 Calculation of reliability index

$$
\kappa=\frac{3564}{1000}=3.564
$$

Step 7 Calculation of reliability

$$
R=1-R_{f}=1-\left[\frac{1}{2}-\varphi(3.564)\right]=99.98 \%
$$

Step 8 Making decision

If the $97 \%$ is the target reliability for the pillar, the conclusion is that this pillar will be stable base on the PESM method.

The results of the reliability for all 14 groups using both the Coulomb and Von Misses failure criteria are summarized in Table 6.17. Figure 6.10 shows the comparison of reliability using different criteria for all groups. It indicates that the difference in reliability is vary small either from crossover of all groups when the same failure criterion is used or for the same group using different failure criteria.

Figure 6.11 show the summary statistics of reliability using different failure criteria. The mean, minimum and maximum reliability are very close for all groups under both failure criteria. However, the pillar central ribs (i.e. MM_L2_P1 and SM_L2_P1) have a relatively lower reliability. 


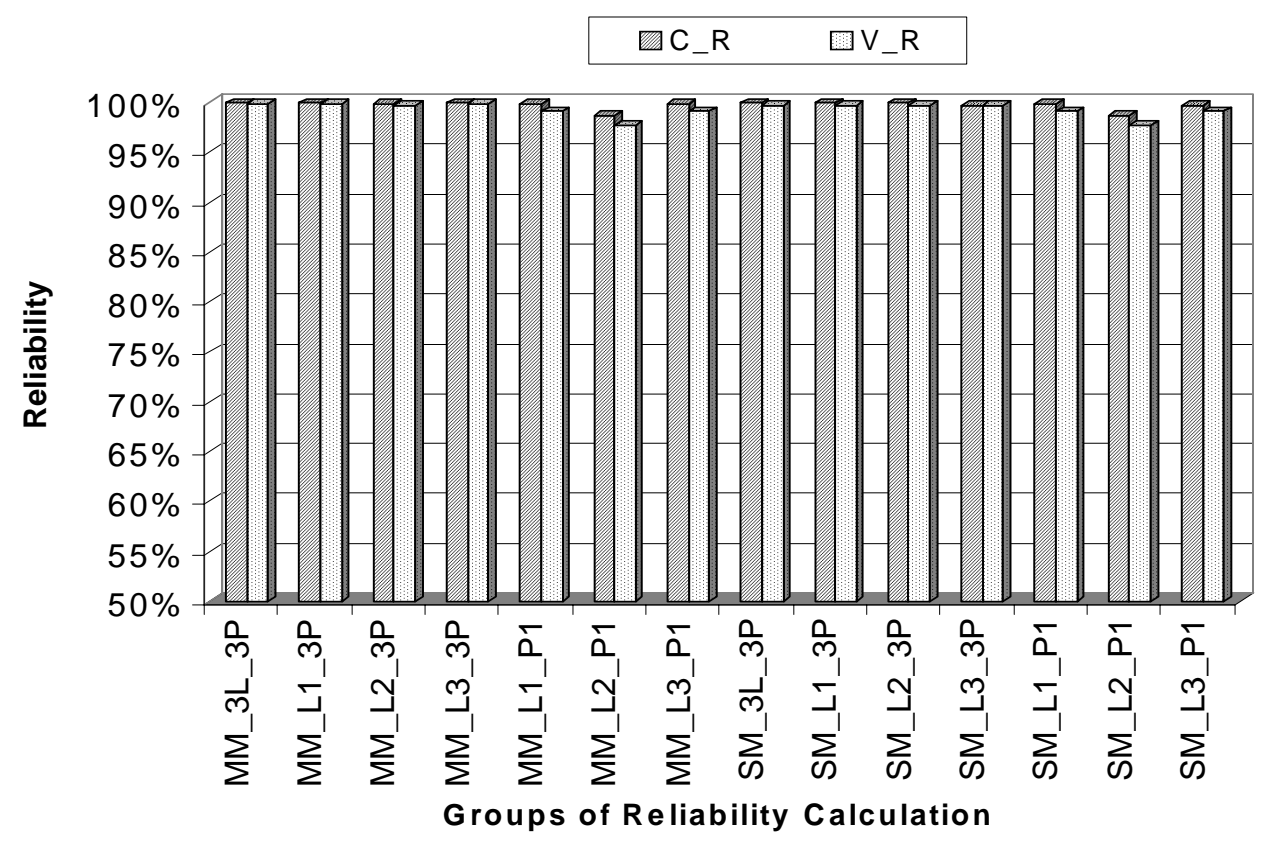

Figure 6.10 Reliability for All Groups

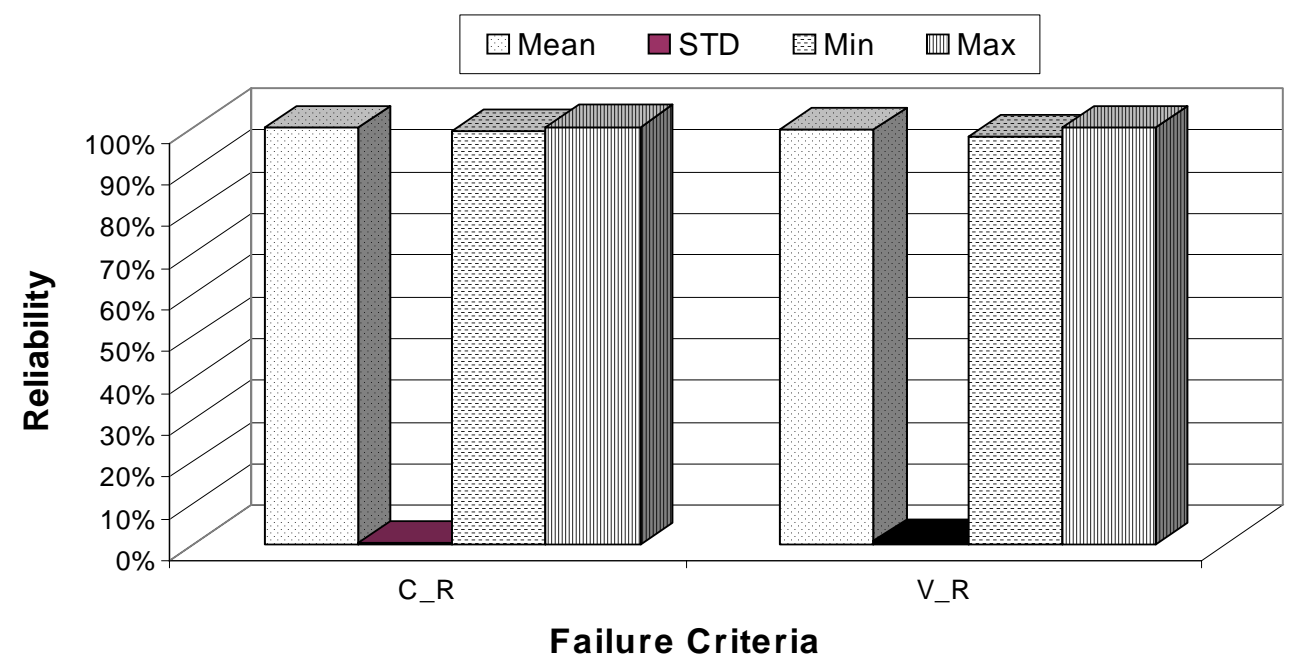

Figure 6.11 Summary Statistics on Reliability 


\subsubsection{Comparison of Longwall Pillar Stability}

This study shows that the SF calculation may vary significantly once different failure criteria are used even for the same group as shown in Table 6.17. Although it is difficult to select a proper value, the strength reduction factor which has much more effect on SF determination although it is difficult to be selected. Under the using same failure criterion, SF has a larger change from location to location. The relationship between strength reduction factor (\%) and SF change (\%) is not the same if different failure criteria are used. $\mathrm{SRF}(\%)$ has more effects on SF when the Von Misses failure criterion is used than when the Coulomb failure criterion is used. The numerical number of SF does not reflect the degree of stability but gives a cutoff line for stable $(\mathrm{SF}>1)$ or failure $(\mathrm{SF}<1)$ condition. The subject will be in neutral condition (or half chance in failure and half chance in stable) if SF is 1. Variations from all parameters involved in the SF calculation can not considered in the process of SF assessment although they are significant. SF itself is, therefore, an uncertain result. It has more risk to judge the structure stability by using SF only.

The PESM method is a reliability-based new approach for assessment of structure stability. It involves some statistical knowledge to deal with the variations of structure strength and stress. The uncertainties of multiple independent variables can be handled without knowing their distributions. The results from this study show that there are relatively 
small change in reliability for the same group using different failure criteria. Under the same failure criterion, the reliability from location to location has a slight change but the difference is the smaller even between the minimum and maximum values as shown in Table 6.18. The reliability is in general lower using Von Misses than that using the Coulomb failure criteria for same group. The reliability does give a degree of structure stability. For example, if the structure has $99.0 \%$ of reliability, there is only $1 \%$ probability of failure. If $99.0 \%$ reliability is assumed as the target reliability to evaluate all groups, only the central ribs (i.e. MM_L2_P1 or SM_L2_P1) will be unstable. Those spots will initiate failure first if the pillar will fail. The chances of those spots being failed are less than $1.3 \%$ and $2.3 \%$, respectively according to the Coulomb and Von Misses failure criteria. 
Table 6.17 Results of SF and Reliability

\begin{tabular}{c|c|c|c|c|c|c}
\hline \multirow{2}{*}{ Group } & \multicolumn{2}{|c|}{ Reliability } & \multicolumn{2}{c}{ SF (t=2) } & \multicolumn{2}{c}{ SF (t=3) } \\
\cline { 2 - 7 } Classification & C & V & C & V & C & V \\
\cline { 2 - 7 } MM_3L_3P & 0.999 & 0.998 & 2.51 & 2.24 & 2.09 & 1.49 \\
\hline MM_L1_3P & 0.999 & 0.998 & 2.57 & 2.30 & 2.15 & 1.53 \\
\hline MM_L2_3P & 0.998 & 0.996 & 2.36 & 2.11 & 1.94 & 1.41 \\
\hline MM_L3_3P & 0.999 & 0.998 & 2.59 & 2.33 & 2.17 & 1.55 \\
\hline MM_L1_P1 & 0.998 & 0.991 & 1.91 & 1.39 & 1.63 & 0.92 \\
\hline MM_L2_P1 & 0.987 & 0.977 & 1.22 & 1.08 & 0.94 & 0.72 \\
\hline MM_L3_P1 & 0.998 & 0.991 & 1.89 & 1.38 & 1.61 & 0.92 \\
\hline SM_3L_3P & 0.999 & 0.997 & 2.42 & 2.13 & 2.00 & 1.42 \\
\hline SM_L1_3P & 0.999 & 0.997 & 2.49 & 2.18 & 2.06 & 1.45 \\
\hline SM_L2_3P & 0.999 & 0.996 & 2.27 & 2.02 & 1.85 & 1.35 \\
\hline SM_L3_3P & 0.996 & 0.997 & 2.50 & 2.20 & 2.08 & 1.47 \\
\hline SM_L1_P1 & 0.998 & 0.991 & 1.86 & 1.34 & 1.58 & 0.89 \\
\hline SM_L2_P1 & 0.987 & 0.977 & 1.20 & 1.07 & 0.91 & 0.71 \\
\hline SM_L3_P1 & 0.997 & 0.991 & 1.83 & 1.33 & 1.55 & 0.89 \\
\hline
\end{tabular}


Table 6.18 Statistical summary of SF and Reliability

\begin{tabular}{c|c|c|c|c|c|c}
\hline \multirow{2}{*}{$\begin{array}{c}\text { Statistical } \\
\text { summary }\end{array}$} & \multicolumn{2}{|c|}{ Reliability } & \multicolumn{4}{c}{ Safety factor } \\
\cline { 3 - 7 } & $\mathrm{C}$ & $\mathrm{V}$ & $\mathrm{C}$ & $\mathrm{V}$ & $\mathrm{C}$ & $\mathrm{V}$ \\
\cline { 2 - 7 } & 0.997 & 0.993 & 2.12 & 1.79 & 1.75 & 1.20 \\
\hline Mean & 0.004 & 0.007 & 0.48 & 0.49 & 0.41 & 0.33 \\
\hline STD & 0.987 & 0.977 & 1.20 & 1.07 & 0.91 & 0.71 \\
\hline Min & 0.999 & 0.998 & 2.59 & 2.33 & 2.17 & 1.55 \\
\hline
\end{tabular}

\subsection{Discussion}

Both SF and PESM method are used throughout the procedure of stability evaluations for two case studies in this research. Both methods are intended to answer the following key questions: (1) is this entry stable ? and if so, (2) how stable is the entry? It clearly shows that both methods have their advantages and disadvantages in the process of mine entry stability in terms of parameter input, stability computation and results interpretations.

The conventional SF can only take the mean value of the coal/rock properties for strength and/or stress estimation even if such variations are known to be very large in most cases. Consequently, it may be difficult to answer questions like: (1) how do the variations 
of coal/rock propertie affect the results computed ? (2) what percentages of the coal/rock strength should be reduced to cover the uncertainty effects ? (3) do the computed results change if the input variables are related or unrelated? (4) which number of SFs should be selected as the critical one ? and (5) which component is in the worse condition ? Conversely, by using the PESM method, the reliability computation, and the variations of coal/rock properties, such as mean, standard deviation and coefficient of variation, can be taken into account during input stages for both strength and stress estimation. No strength reduction factor is required. Hence, by using the reliability approach, there will be less uncertainty regarding the effects on coal/rock properties variation so that the estimated strength and stress for each component of mine entry (i.e., roof, pillar and floor) are more reliable.

The conventional SF method is relatively easy on the stability computation than that of the reliability procedure and no statistical knowledge is required. However, the proposed reliability approach, which uses the safety margin and point estimates methods for reliability determination and parameter estimations, is not only a very easy reliability approach tool, but also has a unique solution no matter how sophisticated the function of random variables are involved. 


\section{CHAPTER 7}

\section{CONCLUSIONS AND RECOMMENDATIONS}

\subsection{Conclusions}

Conventionally, stability design and evaluation on mine entry emphasize both safety and economics. In this respect, a more appropriate design of mine entry is important in reducing cost and efficient use of the resources. One way to satisfy this requirement is to establish a standard criterion for stability assessment of underground mine entry. But this can only be achieved if the uncertainties of material strength and stress can be taken into consideration. Even though the conventional safety factor methods using deterministic analysis can not consider the variability from the nature of rock/coal strength and stress, it has a long standing history and is still the dominant method for the current design and evaluation process in mining practice. Therefore, considerable efforts not only on technique but also on application aspects are required in order to improve, update and eventually replace the existing methods.

This research has initiated a systematic study on stability design and evaluation of mine entry by using reliability approach. The most commonly used conventional methods on mine entry design are summarized. It has shown that (a) the safety factor is the final criterion for assessment of mine entry stability, and it has and still dominates the decision - 
making on mine entry stability despite the fact that several approaches are available; (b) the parameters of coal/rock properties are always involved in all the expressions of SF calculation due to their contribution to strength and stress estimations; and (c) none of the conventional methods can take the strength and stress variation into the assessment process of mine entry stability. In order to identify the disadvantages of using safety factor as a failure criterion, the variability analysis on coal/rock properties are conducted. Because of its inherent and systematic natures, variability of coal/rock physical properties is the rule, not an exception. It changes from site to site with considerable magnitude and disparity. Therefore, one should consider variability of stress and strength in stability design and evaluation of underground mine entry.

Based on the uncertainty analysis in this research, the results have clearly shown that effects of uncertainty in the strength and stress on safety factor are appreciable. They indicate that the conventional safety factor method is only a special case of the more general probabilistic method because it assumes the variability of strength and stress is zero. The results also suggest that the value of safety factor may have less or no meaning in interpreting mine entry stability if no statistical information on strength and stress are incorporated. In other words, there is no one-to-one relationship between a SF and stability of mine entry.

In order to develop a reasonable approach for the design and evaluation of mine entry stability, which can take the uncertainty of rock/coal strength into account, the reliability method is an alternative even though but it is new for mining structure design. In terms of 
practicality, the different methodologies associated with reliability measurement and parameter estimate methods are introduced and evaluated. Then the safety margin (or reliability index) and point estimates are incorporated to form a new design and evaluation approach, called PESM. It stems from an engineering base and is also easy to apply to real problem solving. The critical benefit of using the new method is that no distributions of strength/stress are required. A less simple size may also be enough to obtain the accurate solution. Also, no simulation is involved and the computation process is much simpler than other methods of reliability measurement although uncertainty is involved. These advantages will allow and expand PESM application, especially for underground mines where distributions of strength/stress are usually uncertain not and observations (or simple sizes) are also limited.

The results from the two cases studies show that the conventional safety factor method has a relative simpler process in stability computation than that of the reliability method. However, it has recognized that the conventional SF method has no scientific way to take variability of coal/rock strength and stress into account. The final decision making on the mine entry by using safety factor is questionable. On the contrary, the reliability method is able to take care of the uncertainty of coal/rock properties no mater how complicated calculations between coal/rock properties and the strength and stress. The final assessment using reliability is more logical and suggests a certain confidence for the design object. By using PESM, it shows thehigher the uncertainty, the lower the mine entry stability. 
In retrospect, this research is a fundamental study based on solid scientific foundation and focuses on stability of mine entry design and evaluation with reliability concept. The results show significant impact on current academic research, mining operators and government regulators associated with ground control on underground mines. The mine entry design and evaluation with the reliability approach is a more realistic approach by taking variability and safety confidence into great consideration. The study shows that the risk assessed with the reliability method can be used as a valuable supplement and/or complement to the existing deterministic procedures so that an overly conservative consideration and unknown degree of confidence can be greatly reduced. It is anticipated that, by using the reliability approach, the stability assessment for current techniques of mine entry design will be elevated to a higher level of confidence.

\subsection{Recommendations}

To better facilitate the assessment of the reliability of the mine entry stability analysis, it is recommended that the probabilistic analysis should be utilized as a supplement and/or complement to the current deterministic approach. It is a better tool to alleviate the engineer's decision making process.

$\square \quad$ To develop a general reliability method and to make it applicable on underground mining environment, the incorporation of the safety margin (or reliability index) and point estimate methods is recommended as a tool to perform reliability measurement 
and parameter estimation, respectively.

$\square \quad$ Further research should also be performed to understand correlations among parameters of coal/rock physical properties. It will benefit design accuracy not only for the reliability method but also for the conventional method by reducing redundancy.

$\square \quad$ The target reliability of mining entry is needed to be established by modifying the proposed model with analysis of a collocated data set of mining entry failure if it is available.

$\square \quad$ The mine entry as a whole system is a fact in reality. The stability design and evaluation for mine entry system, therefore, are needed in the future after the reliability of the components of the mine entry system (i.e., roof, pillar and floor) are established.

$\square \quad$ The conclusion drawn from this research is based on a limited study. It is recommended that further research is needed in order to establish a better understanding of this subject. 


\section{APPENDIX}

\section{Reliability Computation of the Roof in Case 1}

For this case study, the stresses applied on the roof are assumed as the constants. The variability only from the coal properties are taken into consideration. The eight steps developed from Chapter 5 are followed in detain as below:

\section{Step 1 Set up safety equation}

Based on Eq. 5.29, then the safety margin for the roof is

$$
M=R-F
$$

where $\mathrm{M}$ is the safety margin of the roof; $\mathrm{R}$ and $\mathrm{F}$ are the nominal strength and stress of the roof, respectively.

\section{Step 2 Select failure criterion}

Assuming the Coulomb failure criterion is selected for this case. Therefore, the nominal strength and stress are estimated as below, respectively.

$$
\begin{gathered}
R=R_{r s}+\left(\frac{1+\sin \beta}{1-\sin \beta}\right) \sigma_{r \min } \\
F=\sigma_{\text {rmax }}
\end{gathered}
$$


Thus, the safety margin of the roof becomes

$$
M=\left(R_{r s}+\frac{1+\sin \beta}{1-\sin \beta} \sigma_{r \min }\right)-\sigma_{r \max }
$$

\section{Step 3 Calculate the statistical parameters for each independent variable}

If any independent variable in the equation of the safety margin is random, then

the statistics for those independent variables should be calculated. Only two independent random variables, and for this case. The statistics calculation for those two variable will be:

a. For the roof strength, $\mathrm{R}_{\mathrm{rs}}$

$$
\begin{gathered}
E\left[R_{r s}\right]=\frac{\sum R_{r s_{i}}}{N}=4500 \\
D\left[R_{r s}\right]=\sqrt{\frac{\sum R_{r s_{i}}-E\left[R_{r s_{k}}\right]^{2}}{N-1}}=1500 \\
H\left[R_{r s}\right]=E\left[R_{r s}\right]+D\left[R_{r s}\right]=6000 \\
L\left[R_{r s}\right]=E\left[R_{r s}\right]-D\left[R_{r s}\right]=3000
\end{gathered}
$$

b. For the internal frictional angle of roof, $\beta$ 


$$
\begin{gathered}
E[\beta]=\frac{\sum \beta_{i}}{N}=30 \\
D[\beta]=\sqrt{\frac{\sum \beta_{i}-E\left[\beta_{k}\right]^{2}}{N-1}}=3
\end{gathered}
$$

$$
H[\beta]=E[\beta]+D[\beta]=33
$$

$$
L[\beta]=E[\beta]-D[\beta]=27
$$

\section{Step 4 Estimate the coefficient of correlation $\left(\rho_{\mathrm{mn}}\right)$ between each pair of random}

\section{independent variable}

The coefficient of the correlation between each pair of the independent random variables need to be estimated according Eq 5.32. It is assumed as 0.5. Then, the weighting wight factor $\mathrm{P}_{\mathrm{ij}}$ can be calculated as

$$
\begin{aligned}
& P_{++}=P_{--}=\frac{1}{4} x(1+\rho)=0.375 \\
& P_{+-}=P_{-+}=\frac{1}{4} x(1-\rho)=0.125
\end{aligned}
$$




\section{Step 5 Calculate the statistical parameters of safety margin}

According to Eqs. 5.34 to 5.37, the mean(E[M]), standard deviation $\mathrm{D}([\mathrm{M}])$ and variance $\operatorname{Var}[\mathrm{M}]$ for the safety margin $(\mathrm{M})$ of the roof. They are:

$$
\begin{aligned}
& M_{++}=H\left(R_{r s}\right)+\frac{1+\sin H(\beta)}{1-\sin H(\beta)} \sigma_{r \min }-\sigma_{r \max }=6000+\frac{1+\sin (33)}{1-\sin (33)} x 150-1050=5459 \\
& M_{+-}=H\left(R_{r s}\right)+\frac{1+\sin L(\beta)}{1-\sin L(\beta)} \sigma_{r \min }-\sigma_{r \max }=6000+\frac{1+\sin (27)}{1-\sin (27)} x 150-1050=5349 \\
& M_{-+}=L\left(R_{r s}\right)+\frac{1+\sin H(\beta)}{1-\sin H(\beta)} \sigma_{r \min }-\sigma_{r \max }=3000+\frac{1+\sin (33)}{1-\sin (33)} \times 150-1050=2458 \\
& M_{--}=L\left(R_{r s}\right)+\frac{1+\sin L(\beta)}{1-\sin L(\beta)} \sigma_{r \min }-\sigma_{r \max }=3000+\frac{1+\sin (27)}{1-\sin (27)} x 150-1050=2349
\end{aligned}
$$

Therefore, we have

$$
\begin{gathered}
E[M]=\sum M_{i j} P_{i j}=0.375 x(5459+2349)+0.125 x(5349+2458)=3904 \\
E\left[M^{2}\right]=\sum M_{i j}^{2} P_{i j}=0.375 x\left(5459^{2}+2349^{2}\right)+0.125 x\left(5349^{2}+2458^{2}\right)=1.75 \times 10^{7} \\
\operatorname{Var}[M]=E\left[M^{2}\right]-(E[M])^{2}=1.75 x 10^{7}-3904^{2}=2.3 \times 10^{6} \\
\sigma[M]=\sqrt{V[M]}=\sqrt{2.3 \times 10^{6}}=1517
\end{gathered}
$$


Step 6 Calculate the Reliability Index

$$
\kappa=\frac{E[M]}{E\left[\sigma_{M}\right]}=\frac{3904}{1517}=2.573
$$

Step 7 Calculate the Reliability of Structure

$$
\begin{gathered}
P_{f}=\frac{1}{2}-\Phi(6.6)=0.5-0.4949=0.0051 \\
P=1-0.0051=99.49 \%
\end{gathered}
$$

\section{Step 8 Make Decision by Comparing the Target Reliability}

Assuming the target reliability for the roof is $97 \%$, the result indicates that the roof

is above stable condition since the calculated reliability of the roof is much higher than the target reliability. 


\section{Reliability Computation of the Pillar in Case 2}

For this case study, all independent random variables in the safety margin equation are assumed as random variables. Therefore, the variation from both strength and stress are taken into the process of the reliability computation. There are 14 groups classified in the Chapter 6.2.2. The reliability computation demonstrated here is only for one group (i.e. MM_3L_3P). Again, the eight steps developed from Chapter 5 are followed in detain as below:

\section{Step 1 Set up safety equation}

Based on Eq. 5.29, then the safety margin for the pillar is

$$
Y=R-F
$$

where $\mathrm{Y}$ is the safety margin of the pillar; $\mathrm{R}$ and $\mathrm{F}$ are the nominal strength and stress of the pillar, respectively.

\section{Step 2 Select failure criterion}

Assuming the Coulomb failure criterion is selected for this case. Therefore, the nominal strength and stress are estimated as below, respectively.

$$
\begin{gathered}
R=R_{r s}+\left(\frac{1+\sin \beta}{1-\sin \beta}\right) \sigma_{r \min } \\
F=\sigma_{\text {rmax }}
\end{gathered}
$$


Thus, the safety margin of the roof becomes

$$
M=\left(R_{r s}+\frac{1+\sin \beta}{1-\sin \beta} \sigma_{r \min }\right)-\sigma_{r \max }
$$

\section{Step 3 Calculate the statistical parameters for each independent variable}

There are four independent random variable in the equation of the safety margin.

The statistics calculation for those four variable will be:

a. For the coal strength, $\sigma_{\mathrm{c}}$

$$
\begin{gathered}
E\left[\sigma_{c}\right]=\frac{\sum \sigma_{c_{i}}}{N}=3210 \\
D\left[\sigma_{c}\right]=\sqrt{\frac{\sum{\sigma_{c_{i}}}-E\left[\sigma_{c_{k}}\right]^{2}}{N-1}}=850 \\
H\left[\sigma_{c}\right]=E\left[\sigma_{c}\right]+D\left[\sigma_{c}\right]=4060 \\
L\left[\sigma_{c}\right]=E\left[\sigma_{c}\right]-D\left[\sigma_{c}\right]=2360
\end{gathered}
$$

b. For the internal frictional angle of coal, $\beta$

$$
E[\beta]=\frac{\sum \beta_{i}}{N}=30
$$




$$
D[\beta]=\sqrt{\frac{\sum \beta_{i}-E\left[\beta_{k}\right]^{2}}{N-1}}=3
$$

$H[\beta]=E[\beta]+D[\beta]=33$

(A36)

$$
L[\beta]=E[\beta]-D[\beta]=27
$$

c. For maximum principal stress, $\sigma_{1}$

$$
\begin{gathered}
E\left[\sigma_{1}\right]=\frac{\sum \sigma_{1_{i}}}{N}=1271 \\
D\left[\sigma_{1}\right]=\sqrt{\frac{\sum \sigma_{1_{i}}-E\left[\sigma_{1_{k}}\right]^{2}}{N-1}}=303 \\
H\left[\sigma_{1}\right]=E\left[\sigma_{c}\right]+D\left[\sigma_{1}\right]=1574 \\
L\left[\sigma_{1}\right]=E\left[\sigma_{c}\right]-D\left[\sigma_{1}\right]=968
\end{gathered}
$$

d. For minimum principal stress, $\sigma_{3}$ 


$$
\begin{gathered}
E\left[\sigma_{3}\right]=\frac{\sum \sigma_{3_{i}}}{N}=527 \\
D\left[\sigma_{3}\right]=\sqrt{\frac{\sum \sigma_{3_{i}}-E\left[\sigma_{3_{k}}\right]^{2}}{N-1}}=115 \\
H\left[\sigma_{3}\right]=E\left[\sigma_{3}\right]+D\left[\sigma_{3}\right]=642 \\
L\left[\sigma_{3}\right]=E\left[\sigma_{3}\right]-D\left[\sigma_{3}\right]=412
\end{gathered}
$$

Step 4 Estimate the coefficient of correlation $\left(\rho_{\mathrm{mn}}\right)$ between each pair of random independent variable

It is assumed that there is no correlations among those four variables. Then, the weighting factor $P_{\text {imnj }}$ can be calculated as

$$
P_{ \pm \pm+ \pm}=\frac{1}{2^{k}}=\frac{1}{2^{4}}=\frac{1}{16}
$$

\section{Step 5 Calculate the statistical parameters of safety margin}

According to Eqs. 5.34 to 5.37, the mean(E[Y]), standard deviation $\mathrm{D}([\mathrm{Y}])$ and variance $\operatorname{Var}[\mathrm{Y}]]$ for the safety margin $(\mathrm{Y})$ of the pillar are: 


$$
\begin{gathered}
M_{++++}=H\left(\sigma_{c}\right)+\frac{1+\sin H(\beta)}{1-\sin H(\beta)} x H\left(\sigma_{3}\right)-H\left(\sigma_{1}\right)=4060+\frac{1+\sin (33)}{1-\sin (33)} x 642-1574=4663 \\
M_{+++-}=H\left(\sigma_{c}\right)+\frac{1+\sin H(\beta)}{1-\sin H(\beta)} x H\left(\sigma_{3}\right)-L\left(\sigma_{1}\right)=4060+\frac{1+\sin (33)}{1-\sin (33)} x 642-968=5268 \\
M_{++--}=H\left(\sigma_{c}\right)+\frac{1+\sin H(\beta)}{1-\sin H(\beta)} x L\left(\sigma_{3}\right)-L\left(\sigma_{1}\right)=4060+\frac{1+\sin (33)}{1-\sin (33)} x 412-968=4489 \\
M_{+---}=H\left(\sigma_{c}\right)+\frac{1+\sin L(\beta)}{1-\sin L(\beta)} x L\left(\sigma_{3}\right)-L\left(\sigma_{1}\right)=4060+\frac{1+\sin (27)}{1-\sin (27)} x 412-968=4189
\end{gathered}
$$

$M_{+--+}=H\left(\sigma_{c}\right)+\frac{1+\sin L(\beta)}{1-\sin L(\beta)} x L\left(\sigma_{3}\right)-H\left(\sigma_{1}\right)=4060+\frac{1+\sin (27)}{1-\sin (27)} \times 412-1574=3582$

$$
M_{+-+-}=H\left(\sigma_{c}\right)+\frac{1+\sin L(\beta)}{1-\sin L(\beta)} x H\left(\sigma_{3}\right)-L\left(\sigma_{1}\right)=4060+\frac{1+\sin (27)}{1-\sin (27)} x 642-968=4799
$$

$M_{+-++}=H\left(\sigma_{c}\right)+\frac{1+\sin L(\beta)}{1-\sin L(\beta)} \times H\left(\sigma_{3}\right)-H\left(\sigma_{1}\right)=4060+\frac{1+\sin (27)}{1-\sin (27)} \times 642-1574=4194$

$M_{++-+}=H\left(\sigma_{c}\right)+\frac{1+\sin H(\beta)}{1-\sin H(\beta)} \times L\left(\sigma_{3}\right)-H\left(\sigma_{1}\right)=4060+\frac{1+\sin (33)}{1-\sin (33)} \times 412-1574=3883$

$M_{---}=L\left(\sigma_{c}\right)+\frac{1+\sin L(\beta)}{1-\sin L(\beta)} x L\left(\sigma_{3}\right)-L\left(\sigma_{1}\right)=2360+\frac{1+\sin (27)}{1-\sin (27)} x 412-968=2789$

$$
M_{--+}=L\left(\sigma_{c}\right)+\frac{1+\sin L(\beta)}{1-\sin L(\beta)} \times L\left(\sigma_{3}\right)-L\left(\sigma_{1}\right)=2360+\frac{1+\sin (27)}{1-\sin (27)} \times 412-1574=1882
$$




$$
\begin{aligned}
& M_{--++}=L\left(\sigma_{c}\right)+\frac{1+\sin L(\beta)}{1-\sin L(\beta)} x H\left(\sigma_{3}\right)-H\left(\sigma_{1}\right)=2360+\frac{1+\sin (27)}{1-\sin (27)} x 642-1574=2494 \\
& M_{-+++}=L\left(\sigma_{c}\right)+\frac{1+\sin H(\beta)}{1-\sin H(\beta)} x H\left(\sigma_{3}\right)-H\left(\sigma_{1}\right)=2360+\frac{1+\sin (33)}{1-\sin (33)} \times 642-1574=2963 \\
& M_{-++-}=L\left(\sigma_{c}\right)+\frac{1+\sin H(\beta)}{1-\sin H(\beta)} x H\left(\sigma_{3}\right)-L\left(\sigma_{1}\right)=2360+\frac{1+\sin (33}{1-\sin (33)} \times 642-968=3954 \\
& M_{-+-+}=L\left(\sigma_{c}\right)+\frac{1+\sin H(\beta)}{1-\sin H(\beta)} x L\left(\sigma_{3}\right)-H\left(\sigma_{1}\right)=2360+\frac{1+\sin (33}{1-\sin (33)} \times 412-1574=2183 \\
& M_{-+--}=L\left(\sigma_{c}\right)+\frac{1+\sin H(\beta)}{1-\sin H(\beta)} x L\left(\sigma_{3}\right)-L\left(\sigma_{1}\right)=2360+\frac{1+\sin (33}{1-\sin (33)} \times 412-968=2789 \\
& M_{--+-}=L\left(\sigma_{c}\right)+\frac{1+\sin L(\beta)}{1-\sin H(\beta)} x H\left(\sigma_{3}\right)-L\left(\sigma_{1}\right)=2360+\frac{1+\sin (27}{1-\sin (27)} x 642-968=3100
\end{aligned}
$$

Therefore, we have

$$
\begin{gathered}
E[M]=\sum M_{i j} P_{i j}=0.0625 x(4663+52681+4489+4189+3582+4799+4194 \\
+3883+2789+1882+2494+2963+3954+2183+2789+3100)=3564 \\
E\left[M^{2}\right]=\sum M_{i j}^{2} P_{i j}=0.0625 x\left(4663^{2}+52681^{2}+4489^{2}+4189^{2}+3582^{2}+4799^{2}+4194^{2}\right. \\
\left.+3883^{2}+2789^{2}+1882^{2}+2494^{2}+2963^{2}+3954^{2}+2183^{2}+2789^{2}+3100^{2}\right)=1.37 x 10^{7} \\
\operatorname{Var}[M]=E\left[M^{2}\right]-(E[M])^{2}=1.37 \times 10^{7}-3564^{2}=1.0 \times 10^{6} \\
\sigma[M]=\sqrt{V[M]}=\sqrt{1.0 x 10^{6}}=1000
\end{gathered}
$$


Step 6 Calculate the Reliability Index

$$
\kappa=\frac{E[M]}{E\left[\sigma_{M}\right]}=\frac{3564}{1000}=3.564
$$

Step 7 Calculate the Reliability of Structure

$$
\begin{gathered}
P_{f}=\frac{1}{2}-\Phi(3.564)=0.5-0.499815=0.000185 \\
P=1-0.000815=99.98 \%
\end{gathered}
$$

Step 8 Make Decision by Comparing the Target Reliability

Assuming the target reliability for the roof is $97 \%$, the result indicates that the pillar is above stable condition since the calculated reliability of the roof is much higher than the target reliability. 


\section{REFERENCE}

Adler, L. and Sun, M. C, 1976, "Ground Control in Bedded Formation,"Virginia Polytechnic Institute and State University, Revised, $266 \mathrm{pp}$.

Ang, A. H. S. and Tang, W. H., 1975, "Probability Concept in Engineering Plan and Design," Vol. I. Basic Principles. Wiley and Sons, Inc.

Ang, A. H. S. and Tang, W. H., 1984, "Probability Concept in Engineering Plan and Design,” Vol. II. Basic Principles. Wiley and Sons, Inc

Barton, N., Lien, R. and Lunde, J., 1974, "Engineering Classification of Rock Masses for the Design Tunnel Support," Rock Mech., Vol. 6, No. 4, pp. 189-236.

Bieniawski, Z. T., 1976, "Rock Mass Classification in Rock Engineering," Proceedings of Exploration for Rock Engineering, Johannesburg, Vol. 1, Balkeman, pp. 97-106.

Bieniawski, Z. T., 1983, "New Design Approach for Room-and-Pillar Coal Mines In the USA," Proceedings of the ISRM Congress on Rock Mechanics, Balkema, Rotterdam, 1983, pp. E27-E36.

Bieniawski, Z. T., 1992, “A Method Revisited: Coal Pillar Strength Formula Based on Field Investigations," Proceedings of the Workshop on Coal Pillar Mechanics and Design, Information Circular/1992, IC9315, Bureau of Mines, pp. 158 - 165.

Bowles, D.S., L.R. Anderson and Glover, T. R., 1987, "Design Level Risk Assessment for Dams," Proc. Dynamic of Structure, N. Y., ASCE, pp. 210-225.

Carr, F. and Willson, A. H., 1982, "A New Approach to the Design of Multi-Entry Development for Retreat Longwall Mining," Proc. $2^{\text {nd }}$ Conference on Ground Control in Mining, WV University, Morgantown, WV 26505, pp. 1- 21.

Carr, F. and Martin, E. and Gardner, B. H., 1985, "How to Eliminate Roof and Floor Failure with Yield Pillars," Coal Mining, Vol. 22, No. 1, pp. 44-52.

Gao, H. and Kim, K., 1994, "Probabilistic Approaches to the Design of Underground Opening in Coal Mines," Proceedings of the $5^{\text {th }}$ Conference on Ground Control for Midwest US Coal Mines, June, 1994, pp. 111-123. 
Casagrande, A., 1964, "Role of the 'Calculated Risk' in Earthwork and Foundation Engineering,", J. Soil Mechanics 91.

Chen, G., Ke, J. and Jia, Z., 1996, “Application of Probabilistic Analysis in Mine Ground Control," Proceedings of the $15^{\text {th }}$ Conference on Ground Control in Mining, Colorado School of Mines, Golden, Colorado, pp. 227-244.

Choi, D. S. and McCain, D. L., 1979, “Design of Longwall System,” Proceedings of MiniSymposium on Underground Coal Mine Design and Planning, SME-AIME Annual Meeting, Atlanta, GA, pp. 15-26.

Cornell, C. A., 1969, “A Probability-Based Structure Code," Journal of the American Concrete Institute, Vol. 66, No. 12, pp. 974-985.

Farihurst, C., 1968, "Laboratory Testing of Rock and Its Relevance to Mining Design," Mining Engineering Handbook, SME, Vol. 1, pp.13-51.

Grosschalk, E.M., Severn, R.T., Charles, J. A., and Hinks. J. L, 1994, "An Engineering Guide to Seismic Risk to Dams in the United Kingdom, and International Relevance," Soil Dynamics and Earthquake Engineering 13, pp. 163-179.

Hart, G. C., 1982, "Uncertainty Analysis, Loads, and Safety In Structure Engineering," PRENTICE-HALL, Inc., Englewood, Cliffs, New Jersey, 224 pp.

Hirt, A.M. and Shakoor, A., 1992, "Determination of Unconfined Compressive Strength of Coal for Pillar Design," Mining Eng., August, 1992, pp. 1073-1041.

Hoek, E. and E. T. Brown, 1980, "Underground Excavation in Rock," The institution of Mining and Metallurgy, London, 527 pp.

Hoek, E., 1989, "A Limit Equilibrium Analysis of Surface Crown Pillars Stability, In Surface Crown Pillar Evaluation for Active and Abandoned Metal Mines," Ed. M.C. Betourney, Ottawa, Dept. Energy, Mines \& Resources Canada, pp. 3 - 13.

Hogg, G, V. and Craig, A. T., 1995, "Introduction to Mathematical Statistics," $5^{\text {th }}$ Edition, Prentice Hall, Englewood Cliffs, NJ 07632, 564 pp.

Haugen, E. B., 1968, "Probabilistic Approaches to Design,” John Willey \& Sons, Inc., 323 pp.

Holland, C. T., 1964, "The Strength of Coal in Mining Pillars," Proceedings of the $6^{\text {th }}$ U.S. Rock Mechanics Symposium, University of MO, Rolla, MO, pp. 456-466. 
Holland, C. T. and Gaddy, F. L., 1957, "Some Aspects of Permanent Support of Overburden on Coal Beds", Proc. of the West Virginia Coal Mining Institute, pp. 43-66.

Hsiung, S. M. and Peng, S. S., 1985, “Chain Pillar Design for U.S. Longwall Panel,” Mining Science and Technology, 2(4): pp. 279-305.

Ingles, O. G., 1979, "Human Factors and Errors in Civil Engineering," $3^{\text {rd }}$ International Conference on Application of Statistics and Probability in Soil and Structure Engineering, Sydney, Australia, pp. 402-417.

Jiang, Y. Q., 1981, Plasticity Mechanical Engineering Publishing House, Beijing, China, $256 \mathrm{pp}$.

Keaton, R.J. and Echoff, D. W., 1990, "Value Engineering Approach to Geological Hazard Risk Management," Transportation Research Record 1288, pp.168-174.

King, H. J. and Whittaker, B. N., 1971, "A Review of Current Knowledge on Roadway Behavior," Proceedings of the Symposium on Roadway Strata Control, Inst. of Min. and Metal., pp. 73-78.

Kirkaldie, L. (ed), 1988, “Rock Classification System for Engineering Purpose,” ASTM Spec. Publ. 984, 161 pp.

Laubscher, D. H. and Taylor, H. W., 1976, “The Importance of Geomechanics Classification of Jointed Rock Masses in Mining operation," Proceedings of Exploration for Rock Engineering, Johannesburg, Vol. 1, Balkeman, pp. 119-128.

Laubscher, D. H., 1984, "Design Aspects and Effectiveness of Support Systems in Different Mining Conditions, Trans, Inst. Min. Metall, Section A, Vol. 93, pp. A70-A81.

Lumb, P., 1970, “Application of Statistics in Soil Mechanics,” Chapter 3 in Soil Mechanics Mew Horizons, I. K. Lee Editor, Newness-Butterworths, London.

Mark, C., Chase F. E. and Campoli, A. A., 1995, “Analysis of Retreat Mining Pillar Stability," Proceedings of the $14^{\text {th }}$ Conference on Ground Control in Mining, WV Univ., Morgantown, WV. pp. 63-71.

Mark, C., 1992, “Analysis of Longwall Pillar Stability (ALPS): Update,” Proceedings of the Workshop on Coal Pillar Mechanics and Design, United States of Department of the Interior, USBM, Information Circular, pp. 238-249.

McCrken, A and Stcey, R. T., 1989, "Geotechnical Risk Assessment for Large Diameter Raised-bored Shafts," Trans. Inst. Min. Metall. Sect. A98: A145-A150. 
McGuffey, V., A-Grivas, D., Iori, J. and Kyfor, Z., 1982, "Conventional and Probabilistic Embankment Design,” J. Geotech. Eng., ASCE, Oct., Vol. 108, GT10, pp. 12461254.

Mischke, C., 1970, “A Method of Relating Factor of Safety and Reliability,” J. Eng. for Ind., Trans. of ASME, Aug. pp. 537-542.

Molinda, G. M. and Mark, C, 1994, "Coal Mine Roof Rating (CMRR): A Practical Rock Mass Classification for Coal Mines," USBM IC 9387, 83 pp.

Nguyen and Chowdhury, 1985, "Simulation for Risk Analysis," Geotechnique 35 (1), pp. $47-58$.

Obert, L. and Duvall, W. I., 1967, "Rock Mechanics and the Design of Structures in Rock," Wiley, pp. 236-274.

Park, D.W. and Ash, N. F., 1985, "Stability Analysis of Entries in Deep Mine Using Finiteelement Method," Mining Science and Technology, Elsevier, V. 3, p. 11-20.

Peng, F. F., Sun, V. Z. and Peng, S. S., 1996, "Assessment of Potential Roof Fall in Mine Entry by Probability Based Dynamic Programming," $26^{\text {th }}$ International Symposium in Application of Computers and Operations Research in the Mineral Industry, Published by SME. Inc., Litteton, Colorado, pp. 77-81.

Peng, S. S. and Chiang, H. S., 1984, Longwall Mining, John Wiley \& Sons, Inc., New York, pp. 708.

Peng, S.S. and Dutta, D., 1992, "Evaluation of Various Pillar Design Methods: A Case Study," Proceedings of the Workshop on Coal Pillar Mechanics and Design, Information Circular/1992, IC9315, Bureau of Mines, pp. 268 - 282.

Peng, S. S., 1986, "Coal Mine Ground Control," John Willey \& Sons, Inc., New York, $2^{\text {nd }}$ ed., $491 \mathrm{pp}$.

Pytel, W. M., Chugh, Y. P. and Yang, G., 1994, "Development of Alternative Room-and Pillar Mining Geometries Based on Rock Mechanics and Reliability Principles," Proceedings of the $12^{\text {th }}$ Annual Workshop, Generic Mineral Technology Center, Mine System Design and Ground Control, Fairbanks, Alaska, Sept., pp. 177-188.

Rosenbluth, E., 1975, "Point Estimates for Probability Moments," Proceedings of National Academy of Science, Vol. 72, No. 10, Math., pp. 3812-3814.

Rosenbluth, E., 1981, “Two-point Estimates in Probabilities,” J. Appl. Math. Modeling, 5, 
Oct., pp. 329 - 335.

Salamon, M.D.G. and Munro, A. H., 1967, “A Study of the Strength of Coal Pillars,” Journal of the South African Institute of Mining and Metallurgy, pp. 55-67.

Su, D. W. H. and Hasenfus, G. T., 1995, "Regional Horizontal Stress and Its Effects on Longwall Mining in the Northern Appalachian Coalfield," Presented at the $14^{\text {th }}$ Conference on Ground Control in Mining, WV Univ., Morgantown, WV, pp. 39-45.

Su, D. W. H. and Hasenfus, G. T., 1996, "Practical Coal Pillar Design Considerations Based on Numerical Modeling," Paper Presented in the $15^{\text {th }}$ Conference on Ground Control in Mining, Colorado School of Mines, Golden, Colorado, 21 pp.

Su, W. H. and S. S. Peng, 1984, "An Investigation of The Causes of Roof Falls in a Deep Underground Coal Mine," Preprint No. 84-433, SME-AIME Fall Meeting, Denver, $\mathrm{CO}, \mathrm{pp}$.

Su, W. H. and S. S. Peng, 1987, "Cutter Roof and Its Causes," Mining Science and Technology, V. 4, p. 113-132.

Sun, G. C. and Peng, S. S., 1993, "Rock Mechanics Property Data Bank for Coal Measure Strata," Proceedings of the $12^{\text {th }}$ Conference on Ground Control in Mining, WV Univ., Morgantown, WV. pp. 330-341.

Sun, V. Z. and Peng, S.S., 1997, "Stability Design and Evaluation for Mine Entry System Based on Reliability Theory," SME, Preprint No. 97-10, 9 pp.

Sun, V. Z. and Peng, S. S., 1997, "ROCKDBASE - A Coal Measure Rock Strata Properties Database", Unpublished Paper, pp. 10.

Suorineni, F.T. and Dusseault, M. B., 1995, "Probabilistic Risk and Reliability Evaluation of Ground Control Practices in Underground Mining: The Safety and Economic Implication," Rock Mechanics, Daemen \& Schultz ed, 1995, Balkema, Rotterdam, pp 579 - 584.

Tsang, P., Peng, S.S. and Biswas, K., 1996, "Current Practice of Pillar Design in US Coal Mines," Mining Engineering, Dec. pp.

Unrug, K. F., Nandy. S. and Thompson, E., 1995, "Evaluation of the Coal Strength for Pillar Calculations," Society of Mining Engineering of AIME, Transactions Vol. 280, pp. 2071-2075.

USBM, 1992, "Preventing Coal Mine Ground Fall Accidents: How to Identify and Respond 
to Geologic Hazards and Prevent Unsafe Worker Behavior," Proceedings: U.S. Bureau of Mines, Technology Transfer seminar, IC 9332, 89 pp.

Vanmarcke, E. K., 1977, "Probabilistic Modeling of Soil Profiles,” J. Geotech. Eng. ASCE, No. GT11, pp. 1227-1246.

Whitman, R.V., 1994, "Evaluating Calculated Risk in Geotechnical Engineering," J. Geotech. Eng. 110: pp. 145-188.

Wane, M.T., Hassialis, M. D. and Boshkov, F., 1964, "The Probabilistic Nature of Failure of the Geologic Universe," Proc. Conf. Strata Control and Rock Mechanics: N.Y.Columbia Univ., pp. 324-330. 


\section{VITA}

\section{Zhouming (Victor) Sun}

Zhouming (Victor) Sun was born on December 28, 1957 in Zhouqu County, GanSu Province, People's Republic of China. He attended Xi'an Mining Institute in China and received a Bachelor of Science Degree in Mining Engineering on July 1982.

On August 1982, he joined, as an engineer, the Xi' an Mining Design and Research Institute, Xi' an, P. R. China and worked for six years. During that period, he was involved in various research projects including $\mathrm{CAD}$ application, ventilation network analysis, coal mine and construction designs, etc.

As a vising scholar, Victor entered the Department of Mining Engineering at West Virginia University in 1988. He initiated his graduate school program in Mining Engineering in 1991, and obtained his M. S. Degree in 1993. In 1994, he enrolled in the Ph.D. program in Mining Engineering and in 1996, and also the M. S. study in Statistics and Computer Science at West Virginia University. He had been working as a Research Assistant in the Department of Mining Engineering until 1997. He completed his M. S. in statistics in August 1998. Currently, he is a permanent employee and is working for Fujisawa Healthcare, Inc. (formerly Fujisawa, USA, Inc.) in Deerfield, Illinois. 